Dados Internacionais de Catalogação na Publicação (CIP) DIVISÃO DE BIBLIOTECA E DOCUMENTAÇÃO - ESALQIUSP

\footnotetext{
Carpinelli, Sônia Marta

Rendimento no desdobro e produtividade em madeira serrada de uma floresta de Eucalyptus grandis / Sônia Marta Carpinelli. - - Piracicaba, 2002.

76 p. : il.

Dissertação (mestrado) - - Escola Superior de Agricultura Luiz de Queiroz, 2002. Bibliografia.

1. Florestas 2. Madeira serrada de eucalipto 3. Método de desdobro primário de tora 4. Rendimento 5. Serrarias I. Título
}

CDD 674.142

TPermitida a copia total ou parcial deste documento deste que citadh a fonte - 0 autor? 
A Deus,

OFERECO.

Ao meu pai Carlos Eduardo (in memorian);

À minha mãe Elizabeth e à minha avó Albertina,

DEDICO. 


\section{Agradecimentos}

Ao meu orientador Prof. Dr. José Nivaldo

Garcia, por sua orientação, incentivo e compreensão sempre constantes. 


\section{SUMÁRIO}

Página

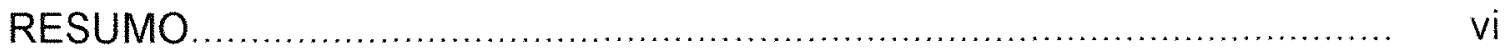

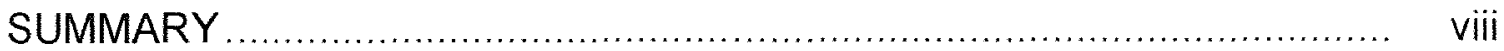

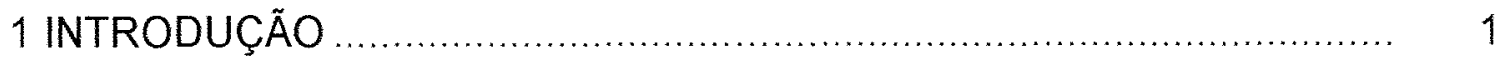

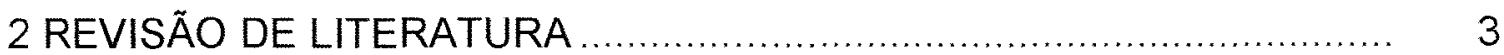

2.1 Considerações gerais................................................... 3

2.2 A madeira serrada no Brasil ................................................. 5

2.3 Incidência de nós na madeira............................................... 8

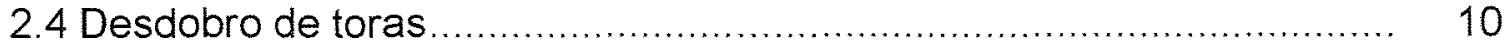



2.6 Desrama artificial............................................................ 16

2.7 Equação de forma de árvores .............................................. 19

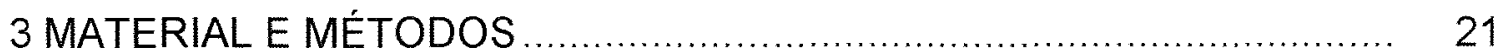

3.1 Determinação do rendimento em madeira serrada ........................... 21

3.2 Determinação de volumes de madeiras serradas e estocados na floresta.

4 RESULTADOS E DISCUSSÃO ................................................... 30

4.1 Defeitos que influenciam no rendimento e qualidade da madeira serrada....................................................................... 30

4.2 Rendimentos no desdobro em função de duas variáveis independentes ............................................................

4.3 Rendimentos em madeiras serradas em função de apenas uma variável

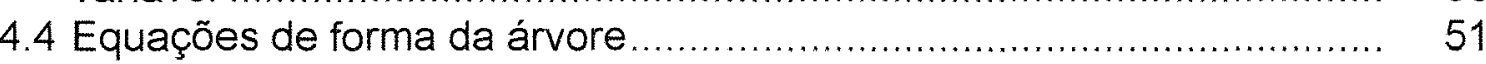

4.5 Volume de madeiras serradas estocados na floresta ...................... 56

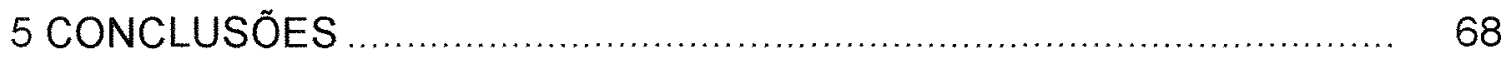

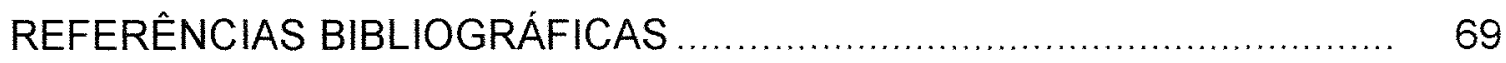




\title{
RENDIMENTO NO DESDOBRO E PRODUTIVIDADE EM MADEIRA SERRADA DE UMA FLORESTA DE Eucalyptus grandis
}

\author{
Autora: SÔNIA MARTA CARPINELLI \\ Orientador: Prof. Dr. JOSÉ NIVALDO GARCIA
}

\section{RESUMO}

O presente trabalho teve por objetivo identificar variáveis que influenciam nas estimativas de volumes de madeiras serradas de diferentes classes de qualidade, estocados na floresta. Foram investigadas duas técnicas de desdobro aplicadas em toras de diferentes diâmetros. Buscou-se também interpretar a interferência da prática de desrama natural e/ou artificial no rendimento em madeira serrada, além de avaliar o impacto gerado pelo uso de duas diferentes equações de forma da árvore nas estimativas de volumes de madeira serrada estocados na floresta. Foram estudados o método de desdobro por cortes tangenciais balanceados, indicado para espécies que possuem altos niveis de tensões de crescimento, como a maioria da espécies de Eucalyptus e o método de desdobro por cortes tangenciais de máximo aproveitamento, que é indicado para espécies com baixos níveis de tensões de crescimento, como as espécies de Pinus. O diâmetro menor da tora confirmou ser um dos fatores que influencia no rendimento em madeira serrada, que em geral aumenta com o aumento desse diâmetro. Contudo, os resultados obtidos neste experimento mostram que o rendimento em madeira serrada não 
aumenta, necessariamente, com o aumento de um diâmetro para um seu sucessor superior. O rendimento em madeira serrada apenas aumenta quando há a possibilidade de obter-se em um determinado diâmetro, pelo menos uma peça a mais do que o número delas tiradas no diâmetro anterior. O rendimento em madeira serrada obtido no sistema de desdobro por cortes tangenciais balanceados não difere do rendimento em madeira serrada obtido no desdobro por cortes tangenciais de máximo aproveitamento para diâmetros mínimos da tora de até $26 \mathrm{~cm}$. Portanto o primeiro método é indicado porque apresenta a vantagem de minimizar os efeitos das tensões residuais. $O$ modelo gerado pela equação de forma da árvore suposta perfeitamente cônica estimou volumes menores que o modelo gerado pela equação de forma de Ormerod, fato que já era esperado por apresentar uma taxa de afilamento do fuste mais elevada. A vantagem deste modelo é a de ser extremamente simples e ajustável para cada árvore, dispensando dados de cubagens rigorosas. O segundo modelo utilizado apresentou a vantagem de não assumir uma forma geométrica rígida para todo o tronco. Contudo, não dispensou o uso de dados de cubagens rigorosas realizadas na população em estudo. A desrama artificial aplicada corretamente e realizada desde os primeiros anos, induz a formação de uma maior quantidade de madeira "clear" ao restringir a ocorrência de nós a uma reduzida área no centro do tronco. Dessa forma, essa operação minimiza a presença de nós em todo o volume comercial do tronco, aumentando o rendimento em madeira serrada de qualidade superior. Verificou-se que a desrama artificial possibilitou maior produtividade em madeira serrada de melhor qualidade que a desrama natural. 


\title{
RECOVERY RATE IN SAWING AND SAWN WOOD PRODUCTIVITY IN A FOREST OF Eucalyptus grandis
}

\author{
Author: SÔNIA MARTA CARPINELLI \\ Adviser: Prof. Dr. JOSÉ NIVALDO GARCIA
}

\section{SUMMARY}

The present work was carried out in order to identify variables that influence the estimates of sawn wood volumes in different classes of wood quality in a forest. Two techniques of sawing applied in logs of different diameters were investigated. It was also interpreted the interference of natural and/or artificial prunning on the recovery rate of obtaining different sawn wood qualities, and evaluate the impact of using two different function taper in the estimates of sawn wood volumes stocked in a forest. The first method of sawing employed was the system of balanced tangential cuts, indicated for species that have high growth stress, as most of Eucalyptus species. The second one was the method of tangential cuts of maximum recovery indicated for species which have low growth stress level, as Pinus species. The minimum log diameter confirmed to be one of the factors that influence sawn wood recovery rates. However, the recovery rate only increases when it is possible to obtain, in a certain diameter, at least one more piece in relation to the number of pieces that were obtained in the previous recommended diameter. The system of sawing of balanced tangential cuts is strongly for the diameters which are normally found in young planted forest up to $26 \mathrm{~cm}$ diameter, in comparison to the system of 
tangential cuts of maximum recovery. It presents also the advantage of minimizing effects of log residual stress. The model generated by the taper function which supposes that the tree is perfectly conical estimated smaller volumes than the model generated by Ormerod's taper function. The first model has the advantage of being extremely simple and adjustable for each tree, neglecting data of rigorous volume measures. The second model has the advantage of not assuming a rigid geometric form for the whole tree. However, it didn't excuse the use of rigorous volume measures data. The artificial prunning applied correctly and accomplished since the first years, induces the formation of a larger amount of clear wood when restrict the occurrence of knots in a reduced area in the log center. This operation minimizes the presence of knots in the whole commercial volume of the log, increasing the recovery rate in sawn wood of superior quality. It was verified that the artificial prunning facilitated larger productivity of better quality than the natural prunning. 


\section{INTRODUÇÃO}

A madeira é um material de ampla utilização desde o surgimento do homem na Terra e a continuidade de seu uso até nossos dias pode ser explicada pela sua beleza e agradabilidade ao tato.

A madeira serrada é um produto que serve como matéria-prima para diversos setores da indústria, entre eles o segmento moveleiro, da construção civil e de embalagens que agregam valores significativos ao produto.

As unidades produtoras de madeira serrada no Brasil, principalmente as de médio e grande porte, preocupam-se em agregar maior valor ao seu produto. Isso tem estimulado a busca de padrões de qualidade superiores durante todo o decorrer do processamento mecânico da madeira dentro da serraria.

O principal gênero utilizado nas unidades produtoras de madeira serrada é o Pinus, juntamente com algumas espécies nativas como o ipê, a imbuia e o jatobá, entre outras. Entretanto, nos últimos anos, a madeira serrada do gênero Eucalyptus tem despertado o interesse de diversos produtores, pois apresenta espécies promissoras com características potenciais e, principalmente, de crescimento rápido. Restrições ambientais quanto à utilização de folhosas nativas aliadas aos custos de transporte para os centros consumidores colaboram ainda mais para um maior interesse sobre o produto serrado do gênero Eucalyptus.

O conhecimento quantitativo de madeira de um plantio florestal vem sendo o fator de decisão que praticamente baliza o direcionamento de toda 
a atividade do setor de produção madeireira. Entretanto o nivel de qualidade dessa madeira voltado à finalidade para a qual ele se propõe, também precisa ser conhecido e avaliado.

Pesquisadores florestais têm buscado identificar e comparar métodos de maior precisão e rapidez que possam estimar a produção volumétrica de uma floresta, adequando-os às diversas situações de interesse. Contudo, pesquisas voltadas à quantificação volumétrica diferenciada para madeira serrada com a finalidade de separar os diferentes tipos de madeira serrada que podem ser obtidos em uma mesmo plantio são escassas.

A justificativa para a realização deste trabalho fundamenta-se na importância do desenvolvimento de estratégias para o uso racional da madeira, pois a madeira como é naturalmente produzida na floresta apresenta características que implicam em grandes perdas quando do seu processamento em serraria.

O setor florestal brasileiro apresenta atualmente perdas consideráveis em produtividade, provenientes da falta de uma elaboração prévia de operações. A necessidade de garantir suprimentos futuros de matéria-prima, com custos compativeis e sob pressão efetiva de órgãos internacionais ambientalistas, vem exigindo das empresas uma postura consciente, que implica na aquisição de níveis operacionais eficientes, dos quais depende sua competitividade no mercado e conseqüente permanência como parte integrante do mesmo.

Este trabalho teve como objetivos:

- identificar variáveis que interferem no rendimento em madeira serrada e nas estimativas de volumes de madeiras serradas estocados na floresta;

- investigar duas técnicas de desdobro de toras e as suas influências no rendimento em madeira serrada;

- observar a influência da prática de desrama natural e/ou artificial no rendimento em madeira serrada e nos volumes de madeira serrada, de diferentes classes de qualidade, estocados na floresta. 


\section{REVISÃO DE LITERATURA}

\subsection{Considerações gerais}

Os processos metabólicos presentes na árvore, responsáveis pelo seu crescimento e desenvolvimento estão intimamente ligados a fatores genéticos e ambientais. Portanto, o manejo florestal influencia nesses processos, implicando em diferentes respostas na estruturação fisiológica do povoamento.

A formação da madeira de uma determinada qualidade depende de tendências que os fatores genéticos e ambientais, combinados entre si e ao manejo florestal empregado, impõem ao povoamento. O conjunto destes fatores interrelacionados condicionam, orientam e alteram comportamentos préestabelecidos.

A produção de madeira serrada de uma determinada qualidade, em plantios florestais, implica na realização de intervenções, durante todo o processo de desenvolvimento das árvores, gerando assim conformações adequadas de tronco. Diante disso, é conveniente aplicar ao povoamento florestal tratos culturais que venham favorecer a produção de madeira de qualidade compativel com a finalidade a que se destina.

O valor da madeira dependerá mais intensamente da presença ou não de defeitos, do que propriamente de variações que esta madeira possa apresentar, relacionadas às suas propriedades físicas e mecânicas (Miranda, 1997). 
A tábua isenta de nós e de outros defeitos que possam desvalorizá-la atinge, no mercado, valores superiores aos encontrados em peças com semelhantes dimensões quando nela se vêem presentes tais defeitos. A madeira "clear" é a madeira isenta de defeitos como os nós, as podridões e as manchas.

A desrama natural em muitas espécies do gênero Eucalyptus ocorre com freqüência, minimizando a ocorrência de nós. Contudo, segundo Wardlaw (2000), são encontrados altos niveis de apodrecimentos de tronco de árvores de florestas de eucaliptos da Tasmânia, sendo em sua maioria originados durante a auto-desrama.

A desrama artificial aplicada corretamente e realizada desde os primeiros anos, induz a formação de uma maior quantidade de madeira "clear" ao restringir a ocorrência de nós a uma reduzida área no centro do tronco. Dessa forma, essa operação deve eliminar os ramos laterais dos indivíduos arbóreos, para minimizar a presença de nós em todo o volume comercial do tronco. Além de aumentar o rendimento em madeira serrada isenta de nó, defeito excessivamente depreciativo ao valor comercial da madeira serrada, essa operação também minimiza a ocorrência de podridões da madeira que surgem associadas aos nós

Portanto, uma questão que precisa ser considerada e esclarecida refere-se à tomada de decisão sobre em quais situações deve-se optar pela realização da desrama artificial e em quais situações a opção pela desrama natural seria mais acertada. 


\subsection{A madeira serrada no Brasil}

O setor madeireiro brasileiro vem crescendo quanto à utilização de madeiras provenientes de reflorestamentos, particularmente, com espécies do gênero Pinus e Eucalyptus. Este fato pode estar vinculado à expansão de mercados para a madeira dita "ambientalmente correta" e ao desafio proposto pela globalização onde o mercado consumidor impõe atendimento a padrões de qualidade cada vez mais exigentes.

O setor industrial no Brasil, responsável pela produção de madeira serrada, dispõe de cerca de 10.000 unidades (Tabela 1) sendo a maioria de pequeno porte. Poucas dessas unidades industriais têm capacidade de produção rotulada entre média e grande e o nível tecnológico adotado por elas, aliada à baixa qualidade de mão-de-obra, contribuem para que esta atividade tenha restrita competitividade.

Tabela 1. Capacitação produtiva das unidades produtoras de madeira serrada.

\begin{tabular}{lccc}
\hline Porte & $\begin{array}{c}\text { Capacidade anual } \\
\text { de produção }\left(\mathrm{m}^{3}\right)\end{array}$ & $\begin{array}{c}\text { Número } \\
\text { de serrarias }\end{array}$ & Proporção (\%) \\
\hline Pequeno & menos de 10.000 & 7228 & 74,52 \\
& $10.000-30.000$ & 2404 & 24,78 \\
Médio & $30.000-50.000$ & 50 & 0,51 \\
& $50.000-100.000$ & 15 & 0,15 \\
Grande & $100.000-150.000$ & 2 & 0,02 \\
& mais de 150.000 & - & - \\
Total & & 9699 & 100 \\
\hline
\end{tabular}

Fonte: STCP (2002) 
A Figura 1 mostra a evolução das exportações brasileiras de madeira serrada de folhosas, coníferas e em valores totais, onde se pode notar o crescimento destas exportações no período indicado entre 1998 e 2000.



Figura 1 - Exportações brasileiras de madeira serrada de 1989 a 2000. Fonte: STCP (2002) e SECEX (2002), adaptado

As exportações de madeira serrada no Brasil tiveram aumento de aproximadamente $8 \%$ ao ano no período de 1989 a 2000, ocorrendo períodos de quase estagnação ou até mesmo de quedas dos volumes exportados, em função de variações de demanda dos países consumidores. Em 1989 os valores exportados representavam cerca de $12 \%$ da madeira produzida e em 2000 atingiam mais de $45 \%$ desse total. 
Ocorreram dois picos exportações de madeira serrada, um deles no ano de 1994 referente ao grande crescimento das exportações de folhosas para os países asiáticos, entre eles, Tailândia e Filipinas e o outro no ano de 1997 com participação expressiva da madeira de coníferas.

A Figura 2 demonstra que o principal país de destino das exportações brasileiras de madeira serrada são os E.U.A., seguido pela França, Espanha, Argentina e pelo Reino Unido.

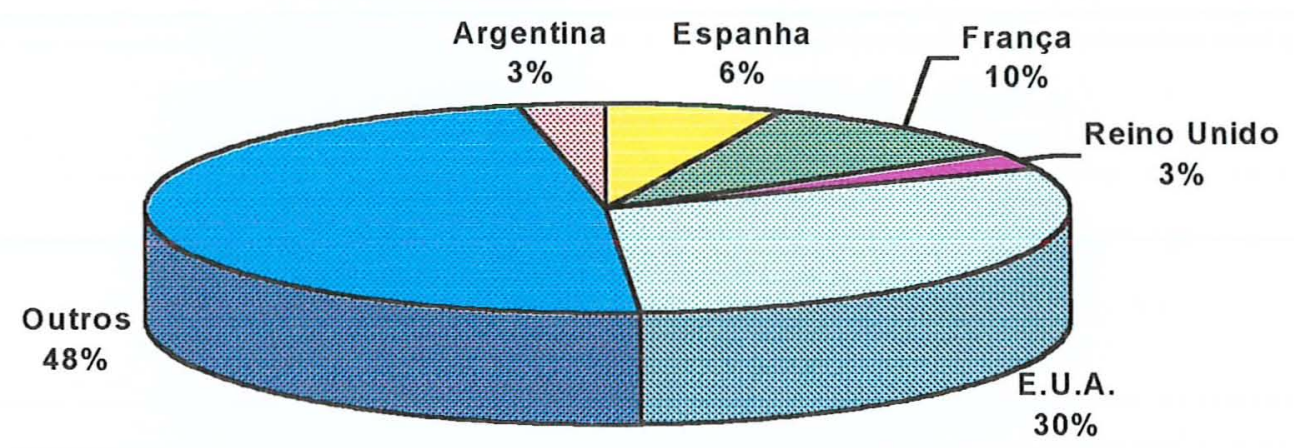

Figura 2 - Principais países importadores de madeira serrada brasileira.

Fonte: STCP (2002)

As crescentes restrições ambientais ao uso de madeira de folhosas nativas e, particularmente, o elevado custo do seu transporte para os centros consumidores, favorece a entrada da madeira de eucalipto no mercado.

A Figura 3 mostra o consumo nacional de madeira serrada ocorrido no ano de 1996 e a previsão para o ano de 2005, que será da ordem de 23 milhões de $\mathrm{m}^{3}$. Desse total estima-se que aproximadamente $70 \%$, seja madeira de folhosas e os $30 \%$ restantes seja madeira de coníferas oriundas de florestas plantadas. 


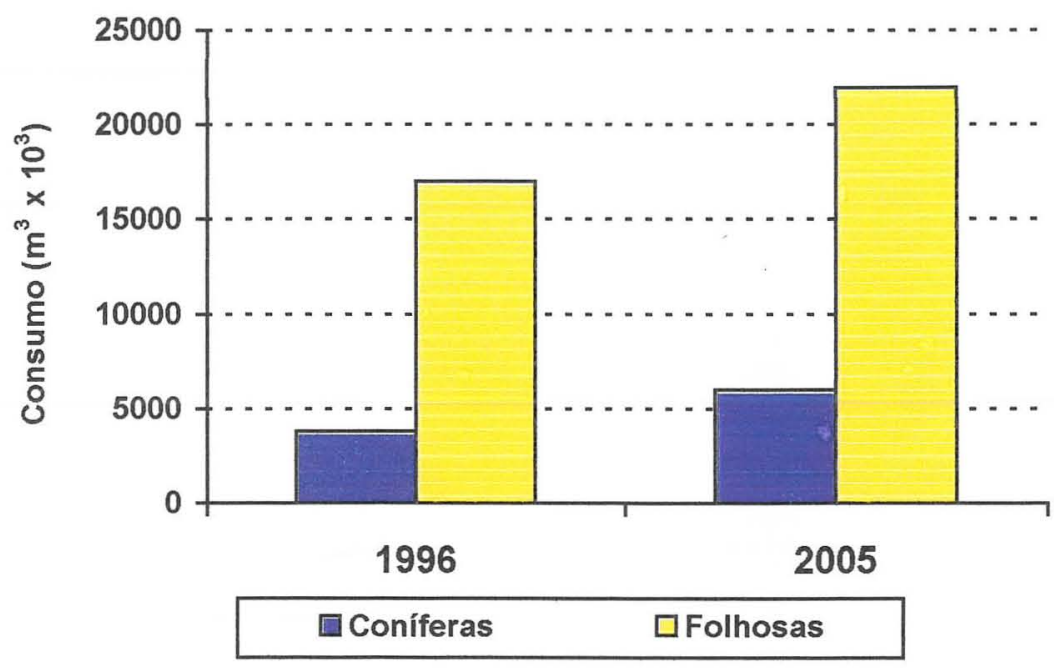

Figura 3 - Consumos, ocorrido e projetado, de madeira sólida no Brasil. Fonte: ABIMCI (2002)

\subsection{Incidência de nós na madeira}

O nó inicia-se na região medular da árvore, seguindo o sentido centro periferia, impondo uma série de desvios ou descontinuidades no tecido lenhoso do tronco. Em sua origem os nós apresentam-se perfeitamente integrados ao tecido lenhoso, contudo podem ser notadas alterações quanto ao sentido da grã na madeira (Wardlaw, 2000).

Para o eucalipto, os nós de dimensões menores se localizam próximos à base da árvore enquanto que a parte superior detém a maior quantidade de nós de maiores dimensões, sugerindo que o tamanho do nó varia de acordo com a altura no tronco (Mohammed, 2000). 
Ponce (1997) conclui que o tamanho e a quantidade de nós encontrados na madeira serrada variam conforme a posição onde são encontrados na tora.

Os nós vivos ocorrem quando os galhos permaneceram ativos fisiologicamente como parte continua da árvore, existindo perfeita integração entre os tecidos lenhosos. Quando de tamanhos reduzidos, se comparados às dimensões da peça serrada, não impedem determinados usos estéticos, como em lambris, forros, assoalhos, móveis, revestimentos de parede ou mesmo estruturais.

O nó morto é assim denominado por fazer parte de um galho ou ramo que morreu, permanecendo não fisiologicamente participativo. Sua continuidade estrutural passa a não mais existir e sua fixação é exclusivamente dependente da compressão periférica exercida pelo crescimento diametral do fuste. Os nós mortos, podem soltar-se durante a secagem da madeira, prejudicando inúmeras possibilidades de uso.

Nas espécies do gênero Eucalyptus, a desrama natural é favorecida e predominantemente impulsionada pela redução do espaçamento entre plantas. Contudo, ramos secos presos ao tronco deixados pela desrama natural em idades jovens da árvore, ocasionam a incidência de nós mortos elou formação de bolsas de resina. Em algumas espécies como no Eucalyptus grandis, os nós estão associados com exudação de resinas durante a secagem das peças que foram serradas. Florestas de eucaliptos mal formadas e manejadas fornecem grande quantidade de madeira com nós (Ponce, 1997).

Assis (1999) afirma que a desrama artificial é vantajosa em relação à natural por diminuir a formação de bolsas de resina e incidência da podridão do cerne e que a seleção de indivíduos de ramos finos e capacidade de desrama natural satisfatória funciona como uma pré-limpeza a ser completada pela desrama artificial. Trata-se, portanto de uma integração da desrama natural e artificial necessária a um bom desempenho produtivo do povoamento. 
Plantios de eucaliptos destinados à produção de lenha, carvão, celulose, painéis, e para alguns usos na construção civil, onde a presença de nós não implica em sérios prejuizos, a eliminação de galhos das árvores não precisa fazer parte do manejo florestal. Portanto, o destino a ser dado ao povoamento deve direcionar as práticas mais adequadas de manejo florestal a serem empregadas (Freitas, 1993). Ainda segundo este autor os investimentos realizados durante a poda das árvores em um plantio destinado à serraria são altamente compensadores.

O Brasil, em relação a outros países de clima temperado, tem posição privilegiada para abastecer o mercado externo de madeira serrada com madeira de boa qualidade e de alto valor comercial.

Nicolielo (1987) comenta que a desrama artificial, efetuada em povoamentos ainda jovens, promove maior facilidade de acesso ao interior do talhão, aumenta a prevenção contra fogo de copa e possibilita a produção de madeira de qualidade superior.

\subsection{Desdobro de toras de espécies do gênero Eucalyptus}

A toragem de árvores é o procedimento pelo qual os troncos são seccionados em partes menores, denominadas toras.

A forma com que se apresenta o tronco, acaba por caracterizá-lo qualitativamente, podendo ser extremamente variável entre espécies e mesmo dentro de algumas espécies em função de procedências (Kageyama, 1980; Rosa, 1982; Yared, 1983 e Caser, 1984).

O corte das toras deve ser orientado de forma a otimizar o rendimento em madeira serrada, evitando-se os prováveis desperdícios. O rendimento em madeira serrada depende de fatores como a qualidade específica da madeira, juntamente com seu estado de sanidade, da forma e da dimensões das peças a serem serradas, do sistema de corte, do tipo de 
máquina em uso e seu grau de perfeição, potência, regularidade de funcionamento, bem como da própria habilidade do operador (Mackay ,1964).

O processamento mecânico da madeira de eucalipto é dificultado em função de suas caracteristicas intrínsecas como tensões de crescimento, madeira juvenil, colapso, nós, empenamento, bolsas de resina e variabilidade de propriedades (Ponce, 1997).

A madeira de eucalipto embora apresente problemas durante seu processamento, muitos deles têm sido amenizados através da realização de diversas pesquisas pelo setor que têm promovido a evolução das técnicas de desdobro. A aquisição de novos conhecimentos do setor, quanto ao comportamento estrutural da madeira de eucalipto e sua manipulação, tem estimulado e ampliado seu uso para diferentes finalidades.

Um dos fatores que contribui para o baixo rendimento em madeira serrada das espécies do gênero Eucalyptus, é a ocorrência do rachamento de toras antes e durante o desdobro. Tensões de crescimento e de secagem são as principais causas desses rachamentos, principalmente nos topos das toras (Villiers, 1973).

Peças serradas de eucalipto podem apresentar, além das limitações em seu uso provenientes das elevadas tensões de crescimento que induzem rachaduras de topo, os nós como um fator que influencia, de forma decisiva, na qualidade e no valor da madeira serrada (Lima, 2000).

Montagna et al. (1993) comenta que após a ocorrência de rachaduras ocasionais no topo, a etapa do desdobro é a que mais permite a manifestação de tensões de crescimento, devido aos desequilibrios de forças que são gerados nos cortes, provocando empenamentos e rachaduras.

De acordo com Otte (2001), os principais defeitos da madeira de eucaliptos durante seu processamento, tomando-se por base a variável custo de produção são, pela ordem de importância: rachadura de topo, fissura de compressão, nós soltos, arqueamento, bolsa de resina, encanoamento, fendilhamento e colapso. Destes são visiveis e mensuráveis durante inspeções 
de recebimento: rachaduras de topo ( $15 \%$ do volume) e os nós soltos ( $4 \%$ do volume). Os defeitos como bolsa de resina, fendilhamento e colapso são parcialmente visiveis e a fissura de compressão é percebida somente no transcorrer do processo ou até mesmo quando do produto pronto.

Métodos de desdobro convenientes para toras de eucaliptos, provaram exercer, dentre as técnicas usadas na neutralização de tensões de crescimento, evidente influência no rendimento final em madeira serrada (Aguiar, 1995).

De acordo com Penfold \& Willis (1961), o método de desdobro em cortes paralelos, para a madeira de eucaliptos, não é o mais indicado, sendo tal afirmação justificada pelas graves perdas em madeira de boa qualidade durante o processo.

Garcia (1995) comenta que os cortes tangenciais sucessivos, do ponto de vista prático, não são indicados para a produção de madeira serrada em espécies que contenham altas deformações de crescimento. Quando da retirada de cada tábua, o bloco remanescente tende a deformar-se por flexão, graças à nova distribuição de tensões. A peça subsequente a ser serrada perde, portanto, em uniformidade de espessura.

Durante longo período de tempo, a produção volumétrica da floresta foi a variável de maior interesse. Contudo, este fato não assegura a qualidade da madeira, tornando-se necessária a inclusão de índices de qualidade, com base em características físicas, químicas e anatômicas da madeira (Vale, 2000). A presença de nós constitui-se em um dos principais critérios para avaliação de qualidade da madeira (Schilling et al., 1998).

Segundo Simula \& Tissari (1998), os desafios enfrentados pelos exportadores brasileiros de madeira de eucaliptos estão vinculados à busca por vantagens que tornem seu produto mais competitivo. As vantagens oferecidas não podem apenas basear-se no fator preço, mas acima de tudo, na disponibilização de produtos classificados e de qualidade satisfatória. 


\subsection{Desrama natural}

A eliminação natural de ramos laterais da árvore é chamada de desrama natural, característica limitante para a produção de madeira serrada isenta de nós. A desrama natural se processa vagarosamente no decorrer de toda a vida da árvore (Brandão, 1984).

Durante a desrama natural, os ramos inferiores, desprovidos de luz, perdem seu vigor, enfraquecem e morrem. Sua queda pode ser impulsionada pelo vento, pela chuva ou pela ocorrência de geadas

Segundo Kramer \& Kozlowski (1960), a morte dos ramos inferiores sombreados das árvores, ao crescerem em povoamentos, pode ser atribuída à incapacidade destes ramos de competirem por água com os ramos superiores expostos a maior incidência de luz. A fotossintese fica prejudicada pela diminuição da intensidade de luz, promovendo redução na concentração de solutos, enfraquecimento de forças osmóticas e perda do potencial de competição por água.

Ramos laterais inferiores vão aos poucos morrendo e acabam por cair. Tal ocorrência se dá com certa facilidade em povoamentos mais adensados e, ao contrário, em casos de amplos espaçamentos, a desrama natural surge mais lentamente e com certa irregularidade (Pickel, 1948).

Quando a desrama ocorre de forma irregular, os ramos que ficam dependurados ao tronco por muito tempo, prejudicam a cicatrização, pois interferem no trabalho de recobrimento da casca (Brandão, 1984).

Kramer \& Kozlowski (1960) colocam que a presença de ramos sombreados nas árvores limita-se à quantidade de hidratos de carbono da própria folhagem. O descompasso entre a produção, onde baixas intensidades de fotossíntese são verificadas e o consumo de energia, em particular pela transpiração, significará a exaustão dos hidratos de carbono ocasionando queda e morte de galhos. 
Segundo Pasztor (1962), a desrama natural é uma característica hereditária. Golfari (1975) afirma que o gênero Eucalyptus quando apresentase bem adaptado tende, fortemente, a apresentar desrama natural.

A maior ou menor ocorrência de desrama natural depende da influência das características genéticas da espécie e do nível de adaptação do material ao local. Na maior parte dos casos, a desrama artificial acaba por fazer-se necessária depois de certa idade do povoamento (Albino, 1982).

Inadaptações de algumas procedências podem redundar na formação de ramos mais vigorosos que precisam ser cortados durante uma desrama artificial, no intuito de obter-se madeira de melhor qualidade. Entretanto devem ser evitados alterações excessivas no ritmo de crescimento das árvores.

Macedo (1991) comenta que "a respeito das relações hídricas, o sucesso de qualquer planta está intimamente ligado à sua capacidade para absorver água com uma velocidade capaz de não permitir o desenvolvimento de prolongadas ou graves deficiências hídricas internas durante os períodos de elevada transpiração. Tal capacidade é diferenciada entre as espécies". Ainda segundo o mesmo autor, os déficits hídricos nas árvores acontecem quando a perda de água supera a absorção, condicionando as plantas a déficit hídricos internos que implicam em diminuições em seu crescimento.

Lima (1993) coloca que "as pesquisas realizadas nas últimas décadas têm revelado que o crescimento estacional ou mesmo diário das árvores está mais diretamente correlacionado com as flutuações de água no solo do que com qualquer outro fator do meio".

Kramer \& Kozlowski (1960) admitem que o déficit hídrico colabora para o declínio da atividade do ramo antecipando sua morte. Os mesmos autores ainda comentam sobre os ramos que ao assumirem proporções exageradas passam a competir com a haste principal por seiva que acaba se deslocando com maior rapidez para os órgãos de crescimento mais intenso, 
podendo provocar no fuste, niveis de atrofiamento proporcionais à desnutrição estabelecida.

Dentro de limites fixados pelo genótipo, a atividade cambial depende da disponibilidade de água, sais minerais, carboidratos e hormônios. Qualquer fator, interno ou externo, que limite a disponibilidade para o câmbio de um destes elementos, pode limitar o crescimento da árvore. Por outro lado, atividades intensivas de manejo que venham promover o estresse da planta, como desbastes muito rigorosos ou desramas muito severas, podem igualmente comprometer o crescimento da árvore (Zimmermann, 1971).

As propriedades mecânicas da madeira sofrem influência do ângulo das fibras, densidade, nós e ataque de organismos, fatores estes muito comumente associados à ausência de uma boa desrama.

Os fatores ambientais mais estudados em relação à atividade cambial são a precipitação pluviométrica e a temperatura, mas existem outros, como umidade do solo, intensidade de luz, fotoperíodo, competição, tamanho da copa, oxigênio, vento, topografia, latitude e altitude. Todos estes fatores podem influenciar na atividade cambial (Philipson, 1971).

De acordo com Montagna et al. (1993), a desrama em níveis mais severos interfere significativamente no crescimento diametral da árvore. A retirada dos ramos vivos diminui a superfície fotossintética, reduzindo também a superfície de respiração. Ramos dominados localizados na base, com poucas folhas, podem vir a consumir durante a respiração todos os hidratos de carbono disponiveis, produzidos na fotossíntese. Dessa forma estes não mais contribuem para o crescimento do tronco. Assim, a retirada destes ramos tornase favorável.

A remoção de ramos mortos não afeta o crescimento da árvore, entretanto uma forte remoção da parte viva da copa pode retardar o crescimento em altura e diâmetro (Seitz, 1995). O grau de intensidade e a época em que se dá o início da queda natural dos ramos está relacionada à 
espécie, ao nível de competição entre copas e às condições climáticas locais (Albino, 1982).

Tais informações evidenciam que o procedimento com a desrama deve ser bem avaliado principalmente quando o plantio estiver em áreas que possam, por algum tipo de deficiência, comprometer os processos fisiológicos da árvore.

\subsection{Desrama artificial}

Segundo Brandão (1984), madeiras provenientes de plantios florestais onde não existiu um adequado controle do crescimento da copa da árvore o que pode induzir um aumento na formação de nós no tronco, estão sujeitas a conseqüências negativas em sua qualidade e, consequentemente, no seu valor comercial.

A desrama artificial é empregada para a melhoria da qualidade da madeira, principalmente quando a produção é destinada à serraria ou laminação (Albino, 1982).

Os prejuizos decorrentes da presença de nós deixados por galhos vivos são menores do que aqueles deixados por galhos mortos. Os nós mortos constituem-se em defeitos mais sérios na madeira, porque quando da obtenção de laminados ou tábuas, podem desligar-se integralmente da madeira (Simões, 1981).

Com a finalidade de evitar o grande inconveniente que causam partes residuais de galhos, longamente presos ao tronco, a desrama artificial sistemática pode ser sugerida para, consequentemente, alcançar-se um produto final de padrão de qualidade superior e compensador.

De acordo com Larguia (1967), a madeira de boa qualidade é aquela livre de nós. A desrama artificial é então indicada para evitar a formação destes nós, deixando-os restritos apenas ao interior do cilindro central de pequeno diâmetro, por sobre o qual deve formar-se madeira limpa. 
A desrama artificial, longe de causar danos à madeira, induz a melhoria de sua qualidade. A eliminação de um ramo vivo é mais vantajosa que permitir que este ramo seque no tronco, com possibilidades de deixar partes residuais (Figuras 4 e 5), que podem permanecer por vários anos prejudicando a cicatrização (Pickel, 1948).

Ferimentos de grandes dimensões realizados durante a desrama precisam ser evitados, pois grandes superfícies abertas são de cicatrização mais demorada. Ao contrário, quando a desrama artificial é efetuada na época adequada a cicatrização processa-se mais rapidamente (Pickel, 1948).

Ferimentos em galhos produzidos por técnicas pobres de desrama, aumentam a probabilidade de incidência de apodrecimento na madeira sendo que o uso de fungicidas elou selantes podem colaborar na redução de infecções, porém têm eficácia variável (Mohammed, 2000)

$O$ apodrecimento do tronco mostrado na Figura 5 tem significativo potencial de redução dos futuros rendimentos em madeira serrada, justificando a necessidade de um controle efetivo sobre as atividades de manejo durante o crescimento de florestas de eucaliptos. As intervenções necessárias para reduzirem-se os impactos provenientes de troncos apodrecidos no rendimento em madeira serrada de qualidade, deve chegar antes, permanecendo durante e continuando depois do procedimento de podas (Wardlaw, 2000).

Segundo Mohammed (2000), o nível de infecção causada pelo grau de apodrecimento em troncos desramados artificialmente correlaciona-se diretamente com o diâmetro do galho cortado.

O mesmo autor aponta a preocupação do setor industrial com a ocorrência de tais infecções que promovem o surgimento de apodrecimentos na madeira, e da necessidade em mantê-las estabilizadas apenas ao centro nodoso da árvore, sem invadir a madeira "clear" produzida depois da desrama.

Brendenkamp (1983) verificou que a madeira de Eucalyptus grandis obtida de árvores desramadas, apresentam qualidade significativamente superior àquela obtida de árvores que não sofreram a 
operação de desrama artificial. Entretanto, ressalta-se que há uma carência efetiva de informações relativas às operações de desrama artificial, o que impede uma avaliação objetiva de sua viabilidade econômica.

É importante ressaltar o fato de que, em silvicultura, um erro cometido durante a implantação ou manejo de uma floresta, pode significar irreparável perda, devido aos longos períodos de tempo que envolvem tais cultivos. Anos podem se passar, sem se ter sequer um diagnóstico deste erro ou qualquer perspectiva de suas conseqüências e repercussões futuras. Um retorno financeiro compatível pode ficar comprometido pois não há, na maioria da vezes, como se conhecer a extensão da interferência advinda de um erro. Dessa forma o cuidado durante o cultivo e planejamento de cada trato são de real importância.

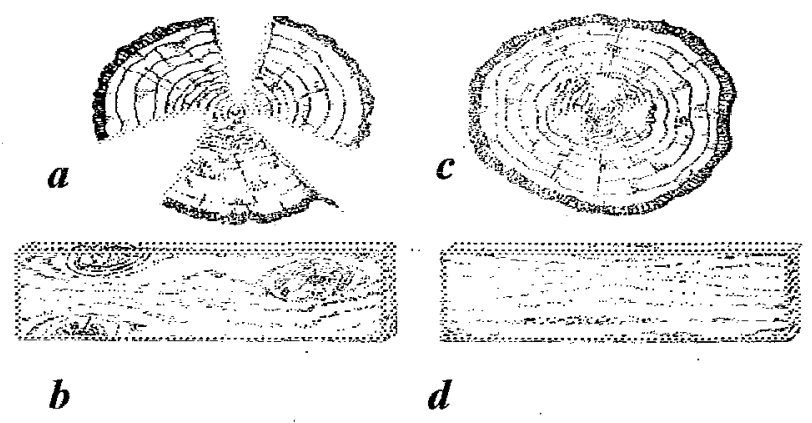

Figura 4 - Corte transversal de um tronco mostrando de onde partem os galhos (a), madeira retirada do tronco com nós (b), corte transversal de um tronco que sofreu desrama (c) e madeira limpa resultante deste tronco (d). 


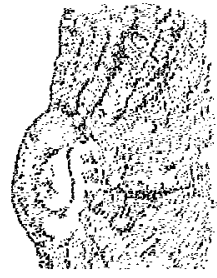

a



b

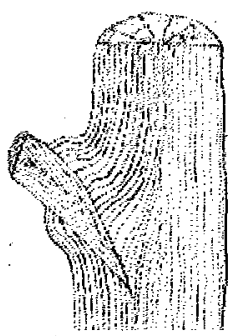

c

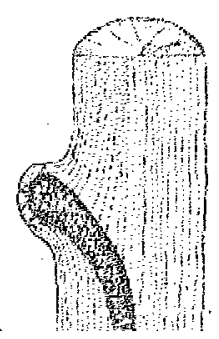

d

Figura 5 - Cicatrização após o corte do galho (a), parte residual de galho que origina o nó morto e facilita a infiltração de água (b), corte mostrado a inserção não contínua do galho ao tronco (c) e podridão na parte interna do tronco (d).

\subsection{Equação de forma}

A equação de forma descreve a forma do tronco de uma árvore à medida que se desloca pelo tronco no sentido base topo da árvore. Existem certas exigências básicas de coerência na forma da árvore obtida por este tipo de equação que necessitam ser satisfeitas para que esta possa produzir resultados razoáveis (Batista, 2001).

Segundo o mesmo autor os melhores modelos de equação de forma satisfazem a todas estas exigências básicas que são:

1. O diâmetro do tronco decresce monotonicamente com o decorrer do aumento em altura ao longo do tronco partindo-se da base.

2. Na base, o diâmetro do tronco é idêntico ao diâmetro da base.

3. No DAP, o diâmetro do tronco é idêntico ao diâmetro à $1,3 \mathrm{~m}$ da base (DAP).

4. No topo, o diâmetro do tronco é nulo. 
O fuste é a parte da árvore de maior importância, em termos de uso geral, sua forma apresenta-se bastante variada em razão do meio ambiente, da espécie, idade, manejo e de suas aptidões genéticas. Mesmo em um povoamento de uma única espécie pode-se observar diferentes formas entre as árvores (Finger, 1992).

Ainda segundo o mesmo autor, árvores da periferia de povoamentos, isoladas ou largamente espaçadas, sujeitas a uma maior exposição e livres de competição, apresentam-se sob uma forma denominada de forma natural, espontânea ou específica. Árvores do interior do povoamento, cuja sobrevivência ocorre juntamente com a competição por água, luz e nutrientes, tendem a reduzir suas ramificações laterais, assumindo forma mais reta, com copa reduzida.

Não é fácil dominar com precisão questões que envolvem determinações diamétricas ou de altura, o problema do estudo da forma das árvores é ainda mais delicado. 


\section{MATERIAL E MÉTODOS}

\subsection{Determinação do rendimento em madeira serrada}

O rendimento em madeira serrada foi determinado a partir de dois lotes de toras (lote A e lote B) de Eucalyptus grandis que haviam sido desdobradas, segundo dois métodos de desdobro distintos aplicados um para cada lote. Foram amostradas apenas, pelo seu diâmetro mínimo, 21 toras de cada lote, sendo 3 toras de diâmetro mínimo de $14 \mathrm{~cm}$ aproximadamente, 3 de $17 \mathrm{~cm}, 3$ de $20 \mathrm{~cm}, 3$ de $23 \mathrm{~cm}, 3$ de $26 \mathrm{~cm}, 3$ de $29 \mathrm{~cm}$ e 3 de $32 \mathrm{~cm}$.

As toras do lote $A$ foram serradas segundo o método de desdobro por cortes tangenciais balanceados, que é indicado para espécies que possuem altos niveis de tensões de crescimento, como é o caso da maioria da espécies de Eucalyptus, e as toras do lote $\mathrm{B}$ foram serradas segundo o método de desdobro por cortes tangenciais de máximo aproveitamento, que é indicado para espécies com baixos níveis de tensões de crescimento, como é o caso das espécies de Pinus.

A Figura 6 mostra as etapas do desdobro que foram comuns aos dois lotes, iniciando-se com um corte duplo feito numa serra de fita dupla (Figura 6(a)), um corte simples feito numa ressera de aproveitamento de costaneira (Figura $6($ b) ) e um corte múltiplo feito numa serra circular múltipla (Figura 6(c)). 


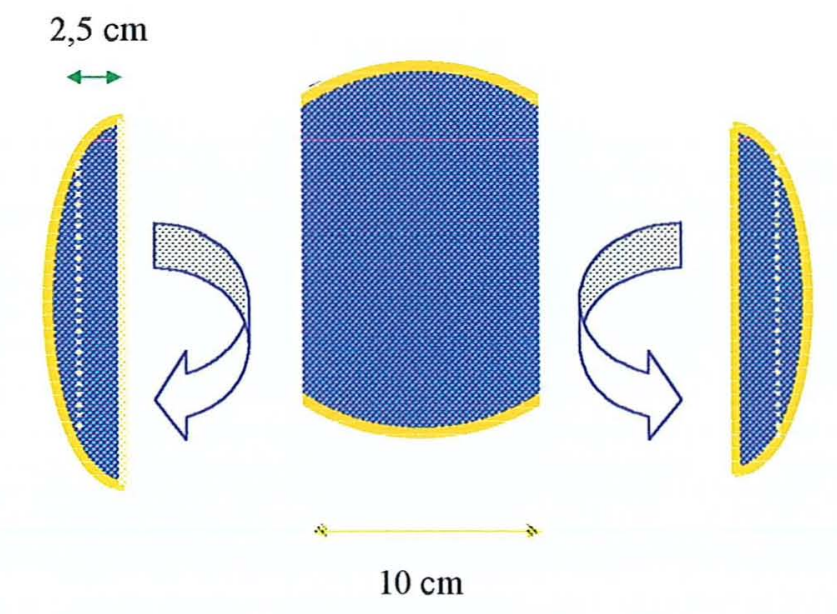

(a)

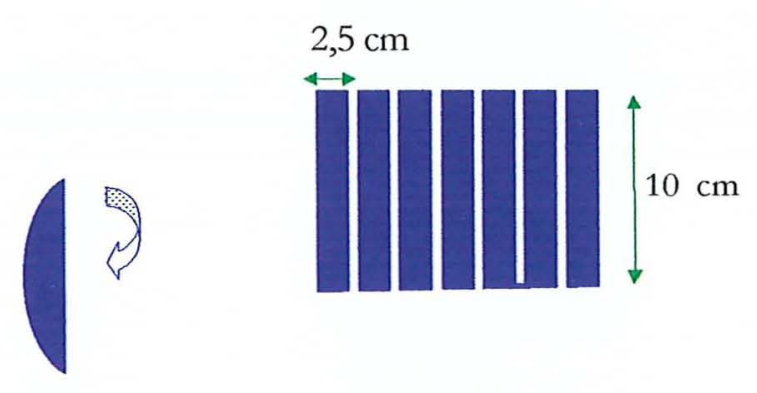

(c)

Figura 6 - Esquema do desdobro utilizado mostrando os cortes simultâneos efetuados numa serra de fita dupla (a), o corte simples de aproveitamento da costaneira numa ressera de fita simples (b) e os cortes simultâneos efetuados numa serra circular múltipla (c).

A Figura 7 mostra a diferença entre o desdobro por cortes tangenciais balanceados e o desdobro por cortes tangenciais de máximo aproveitamento. A Figura 7(a) mostra, no primeiro tipo de desdobro, a obtenção de apenas uma tábua desejada, qualquer que seja a largura da peça aproveitada da costaneira. Essa tábua é retirada da parte central da peça 
aproveitada da costaneira, de tal forma que seus bordos fiquem eqüidistantes da medula da tora.

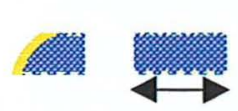

$10 \mathrm{~cm}$

(a)

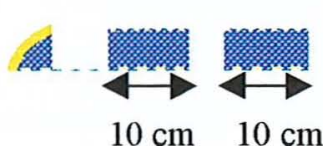

(b)

Figura 7 - Etapa final do desdobro por cortes balanceados (a) efetuado numa serra circular dupla e desdobro para máximo aproveitamento (b) efetuando numa serra circular tripla, mostrando o corte central, de desequilíbrio de tensões residuais.

A Figura $7(b)$ demonstra que no desdobro de máximo aproveitamento podem ser obtidas duas tábuas serradas, dependendo da largura da peça obtida da costaneira. Nesse caso as bordas de cada tábua não estão eqüidistantes da medula da tora.

Observa-se nas Figuras 6 e 7 que os equipamentos foram regulados para tábuas com dimensões da peça da Figura 8 , tomada como padrão, por ser a peça mais comumente encontrada no mercado de madeira serrada.

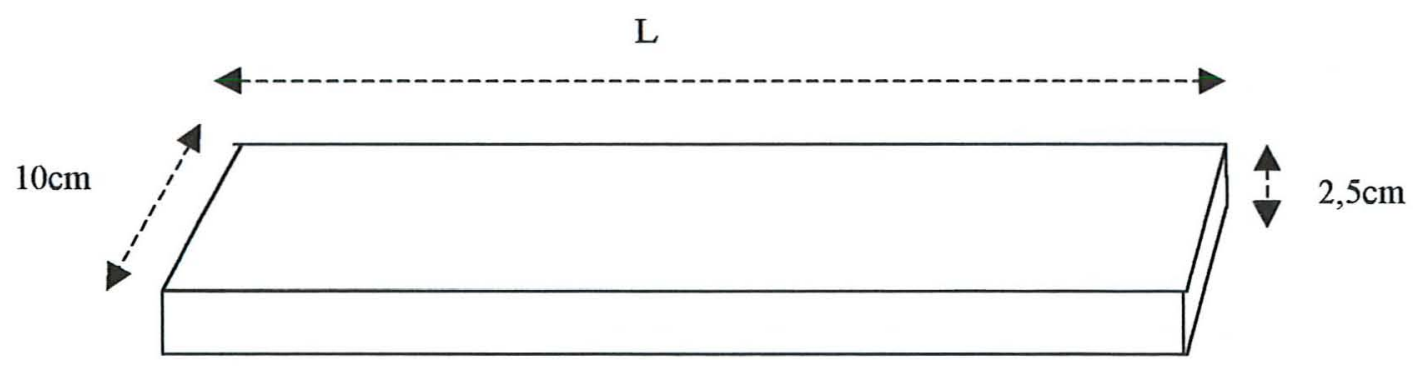

Figura 8 - Dimensões da tábua produzida. 
A partir dos resultados obtidos nos desdobros das toras foram determinados três tipos de rendimentos para cada tora, de acordo com a eq. (1), que mostra que os comprimentos foram cancelados por serem considerados iguais.

$$
\mathrm{RMS}_{\mathrm{tj}}=\frac{\mathrm{VMS}_{\mathrm{tj}}}{\mathrm{VT}_{\mathrm{j}}}=\frac{\mathrm{AMS}_{\mathrm{tj}} \mathrm{L}}{\mathrm{AT} \mathrm{T}_{\mathrm{j}} \mathrm{L}}=\frac{\mathrm{AMS}_{\mathrm{tj}}}{\mathrm{AT} \mathrm{T}_{\mathrm{j}}}
$$

onde:

$\mathrm{RMS}_{\mathrm{tj}}$ : rendimento em madeira serrada do tipo t na tora $\mathrm{j}(\%)$;

$\mathrm{VMS}_{\mathrm{tj}}$ : volume de madeira serrada do tipo t na tora $\left(\mathrm{m}^{3}\right)$;

$V T_{j}$ : volume da tora $j\left(m^{3}\right)$;

$\mathrm{L}$ : comprimento da tora $(\mathrm{m})$;

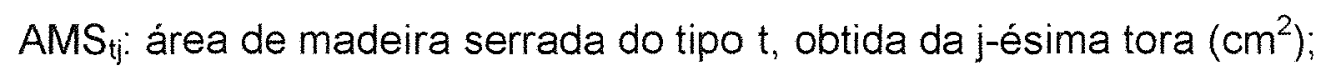

$\mathrm{AT}_{\mathrm{j}}$ : área da seção transversal na extremidade do menor diâmetro da j-ésima tora $\left(\mathrm{cm}^{2}\right)$.

A eq.(1) mostra que os comprimentos foram cancelados por serem iguais e que os rendimentos foram calculados com base numa tora cilíndrica de diâmetro igual ao diâmetro menor da tora e perfeitamente reta. Posteriormente esse rendimento foi minimizado por um fator de correção (eq.(7)) que leva em conta a forma da tora dada pela equação de forma da árvore. As variáveis $\mathrm{AMS}_{\mathrm{tj}}$ e $\mathrm{AT}_{\mathrm{j}}$ foram calculadas pelas equações (2) e (3), respectivamente.

$$
\begin{array}{r}
\operatorname{AMS}_{\mathrm{tj}}=\sum_{\mathrm{i}} \mathrm{a}_{\mathrm{i}_{\mathrm{tj}}} \mathrm{b}_{\mathrm{i}_{\mathrm{tj}}} \\
\mathrm{AT}_{\mathrm{j}}=\frac{\pi \mathrm{dj}^{2}}{4}
\end{array}
$$

onde:

$a_{i_{i j}} ; b_{i_{1 j}}$ : dimensões da seção transversal da i-ésima tábua, do tipo $t$, da tora $j$ $(\mathrm{cm})$;

$d_{\mathrm{j}}$ : menor diâmetro, sem casca, da tora $\mathrm{j}(\mathrm{cm})$. 
Foram definidos três tipos de madeira serrada em função do número de faces que continham nó. A tábua serrada que não continha nenhum nó em nenhuma de suas faces foi classificada como sendo do tipo 1. A tábua que continha um ou mais nós em uma única face foi classificada como tipo 2 e a peças serrada que continha pelo menos um nó em ambas as faces da tábua foi classificada como sendo do tipo 3 (Figura 9).

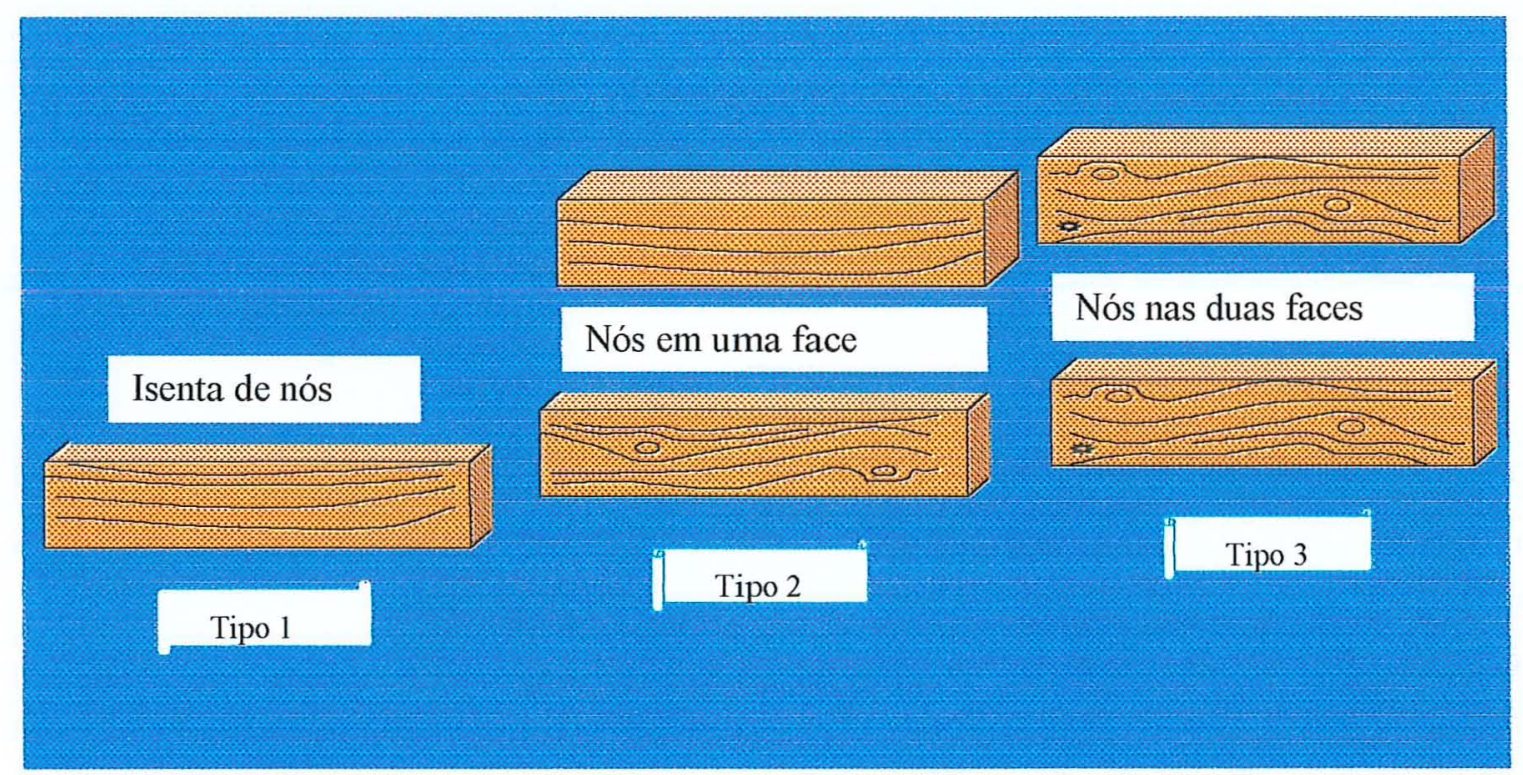

Figura 9 - Classes de qualidade da tábua em função da presença ou ausência de nós em suas faces.

Para a determinação do número de peças serradas de cada tipo reconstituiu-se a disposição espacial das tábuas na tora (Figura 10) e em seguida foi delimitado um circulo central, simbolizando o centro nodoso da árvore, formado em conseqüência da desrama, como mostra a Figura 11. 


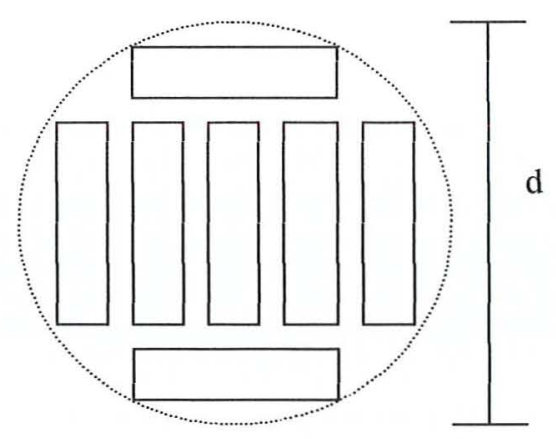

Figura 10 - Disposição das peças serradas na seção de menor diâmetro da tora.

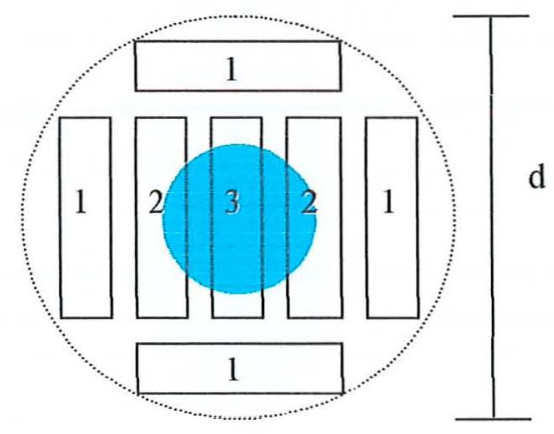

Figura 11 - Centro nodoso simulado para a classificação da peça serrada.

Observa-se na Figura 11, uma certa área de madeira isenta de nó, de espessura variável em função do diâmetro da tora e do diâmetro do centro nodoso. Foi então definida a variável $\Delta$ dada pela eq. (4), como sendo a variável que define o número de peças serradas de cada tipo.

$$
\Delta=d-d_{N}
$$

onde:

$\Delta$ : variável representativa da dupla espessura do anel de madeira isenta de nós $(\mathrm{cm})$;

d: diâmetro menor da tora $(\mathrm{cm})$;

$\mathrm{d}_{\mathrm{N}}$ : diâmetro do centro nodoso $(\mathrm{cm})$. 
Com os rendimentos obtidos de cada tipo de madeira serrada nos vários diâmetros de tora e com vários valores simulados de $d_{N}$ procurou-se obter uma função do tipo indicado pela eq. (5).

$$
\mathrm{RMS}_{\mathrm{t}}=\mathrm{f}(\Delta, \mathrm{d})
$$

Entretanto, talvez pelo número reduzido de diâmetros estudados, não foi conseguido nenhum modelo satisfatório para predizerem-se os rendimentos em madeira em função das variáveis $d$ e $\Delta$. Foram, então, ajustadas novas equações do tipo daquela da eq. (6), onde os rendimentos em madeira serrada são dependentes apenas da variável $\Delta$.

$$
\operatorname{RMS}_{\mathrm{t}}=\mathrm{f}(\Delta)
$$

\subsection{Determinação de volumes de madeiras serradas estocados na floresta}

A partir dos dados de inventário florestal de uma empresa florestal foram obtidas freqüências de árvores para cada uma das quatro classes de diâmetro existentes e os volumes de madeiras serradas estocados na floresta, foram calculados através da eq. (7).

$$
\mathrm{VMS}_{\mathrm{tc}}=\sum_{\mathrm{k}} \sum_{\mathrm{j}} \mathrm{RMS}_{\mathrm{ktj}} \cdot \mathrm{VT}_{\mathrm{kjc}} \cdot\left(\frac{2 \mathrm{~d}_{\mathrm{cj}}{ }^{2}}{\mathrm{~d}_{\mathrm{cj}}{ }^{2}+\mathrm{D}_{\mathrm{cj}}{ }^{2}}\right)
$$

onde:

VMS $_{\text {tc: }}$ volume de madeira serrada do tipo $t$ e comprimento $c$, estimado na floresta $\left(\mathrm{m}^{3}\right)$;

$\mathrm{RMS}_{\mathrm{ktj}}$; rendimento em madeira serrada do tipo t na tora j da árvore $\mathrm{k}$;

$V T_{\text {kjc: }}$ : volume da tora j de comprimento $\mathrm{c}$ da árvore $\mathrm{k}\left(\mathrm{m}^{3}\right)$;

$\mathrm{d}_{\mathrm{cj}}$ : diâmetro menor da tora j de comprimento $\mathrm{c}(\mathrm{cm})$;

$D_{\mathrm{cj}}$ : diâmetro maior da tora $\mathrm{j}$ de comprimento $\mathrm{c}(\mathrm{cm})$. 
O termo entre parentes do segundo membro da eq.(7) foi introduzido para corrigir o rendimento em madeira serrada, que depende do comprimento da tora que, por sua vez, depende do comprimento comercial da peça serrada.

Para o cálculo de $V T_{k j c}$ foram utilizadas duas equações de forma da árvore. A primeira delas foi a forma cônica, mostrada na Figura 12, sendo que a obtenção da variável diâmetro foi calculada em função da altura $\mathrm{h}$ ao longo do tronco da árvore através da eq (8). Esse modelo foi utilizado por ser extremamente simples e ajustável para cada árvore, sem necessidade do uso de informações sobre dados de cubagens rigorosas.

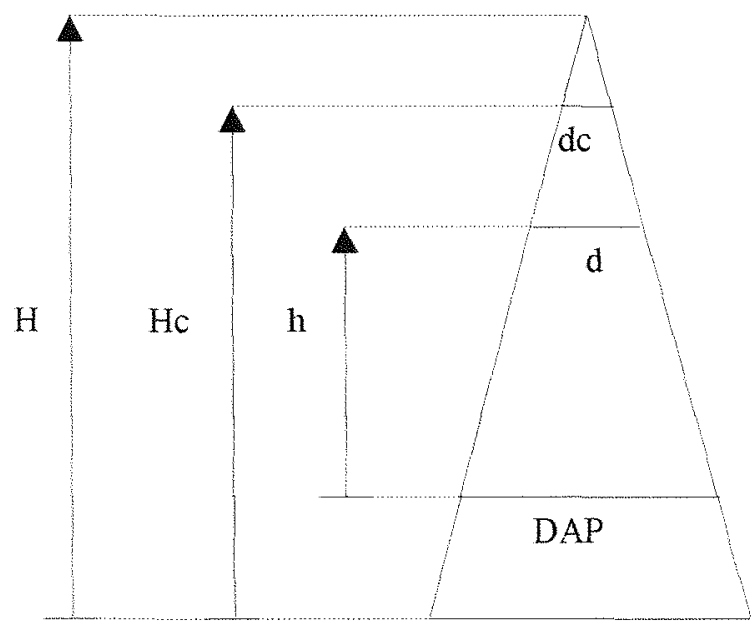

$\mathrm{H}$ : altura total da árvore $(\mathrm{m})$; dc: diâmetro comercial $(\mathrm{cm})$;

Hc: comprimento do fuste correspondente ao diâmetro comercial (m); d: variável diâmetro correspondente à variável altura na árvore $h(\mathrm{~cm})$.

Figura 12 - Forma simplificada da árvore suposta cônica.

$$
d=\operatorname{DAP}\left[1-\left[\frac{\mathrm{h}-1,3}{\mathrm{H}-1,3}\right]\right]
$$


A segunda equação de forma utilizada foi a de Ormerod $^{1}$ (1973), citado por Garcia (2000), dada pela eq. (9). Essa equação foi utilizada porque é de ajuste simples, embora exija os dados de uma cubagem rigorosa.

$$
d=D A P\left(\frac{H-h}{H-1,3}\right)^{k}
$$

Para a utilização da eq. (7), nos cálculos de volumes de madeiras serradas estocados na floresta em estudo, elaborou-se um programa, utilizando-se a planilha eletrônica EXCEL.

O programa gerado, embora complexo do ponto de vista de programação é muito simples de ser utilizado, sendo preciso digitar apenas os valores do DAP, altura total e diâmetro comercial da árvore representativa de cada classe de altura dentro de classe de diâmetro.

A planilha elaborada possibilita simulações de produção de madeira serrada em diferentes situações, podendo-se variar o comprimento da madeira serrada, uso de diferentes modelos da equação de forma da árvore e tipos de desrama. Dessa forma foi possível observar relações importantes entre variáveis de interesse que, por interferirem nos resultados, devem ser consideradas no manejo florestal voltado à produção de madeira serrada.

${ }^{1}$ ORMEROD, D.W. 1973. A simple bole model. Forestry Chronicle, v.41,p.136-138, 1973. 


\section{RESULTADOS E DISCUSSÃO}

4.1 Defeitos que influenciam no rendimento e qualidade da madeira serrada

O rendimento em madeira serrada resultante do desdobro de toras é influenciado por fatores inerentes à madeira, ao processo e ao equipamento utilizado. O nó (Figura 13), dentre os fatores inerentes à madeira, não afeta o rendimento em madeira serrada, mas influencia na qualidade da madeira serrada, tanto por sua incidência propriamente dita quanto pela podridão que vem, normalmente, a ele associada.
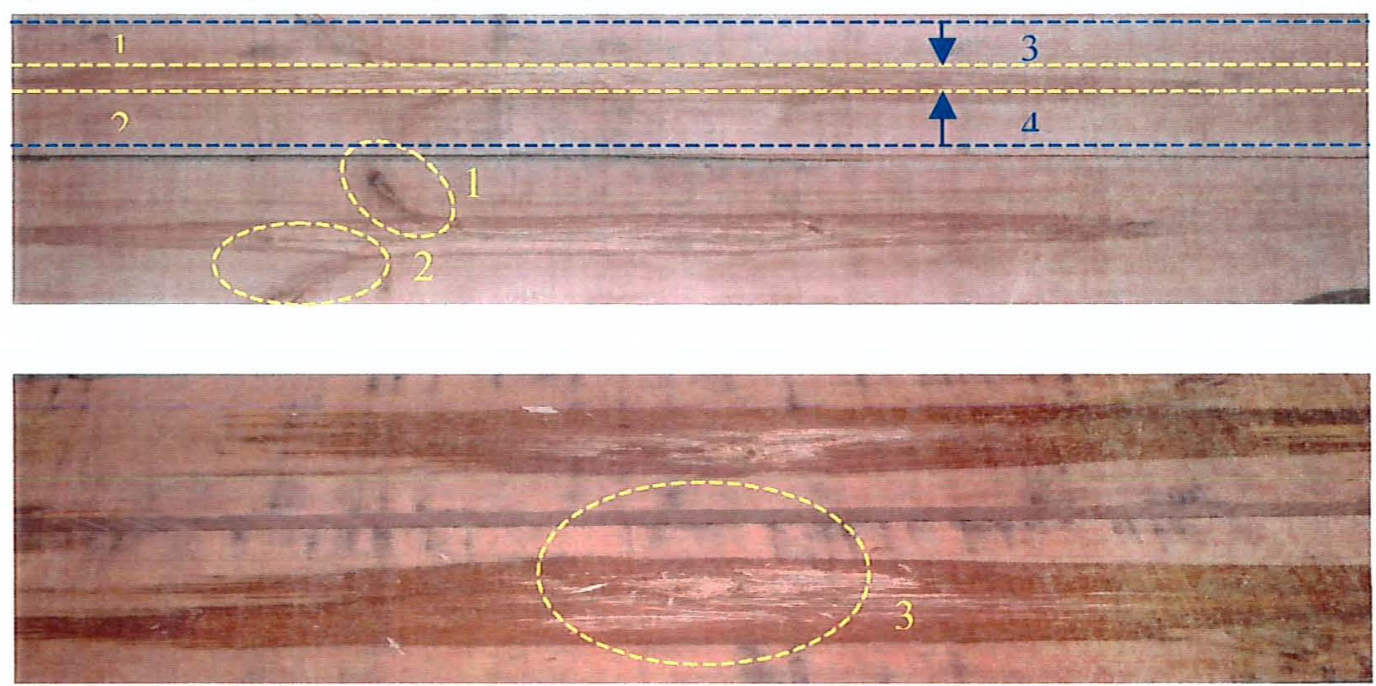

Figura 13 -Tábuas de Eucalyptus grandis mostrando a presença de nós (a) e podridão da madeira associada ao nó (b), ambos evidenciando efeitos depreciativos na qualidade da madeira serrada. 
O círculo pontilhado 1 da peça (a) destaca um exemplo de nó morto, que é de fácil detecção visual pois não faz parte do contínuo da peça e apresenta uma coloração demasiadamente escura em relação à normal. A tendência do nó morto é soltar-se durante o desdobro podendo causar depreciação significativa na qualidade da peça, dependendo de sua posição e de sua dimensão relativa às dimensões da tábua serrada. Sua incidência pode inviabilizar totalmente a madeira para diversos usos.

O círculo pontilhado 2 mostra um exemplo de nó vivo, oriundo de um galho que permaneceu ativo fisiologicamente na árvore até o momento de sua exclusão. Este tipo de nó integra-se perfeitamente ao tecido lenhoso e sua presença na peça serrada, quando de tamanho reduzido, não impede seu uso para lambris, assoalhos, móveis, forros, revestimentos ou mesmo para determinados fins estruturais. Todavia, determinados usos estéticos podem rejeitar a madeira com este tipo de defeito. Na produção de peças serradas ditas "clear", limpas de qualquer defeito depreciativo, visual ou estrutural, a incidência de qualquer tipo de nó faria com que este material fosse descartado.

As linhas pontilhadas 1 e 2 da Figura 13 da peça de madeira (a) simulam a demarcação da região de madeira juvenil da árvore, madeira que em princípio, já seria desprezada.

O rendimento em madeira serrada de primeira classe também é influenciado pela proporção de madeira adulta e madeira juvenil. Todas as propriedades da madeira juvenil, tanto físicas como químicas, apresentam-se excessivamente variáveis sendo muito mais constantes na madeira adulta (Miranda, 1997).

A desrama artificial é uma forma de induzir a formação de maior quantidade de madeira isenta de nós ao restringir a zona de sua ocorrência a um reduzido volume ao centro do tronco. Tal atividade de manejo florestal pode ser orientada e desenvolvida para fazer com que a região nodosa coincida com a região de madeira juvenil. Neste contexto o exemplo da Figura 13(a) mostra que se a prática da desrama artificial restringisse mais ao centro da tora a região da 
peça demarcada pelas linhas pontilhadas 3 e 4, que delimita a região nodosa, fazendo-a coincidir com as linhas pontilhadas 1 e 2 (região de madeira juvenil) a perda em produtividade de madeira serrada resultante da presença de áreas defeituosas seria reduzida, além de haver aumento de rendimento em madeira serrada do tipo 1 (melhor qualidade) por aumentar a disponibilidade na de madeira isenta de nó na tora.

O círculo pontilhado 3 da peça (b) da Figura 13 mostra um exemplo de podridão da madeira associada a um nó. A podridão é causada por fungos que são trazidos pelo vento e se desenvolvem no entorno do nó onde normalmente existe um teor de umidade adequado ao seu desenvolvimento. A presença do nó favorece a infiltração de água no interior da madeira aumentando a probabilidade da propagação da podridão para o interior do tronco.

A podridão da madeira não é detectada na árvore em pé. Assim, grande quantidade de recursos podem ser desperdiçados nas atividades de colheita, transporte e desdobro de toras que apresentam podridão interna da madeira. Portanto, a desrama artificial é também recomendada do ponto de vista da otimização do conjunto de operações voltadas à produção de madeira serrada.

As características da árvore que influenciam diretamente na produtividade em madeira serrada são a forma do seu tronco, o diâmetro da tora desdobrada e a intensidade da tensão de crescimento, que afeta o rendimento em madeira serrada por causa das rachaduras de extremidades de tábua e também pelos empenamentos provocados nas peças serradas. Entretanto, essa característica não foi considerada no presente trabalho. 


\subsection{Rendimentos no desdobro de toras em função de duas variáveis independentes}

$\mathrm{Na}$ Figura 14 estão apresentados os resultados médios do rendimento em madeira serrada e do rendimento em resíduo composto pelas costaneiras, aparas e serragem para as duas técnicas de desdobro aplicadas em toras de diferentes diâmetros.

O diâmetro mínimo da tora é um dos fatores que influência fortemente o rendimento em madeira serrada, que em geral aumenta com o aumento do diâmetro da tora. Contudo, os resultados de rendimento em madeira serrada fornecidos neste experimento para as toras desdobradas com diâmetros de $14 \mathrm{~cm}, 17 \mathrm{~cm}, 20 \mathrm{~cm}, 23 \mathrm{~cm}, 26 \mathrm{~cm}, 29 \mathrm{~cm}$ e $32 \mathrm{~cm}$, foram respectivamente de $56,45 \%, 43,99 \%, 57,96 \%, 48,62 \%, 61,83 \%, 51,38 \%$ e $47,33 \%$ para o desdobro por cortes balanceados e $56,38 \%, 44,16 \%, 57,89 \%$, $48,86 \%, 61,97 \%, 58,02 \%$ e $59,17 \%$ para o desdobro por cortes tangenciais de máximo aproveitamento.

A diferença entre os sistemas de desdobro aumenta com o aumento do diâmetro da tora, mas somente a partir do ponto em que o diâmetro utilizado possibilite o aproveitamento de uma peça da costaneira, que por sua vez possibilite a obtenção de mais de uma peça serrada. 


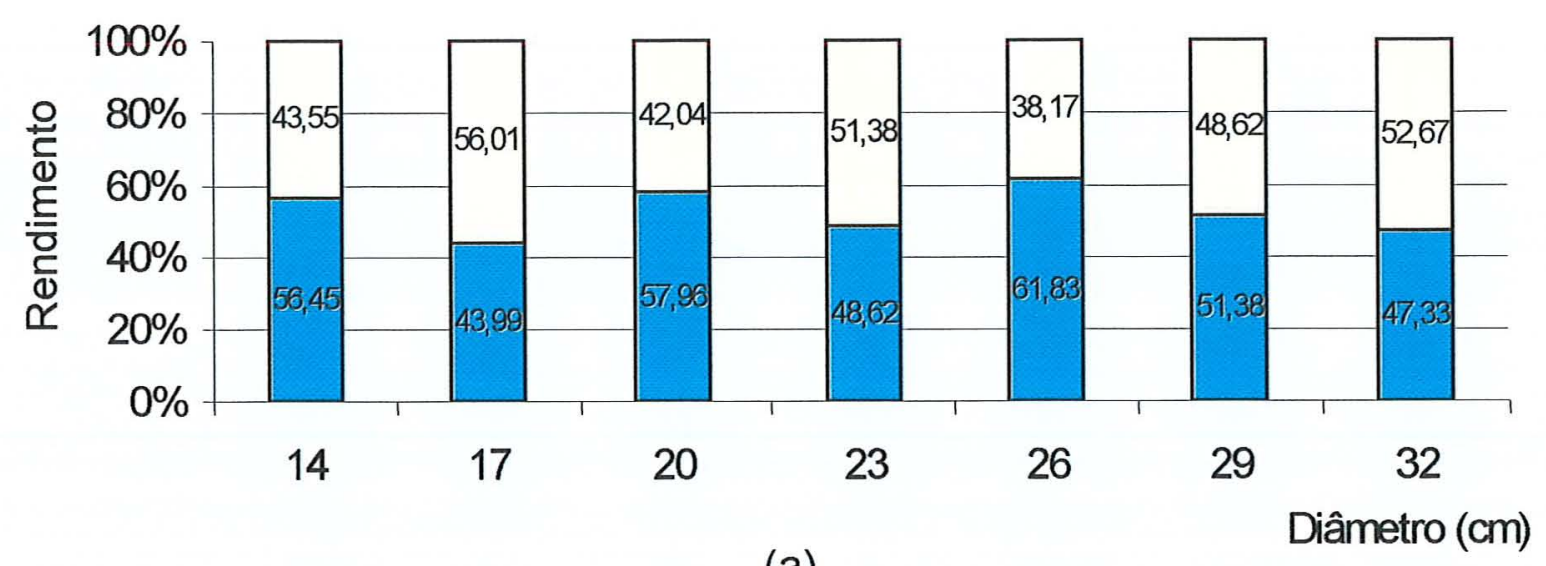

(a)

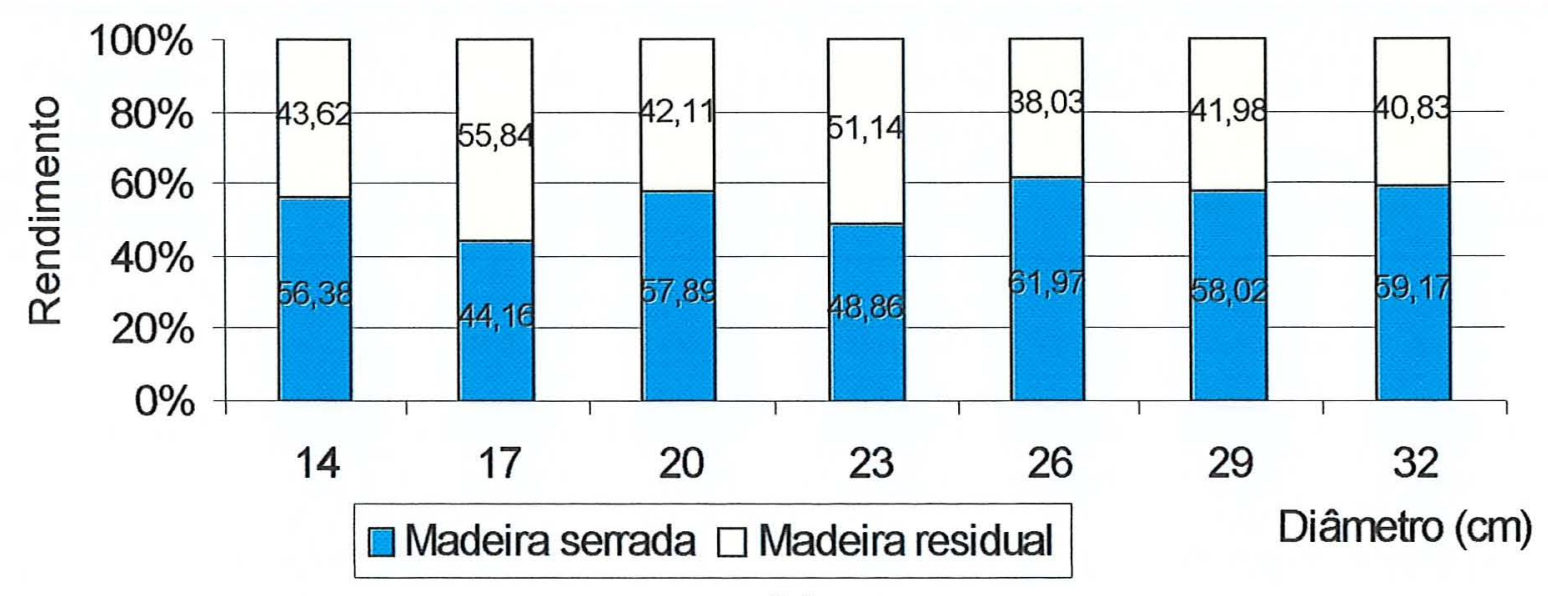

(b)

Figura 14 - Rendimentos médios em madeira serrada e em resíduo, obtidos no desdobro de toras de Eucalyptus grandis segundo a técnica de desdobro por cortes tangenciais balanceados (a) e por cortes tangenciais de máximo aproveitamento (b). 
O sistema de desdobro por cortes tangenciais balanceados foi o mais indicado em comparação ao sistema de desdobro por cortes tangenciais de máximo aproveitamento para os diâmetros comumente encontrados em reflorestamentos jovens, inferiores a $26 \mathrm{~cm}$, além da vantagem de minimizar os efeitos das tensões residuais, para diferenças não significativas de rendimentos.

Observa-se que o rendimento em madeira serrada total variou, aproximadamente, dentro do intervalo de 33 a $61 \%$ compreendendo todas as variações impostas pela variação do diâmetro da tora e pelas técnicas de desdobros aplicadas.

A experiência tem demonstrado que 0 rendimento em madeira serrada para o gênero Eucalyptus encontra-se entre 35 e 60\%, dependendo, do diâmetro da tora e da ocorrência de rachamentos (Miranda, 1997).

Os valores de rendimento em madeira serrada obtidos podem ser considerados satisfatórios, porém é necessário lembrar que houveram características da tora importantes que precisam ser comentadas como o fato de se ter utilizado durante o experimento toras isentas de casca e retas.

A utilização de toras com estas características implica em perdas menores durante os desdobro para ambos os tipos de métodos. A madeira serrada com características dimensionais adequadas, melhora o rendimento ao reduzir as variações e sobremedidas.

Um dos fatores que contribuem para reduzir o rendimento em madeira serrada de espécies do gênero Eucalyptus é a ocorrência do rachamento de toras antes e durante o desdobro. 
Tensões de crescimento e secagem são as principais causas de rachamentos das toras, principalmente em suas extremidades. Peças serradas de eucalipto podem, portanto apresentar limitações em seu uso provenientes destas características.

O processamento mecânico da madeira de eucalipto é dificultado em função de suas características intrínsicas como tensões de crescimento, madeira juvenil, colapso, nós, empenamento, bolsas de resinas e variabilidades de propriedades (Ponce, 1997).

A madeira de eucalipto embora apresente problemas durante seu processamento, muitos deles têm sido amenizados através da realização de diversas pesquisas pelo setor que tem promovido a evolução das técnicas de desdobro.

A aquisição de novos conhecimentos pelo setor, quanto ao comportamento estrutural da madeira de eucalipto, bem como sua manipulação, tem estimulado e ampliado seu uso para diferentes finalidades.

A escolha de métodos de desdobro convenientes para toras de eucaliptos, podem exercer evidente influência no rendimento final em madeira serrada ao minimizar os efeitos de tensões de crescimento, como é o caso do desdobro por cortes tangenciais balanceados.

É importante ressaltar o fato de que o experimento foi realizado de forma controlada onde erros operacionais foram evitados ao máximo por tratarse de um desdobro de caráter experimental voltado à pesquisa.

As Figuras 15, 16 e 17 mostram, respectivamente, as superfícies de resposta da variável rendimento em madeira serrada do tipo 1, 2 e 3 no desdobro por cortes tangenciais balanceados, sendo que o tipo 1 representa a quantidade de madeira serrada isenta de nós, portanto, de qualidade superior. 
O rendimento em madeira serrada pode ser analisado nos diâmetros mínimos de tora de $14 \mathrm{~cm}, 17 \mathrm{~cm}, 20 \mathrm{~cm}, 23 \mathrm{~cm}, 26 \mathrm{~cm}, 29 \mathrm{~cm}$ e 32 $\mathrm{cm}$ e em distintos valores assumidos pela variável $\Delta$ no intervalo de 0 a $26 \mathrm{~cm}$.

A variável $\Delta$ foi obtida subtraindo-se o diâmetro do centro nodoso do diâmetro total da tora como já foi explicado detalhadamente no item 3.1. Esta variável foi considerada no presente trabalho como uma variável preditora do rendimento em madeira serrada dos diferentes tipos.

Na Figura 15(a) verifica-se um aumento do rendimento em madeira serrada do tipo 1 com o aumento da variável $\Delta$. Esta ocorrência é explicada pelo fato de que a variável $\Delta$ representa a região do tronco isenta de nós e, portanto, o seu aumento implica na maior possibilidade de obtenção de tábuas limpas, ou seja, sem nós

Verifica-se também que existe uma tendência de aumento do rendimento em madeira serrada do tipo 1 , com o aumento do diâmetro mínimo da tora.

Na Figura 15(b) pode-se observar que as regiões demarcadas por cores representativas de rendimentos superiores caminham em direção ao nordeste da própria figura, coincidindo, com os aumentos simultâneos das variáveis diâmetro e $\Delta$. 

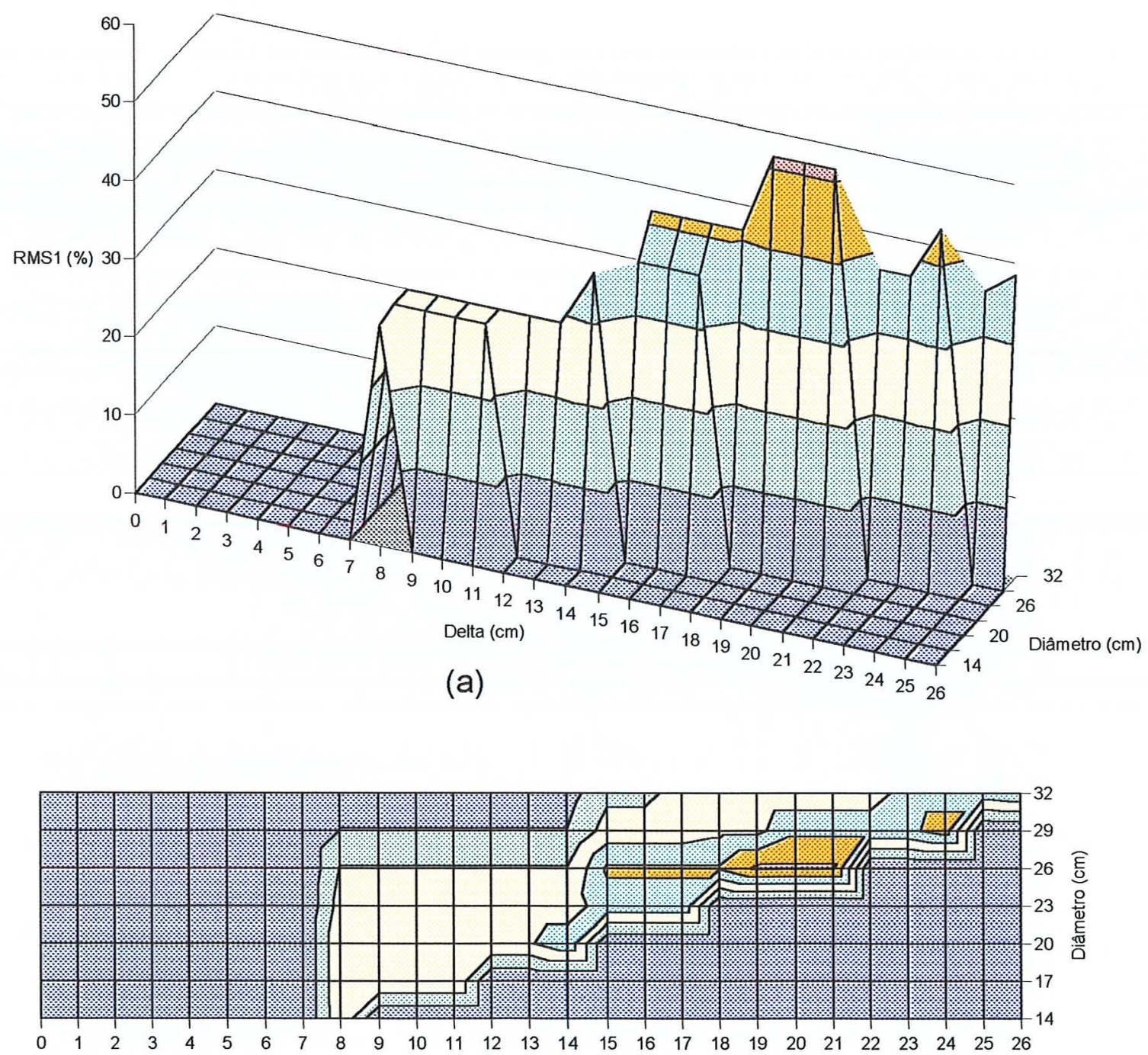

Delta $(\mathrm{cm})$

RMS1 (\%)

⿴囗十0-60

$\square 40-50$

(b)

․ $30-40$

ㅁ20-30

ब10-20

回-10

Figura 15 - Rendimento em madeira serrada do tipo 1 de Eucalyptus grandis obtido na técnica de desdobro por cortes tangenciais balanceados representado como uma superfície de resposta (a) ou como curvas de níveis de rendimento (b). 
Pode-se inferir, portanto, que a quantidade de madeira serrada isenta de nó é encontrada em maior porcentagem na base da árvore, região onde são encontrados maiores valores em diâmetros e maiores valores da variável $\Delta$.

O sistema de desdobro por cortes tangenciais balanceados apresentou para toras de diâmetros mínimos entre 14 e $26 \mathrm{~cm}$, rendimentos crescentes em madeira serrada do tipo 1.

$\mathrm{Na}$ Figura 15(b) pode-se observar a ocorrência das maiores porcentagens de rendimento em madeira serrada na região próxima da marca de $26 \mathrm{~cm}$ em diâmetro para as toras desdobradas indicando que este diâmetro pode ser considerado o diâmetro ótimo para obtenção da peça padrão de $2,5 \mathrm{X}$ $10 \mathrm{~cm}$ no desdobro por cortes tangenciais balanceados. A partir deste diâmetro o rendimento apresenta um declínio contínuo até o diâmetro de $32 \mathrm{~cm}$.

O rendimento de madeira serrada seja ele de qualquer dos tipos analisados (1,2 ou 3) apresenta rendimentos maiores, geralmente, com o aumento dos diâmetros mínimos da tora.

Contudo, o rendimento em madeira serrada somente aumenta quando existe a possibilidade de conseguir-se para um determinado diâmetro, um número de peças superior em relação ao número de peças obtidas no diâmetro anterior.

A redução do rendimento em madeira serrada significa aumento de perdas residuais representadas predominantemente pelo rendimento em costaneira, que sobe conforme mais deficiente for o aproveitamento das tábuas durante o desdobro. 
As regiões de pico relacionadas ao rendimento de madeira serrada verificadas no gráfico (a) da Figura 15 não necessariamente coincidem com os maiores valores das variáveis $\Delta$ e diâmetro, pois diâmetros maiores não implicam na certeza da obtenção de maior produtividade de madeira serrada durante o desdobro de toras.

A Figura 16 mostra a variação da variável rendimento em madeira serrada do tipo 2 que representa a madeira serrada contendo tábuas com apenas uma face com presença de nós.

O rendimento em madeira serrada do tipo 2 , em geral, declina com o aumento da variável $\Delta$. Tal fato pode explicado pela mudança do tipo 2 para o tipo 1, uma vez que a região nodosa diminui com o aumento da variável $\Delta$.

A Figura 16(b) mostra uma maior concentração dos maiores rendimentos em madeira serrada do tipo 2 nos menores valores da variável $\Delta \mathrm{e}$ da variável diâmetro mínimo da tora, dentro dos intervalos estudados.

O rendimento em madeira serrada do tipo 2, possuí um intervalo de variação entre 0 e $30 \%$, sendo portanto, menor que os demais tipos. Essas menores porcentagens no rendimento em madeira serrada do tipo 2 eram esperadas, já que este tipo de tábua ocorre em menor número que os outros tipos. A madeira, do tipo 3, por exemplo, pode ser encontrada em todo o raio do tronco da árvore, sendo portanto sua ocorrência muito mais freqüente. 

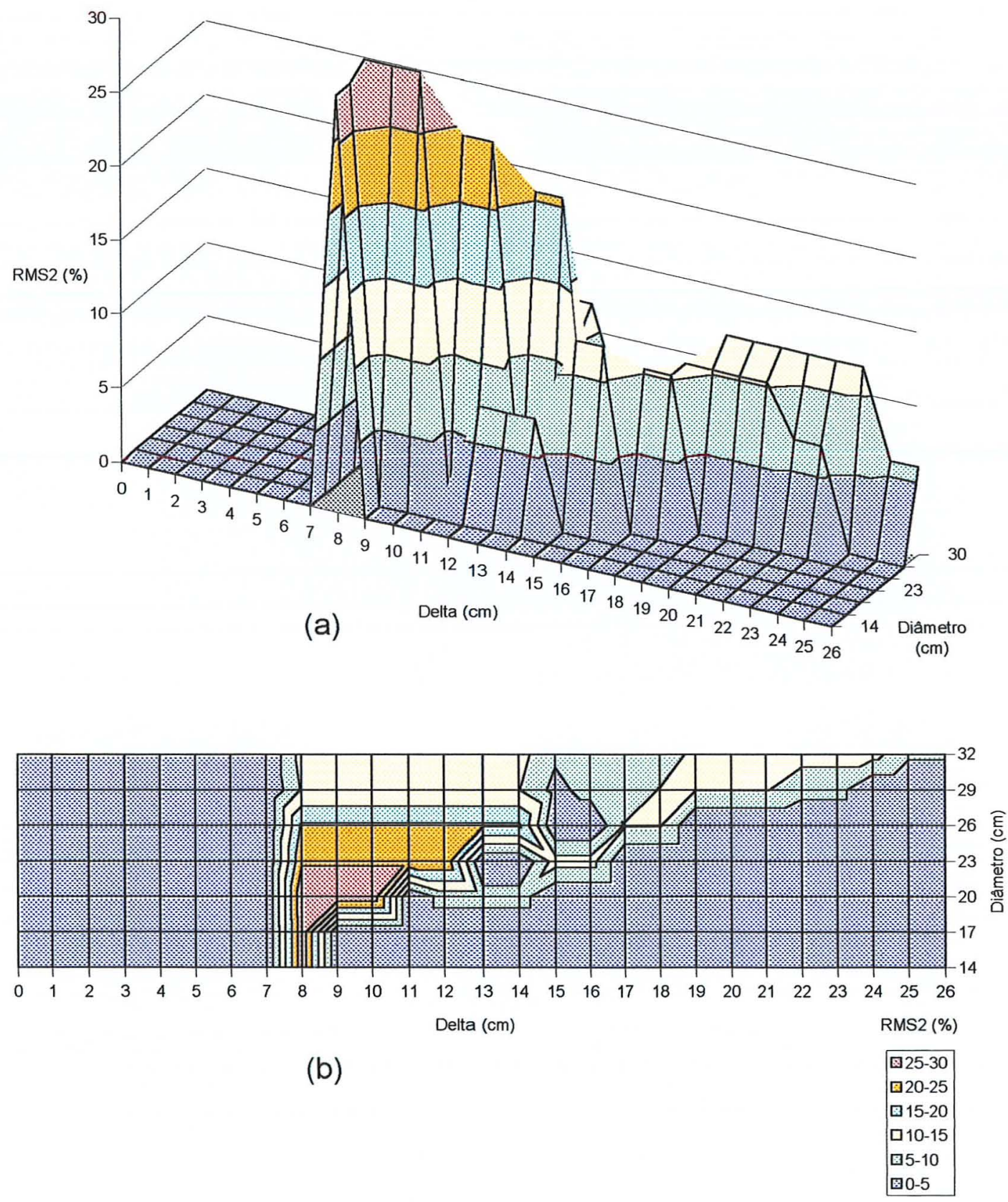

Figura 16 - Rendimento em madeira serrada do tipo 2 de Eucalyptus grandis, obtido na técnica de desdobro por cortes tangenciais balanceados representado como uma superfície de resposta (a) ou como curvas de níveis de rendimento (b). 
A Figura 17(a) apresenta a superfície de resposta da variável rendimento em madeira serrada do tipo 3 , que representa a quantidade de madeira serrada com presença de nós nas duas faces da tábua, nas peças obtidas durante o desdobro por cortes tangenciais balanceados.

Os gráficos (a) e (b) da Figura 17 mostram que este tipo de tábua tende a desaparecer para altos valores da variável $\Delta$, porque parte delas se transformam em tipo 2 e parte em tipo 1.

Verifica-se que, ao contrário do rendimento em madeira serrada tipo 1 , o aumento no rendimento em madeira serrada do tipo 3 , geralmente ocorre com a diminuição da variável $\Delta$, para os diâmetros mínimos considerados.

$\mathrm{O}$ aumento do rendimento em madeira serrada do tipo $3 \mathrm{com}$ a diminuição dos valores da variável $\Delta$, tende a ocorrer porque quanto menor for a região diametral do tronco isenta de nós, indicada pela variável $\Delta$, menor a possibilidade da retirada de tábuas limpas, ocorrendo então, maior freqüência de tábuas com nós.

$\mathrm{Na}$ Figura 17 (b) pode-se observar que as regiões demarcadas por cores representativas de rendimentos superiores caminham em direção a oeste da própria figura, coincidindo com a redução da variáveis $\Delta$. 

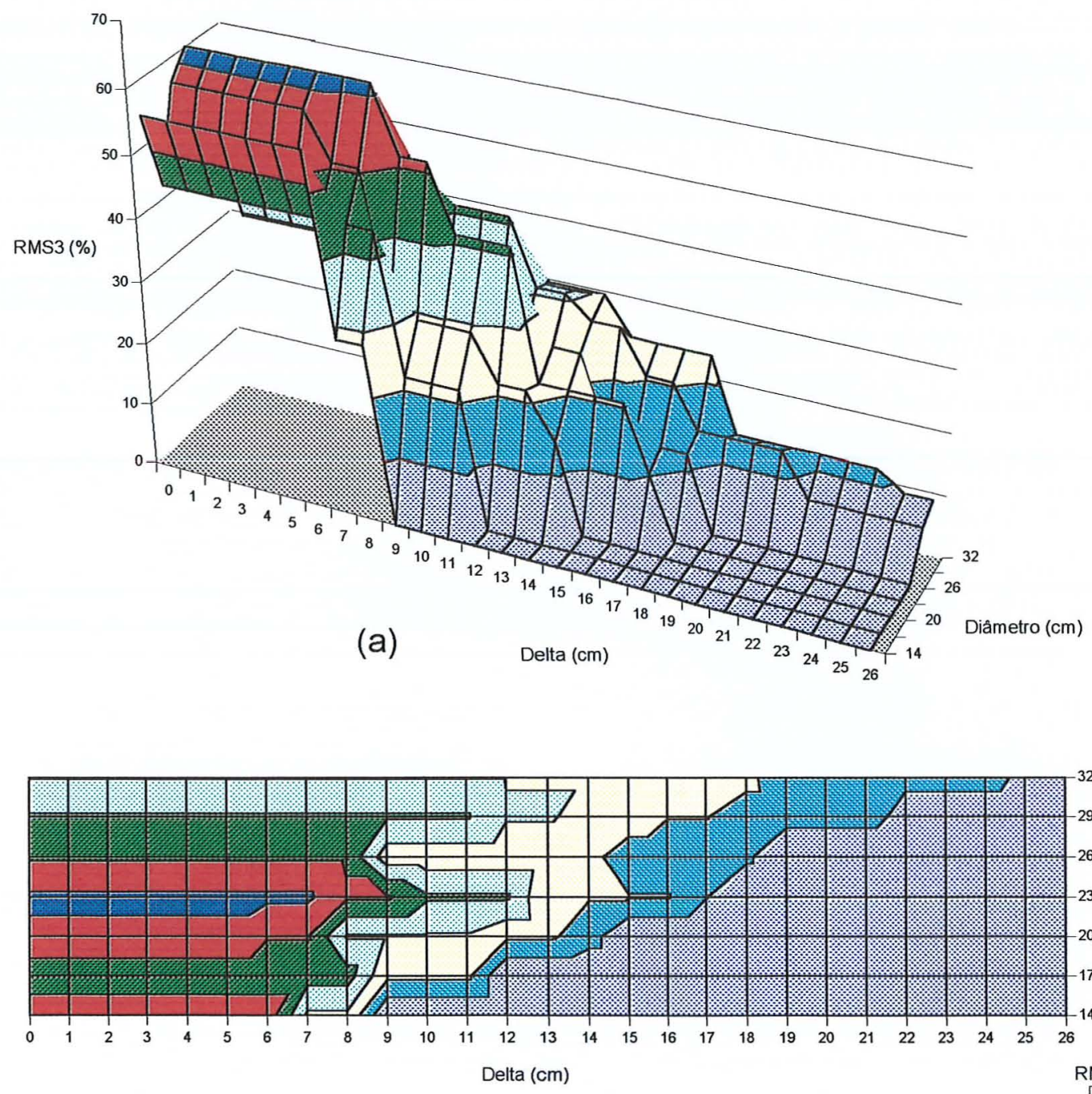

(b)

Figura 17 -Rendimento em madeira serrada do tipo 3 de Eucalyptus grandis obtido na técnica de desdobro por cortes tangenciais balanceados representado como uma superfície de resposta (a) ou como curvas de níveis de rendimento (b). 
A Figura 18 demonstra graficamente a superfície de resposta da variável rendimento em madeira serrada do tipo 1 obtida para o sistema de desdobro por cortes tangenciais de aproveitamento máximo.

No gráfico (a) da Figura 18 verifica-se o rendimento em madeira serrada do tipo 1 aumenta com o aumento da variável $\Delta$. Esta ocorrência é facilmente compreendida porque quanto maior a região diametral do tronco isenta de nós, representada pela variável $\Delta$, maior a possibilidade de retirada de tábuas isentas de nós. Estes aspectos, também comentados no desdobro por cortes tangenciais balanceados podem ser visualizados, com relativa facilidade no gráfico (b) da Figura 18, onde as regiões demarcadas por cores representativas de rendimentos superiores localizam-se nas faixas de diâmetros maiores e de valores da variável $\Delta$ mais altos.

Repete-se, portanto o comportamento já demonstrado anteriormente durante a análise do rendimento em madeira serrada do tipo 1 para o desdobro por cortes tangenciais balanceados.

Observa-se que, ao contrário do esperado, o método de desdobro por cortes tangenciais de máximo aproveitamento não apresentou resultados de rendimento em madeira serrada do tipo 1 mais satisfatórios que os resultados obtidos através do desdobro por cortes tangenciais balanceados para todos os diâmetros de tora de até $26 \mathrm{~cm}$.

A diferença entre os dois tipos de desdobro começa a aparecer somente quando a peça aproveitada da costaneira tem uma largura tal que possibilite a obtenção de mais de uma tábua. 

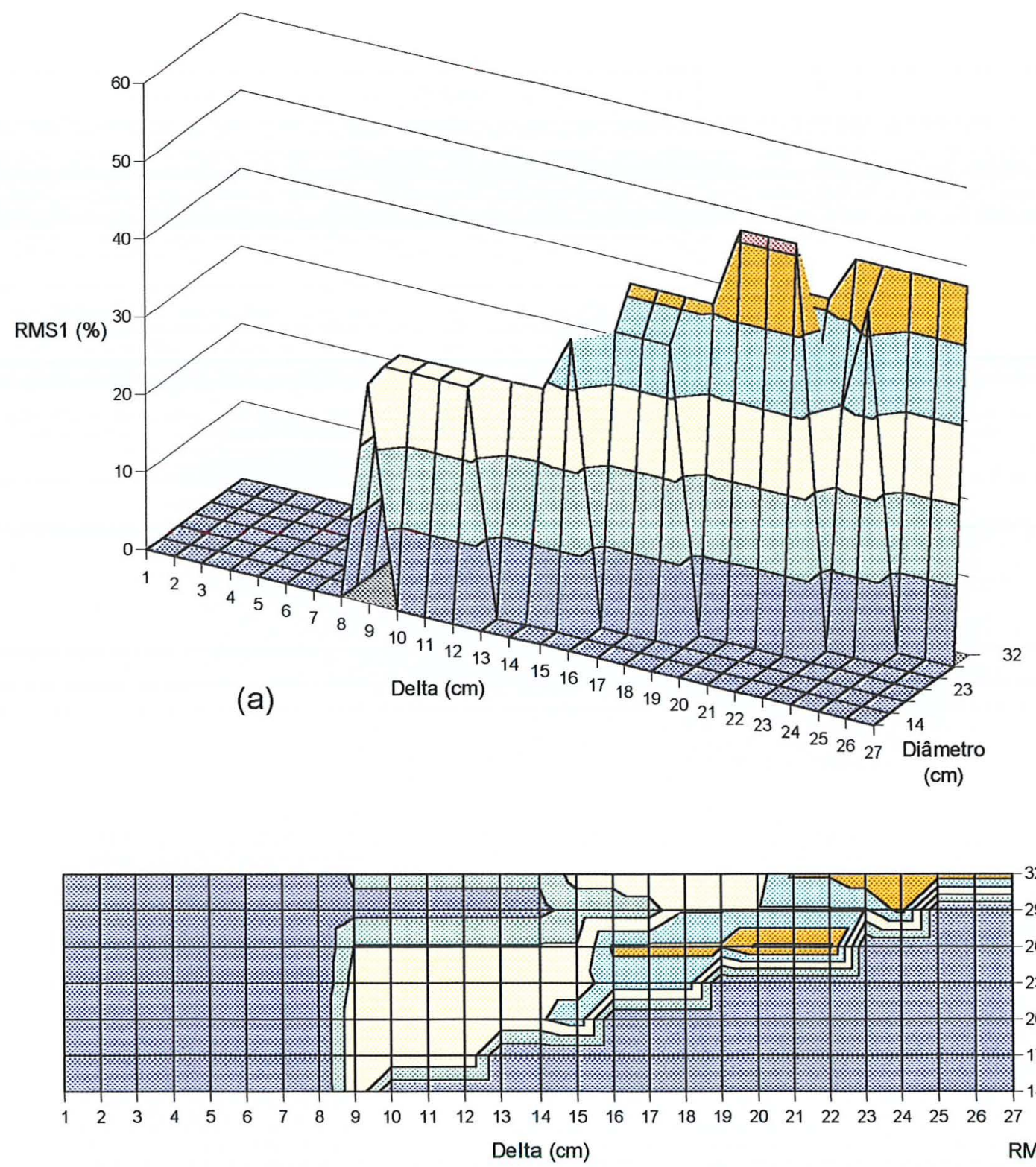

(b)

RMS1 (\%)

ब50-60

๑40-50

⿶30-40

口20-30

๑10-20

B0-10

Figura 18 - Rendimento de madeira serrada do tipo 1 para as toras desdobradas de Eucalyptus grandis no sistema de desdobro por cortes tangenciais para máximo aproveitamento representado como uma superfície de resposta (a) ou como curvas de níveis de rendimento (b). 
A partir deste ponto o rendimento em madeira serrada no desdobro por cortes tangenciais balanceados começa a diminuir pelas perdas laterais provenientes da peça aproveitada da costaneira, pelo fato de ser retirada apenas uma tábua central dessa peça e o rendimento de madeira serrada no desdobro por cortes tangenciais de máximo aproveitamento começa a aumentar porque permite, que seja aproveitada toda a largura da peça útil da costaneira.

Picos diferenciados foram detectados para as superfícies de respostas apresentadas para $\circ$ rendimento em madeira serrada tipo 1 representadas nas Figura 15 e 18 para os respectivos sistemas de desdobro por cortes tangenciais balanceados e por cortes tangenciais de máximo aproveitamento. Estes picos em regiões distintas, mesmo em se tratando da mesma variável resposta, são explicadas pelo número diferente de tábuas obtido, em regiões idênticas, explicado pelo uso das diferentes técnicas de desdobro que fornecem uma solução diferenciada de corte para a tora em cada situação.

A Figura 19 mostra a superfície de resposta da variável rendimento em madeira serrada do tipo 2, no desdobro por cortes tangenciais de máximo aproveitamento. A discussão desta figura é, praticamente, a mesma efetuada na Figura 16, quanto então foi analisado o desdobro por cortes tangenciais balanceados.

A Figura 20 apresenta a superfície de resposta da variável rendimento em madeira serrada do tipo 3 , no desdobro por cortes tangenciais de máximo aproveitamento e suas características mais marcantes são as mesmas comentadas na Figura 17, quando então foi analisado o desdobro por cortes tangenciais balanceados.

Foram investigadas portanto duas técnicas de desdobro aplicadas em toras de diferentes diâmetros. O primeiro método de desdobro empregado foi - sistema por cortes tangenciais balanceados, indicado para espécies que possuem altos niveis de tensões de crescimento, como é o caso da maioria das espécies do gênero Eucalyptus e o segundo foi o método de desdobro por cortes 
tangenciais de máximo aproveitamento, que é indicado para espécies com baixos niveis de tensões de crescimento, como é o caso das espécies do gênero Pinus.

O diâmetro menor da tora confirmou ser um dos fatores que influencia no rendimento em madeira serrada, que em geral aumenta com o aumento desse diâmetro. Contudo, os resultados obtidos neste experimento mostram que o rendimento em madeira serrada não aumenta, necessariamente, com o aumento de um diâmetro para um seu sucessor superior.

O rendimento em madeira serrada apenas aumenta quando há a possibilidade de obter-se em um determinado diâmetro, pelo menos uma peça a mais em relação ao número de peças que foram tiradas no diâmetro anterior.

O sistema de desdobro por cortes tangenciais balanceados é mais indicado, para os diâmetros de até $26 \mathrm{~cm}$, do que o sistema de desdobro por cortes tangenciais de máximo aproveitamento. Isso ocorre porque os rendimentos apresentados foram semelhantes, mas o primeiro método de desdobro apresenta a vantagem de minimizar os efeitos de tensões residuais. 

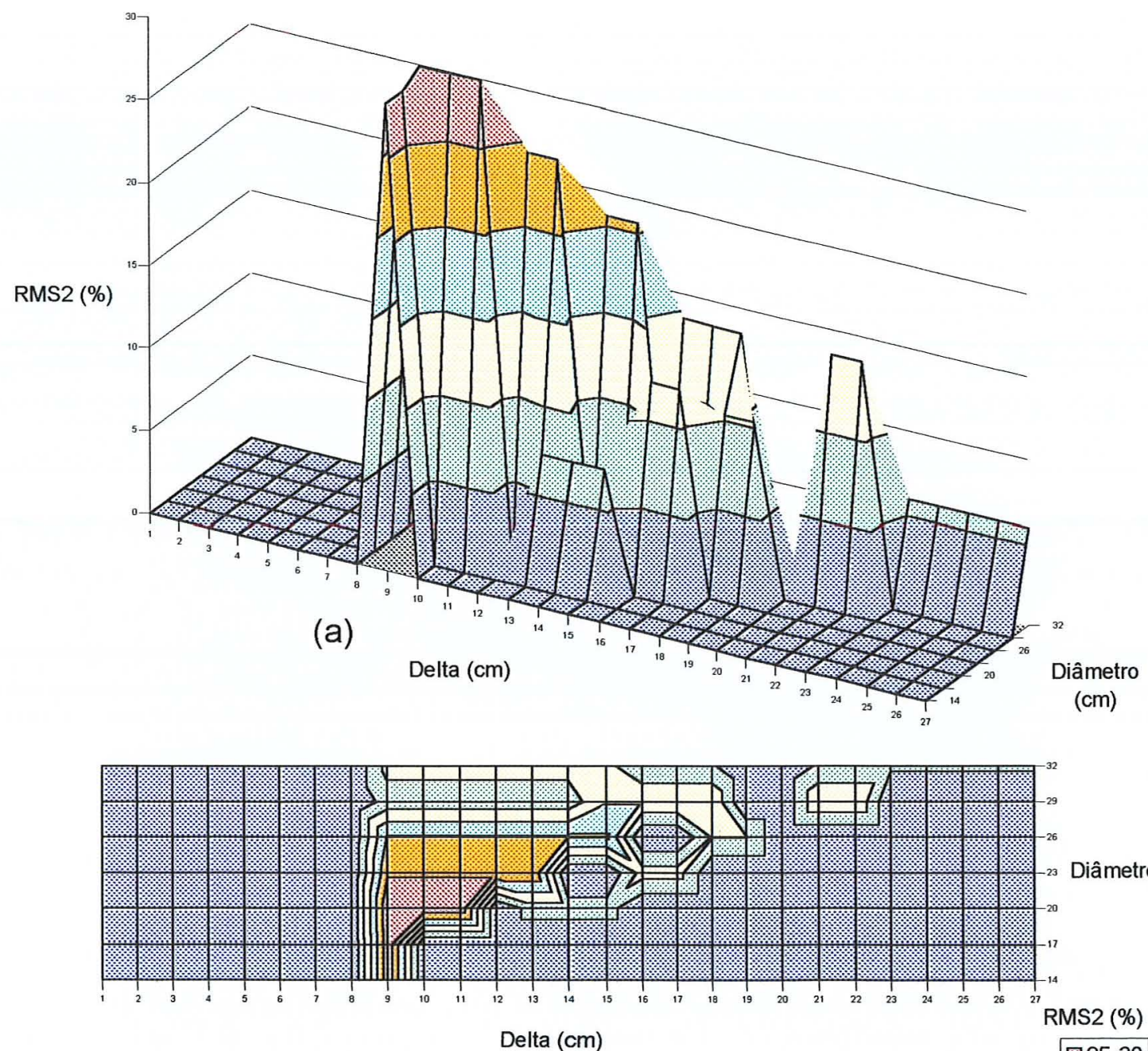

(b)

RMS2 (\%)
\begin{tabular}{|l|}
\hline 迆5-30 \\
⿴囗2 20-25 \\
$015-20$ \\
$\square 10-15$ \\
$05-10$ \\
$00-5$ \\
\hline
\end{tabular}

Figura 19 - Rendimento de madeira serrada do tipo 2 para as toras desdobradas de Eucalyptus grandis no sistema de desdobro por cortes tangenciais de máximo aproveitamento representado como uma superfície de resposta (a) ou como curvas de níveis de rendimento $(b)$. 

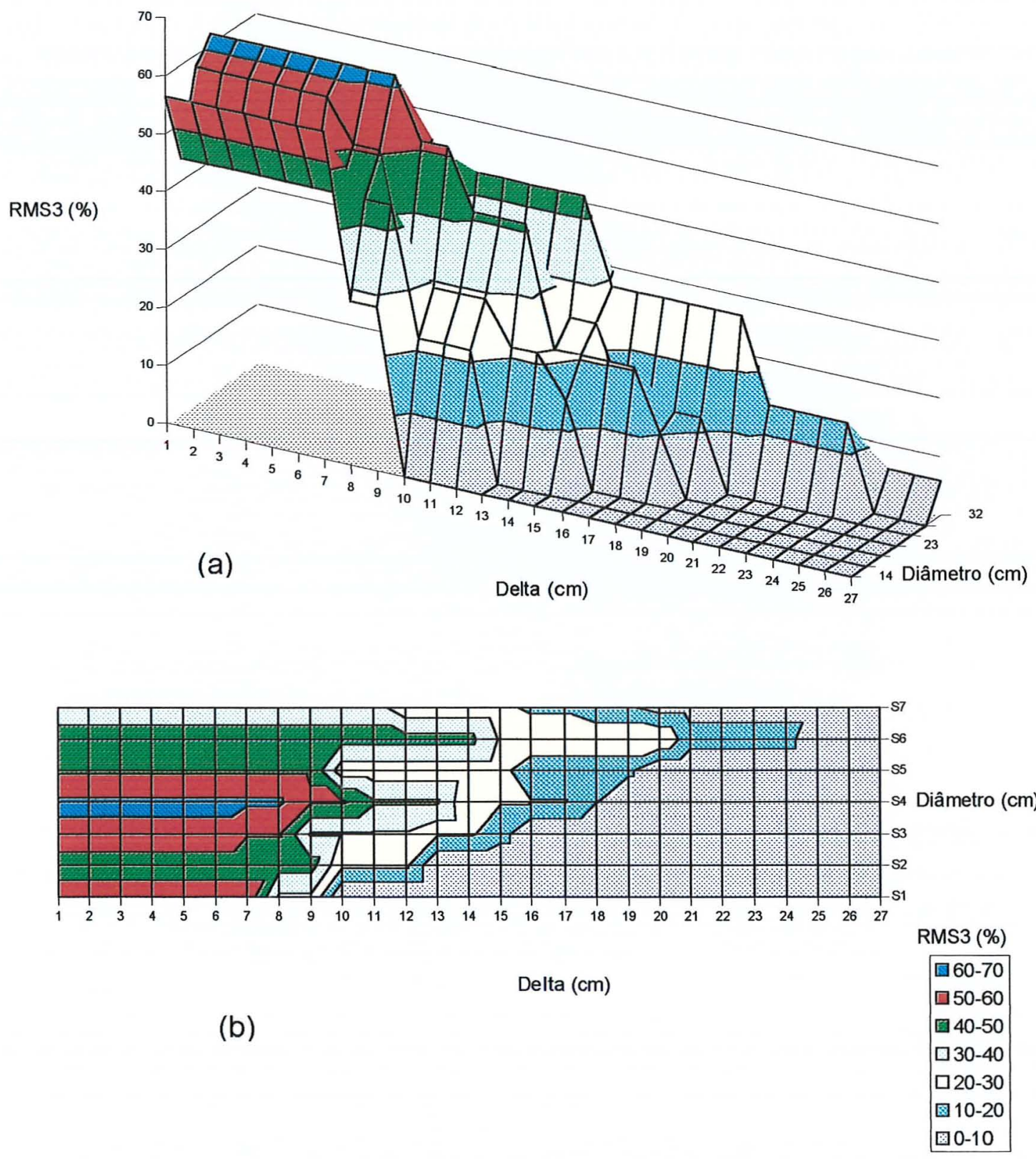

Figura 20 - Rendimento de madeira serrada do tipo 3 para as toras desdobradas de Eucalyptus grandis no sistema de desdobro por cortes tangenciais para máximo aproveitamento representado como uma superfície de resposta (a) ou como curvas de níveis de rendimento (b). 
4.3 Rendimentos em madeiras serradas em função de apenas uma variável independente

Os rendimentos em madeiras serradas dos tipos 1, 2 e 3 , em função apenas da variável $\Delta$, estão apresentados nas Figuras 21, 22 e 23, respectivamente.

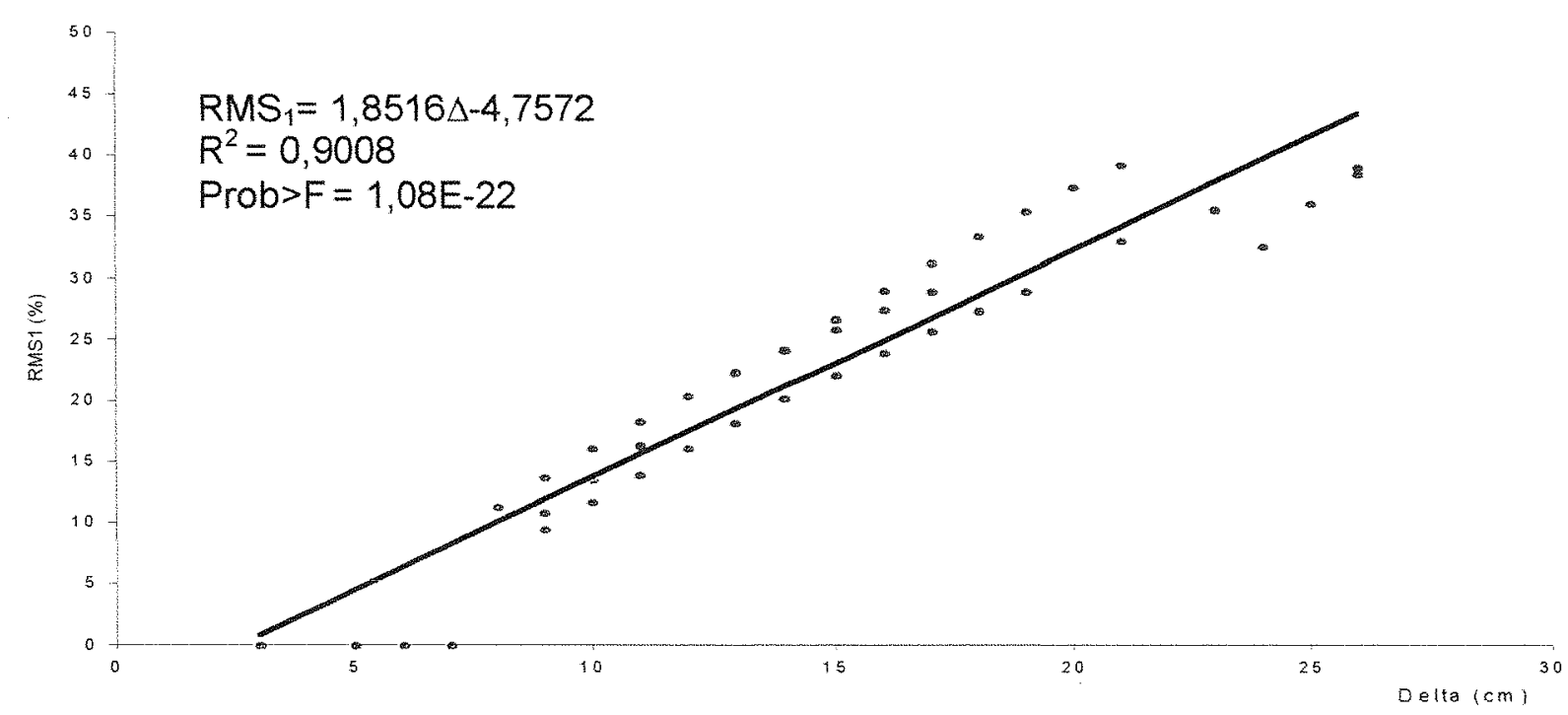

Figura 21 - Rendimento em madeira serrada do tipo 1 de Eucalyptus grandis.

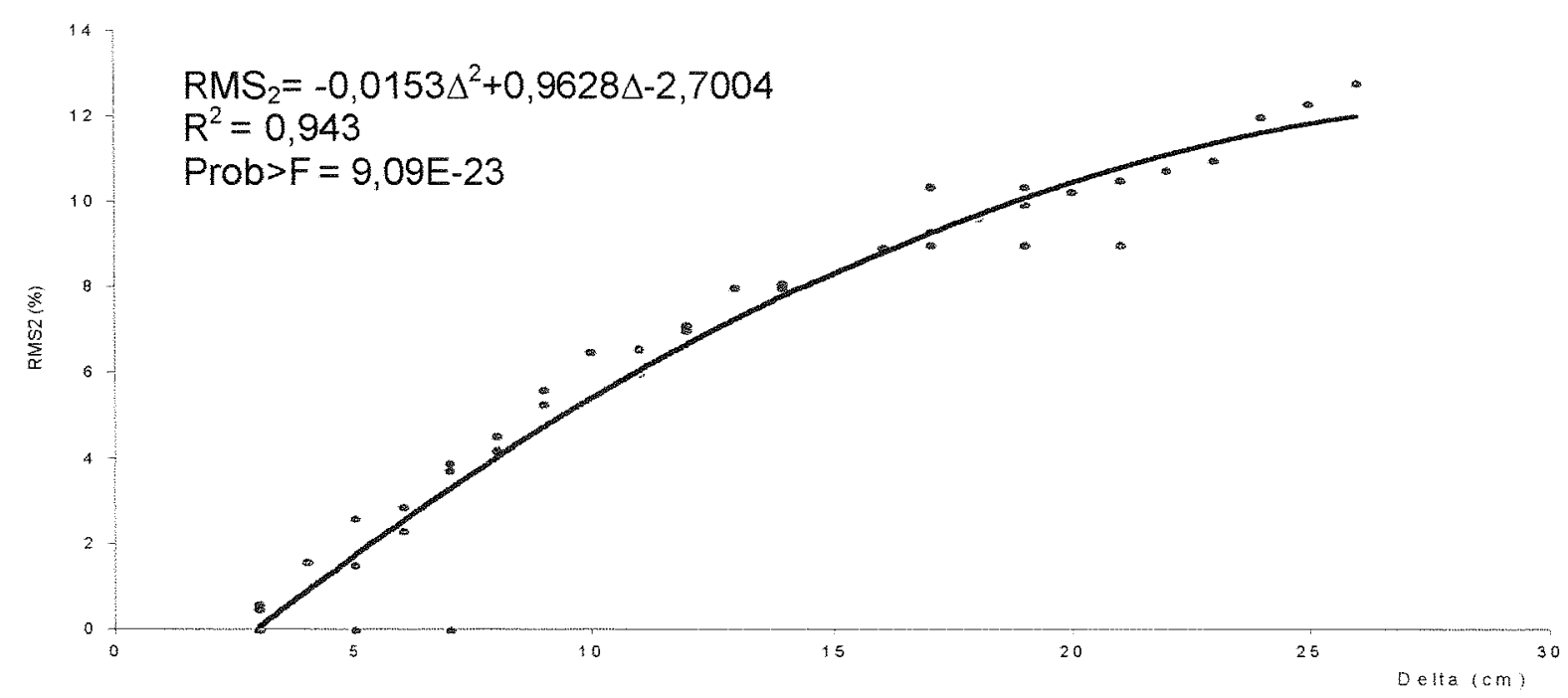

Figura 22 - Rendimento em madeira serrada do tipo 2 de Eucalyptus grandis. 


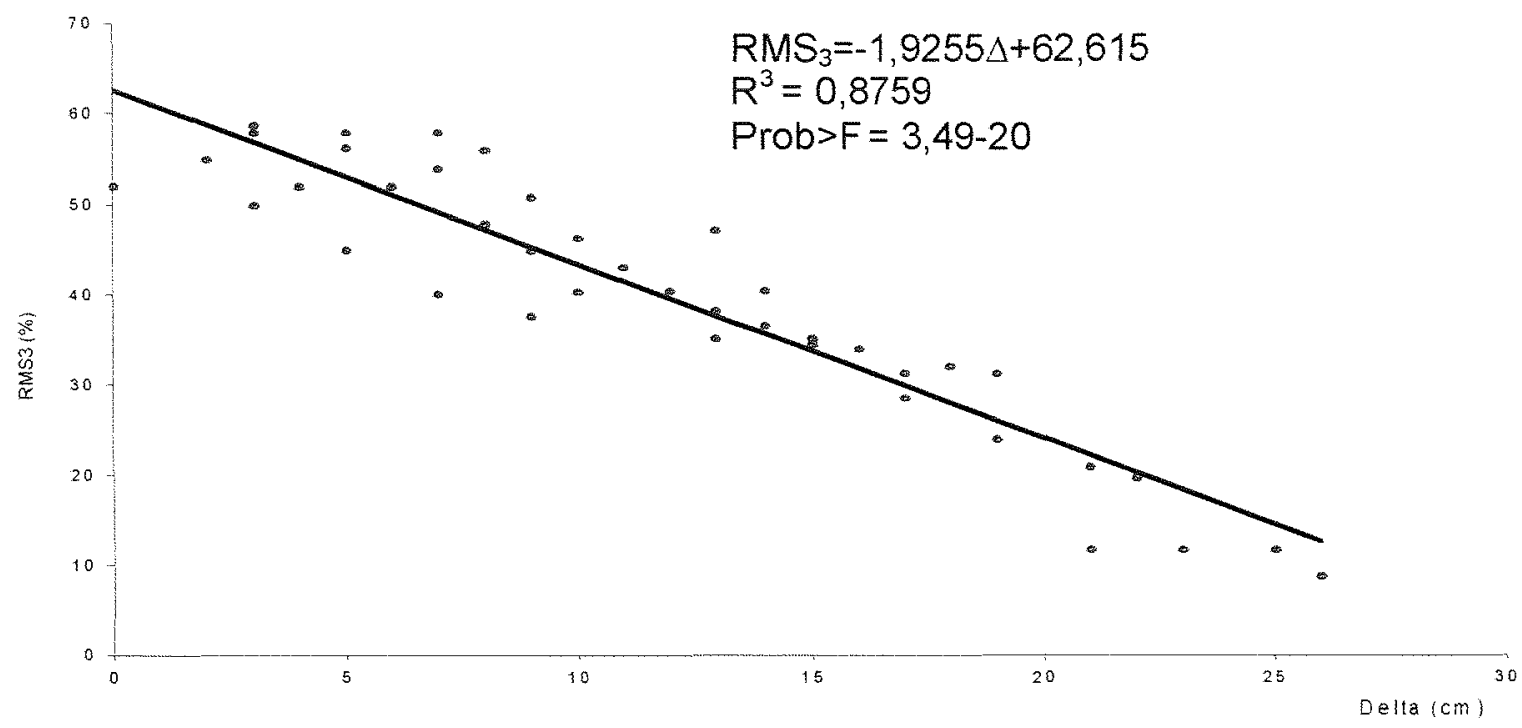

Figura 23 - Rendimento em madeira serrada do tipo 3 de Eucalyptus grandis.

\subsection{Equações de forma da árvore}

A Figura 24 mostra as predições feitas pelas equações 8 e 9 comparadas com os dados reais obtidos na cubagem rigorosa e de uma árvore de Eucalyptus grandis.

O modelo gerado pela eq. (8) supõe a forma da árvore como sendo cônica. Observa-se na Figura 24 que ele substima o volume do tronco por predizer diâmetros menores que os reais. 


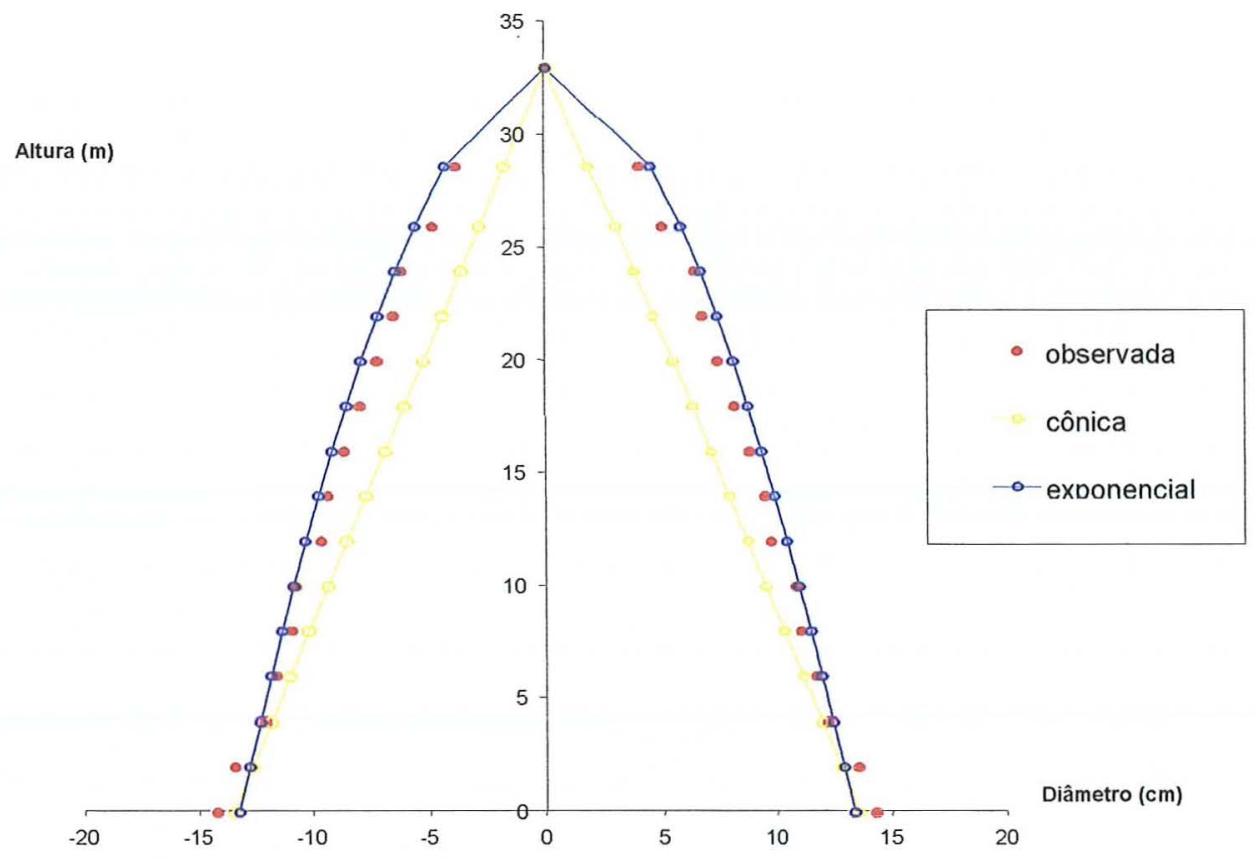

Figura 24 - Formas de uma árvore de Eucalyptus grandis, preditas por diferentes modelos.

O modelo gerado pela eq. (9), de Ormerod, foi utilizado por ser de fácil ajuste produzindo resultados satisfatórios. Sua vantagem, quando comparado ao anterior é a de não assumir uma forma geométrica rígida para todo o tronco. Apresenta uma predição muito, mais realística do que a anterior. Contudo, não dispensa o uso de dados de cubagens rigorosas. A cubagem rigorosa de dez árvores da espécie Eucalyptus grandis cujos dados serviram de referência para a obtenção do parâmetro $\mathrm{K}$, que é o expoente do segundo membro da equação 10 , consta da Tabela 2.

$$
\mathrm{d}=\mathrm{DAP}\left(\frac{\mathrm{H}-\mathrm{h}}{\mathrm{H}-1,3}\right)^{0,6258}
$$

$$
\left(\mathrm{R}^{2}=0,79 ; \text { Prob }>\mathrm{F}=3,64 \mathrm{E}-07\right)
$$


Tabela 2. Cubagens rigorosas de árvores de Eucalyptus grandis.

\begin{tabular}{|c|c|c|c|c|c|}
\hline Árvore & $\mathrm{DAP}(\mathrm{cm})$ & $\begin{array}{c}\mathrm{H} \\
(\mathrm{m})\end{array}$ & $\begin{array}{l}\mathrm{HC} \\
(\mathrm{m})\end{array}$ & $\begin{array}{c}h \\
(m)\end{array}$ & $\begin{array}{l}\mathrm{D}_{\text {médio }} \\
(\mathrm{cm})\end{array}$ \\
\hline \multirow[t]{15}{*}{1} & 26 & 33 & 28,6 & 0,00 & 28,5 \\
\hline & & & & 1,78 & 27,0 \\
\hline & & & & 3,75 & 24,3 \\
\hline & & & & 5,73 & 23,3 \\
\hline & & & & 7,72 & 22,0 \\
\hline & & & & 9,70 & 21,6 \\
\hline & & & & 11,69 & 19,4 \\
\hline & & & & 13,68 & 18,8 \\
\hline & & & & 15,68 & 17,4 \\
\hline & & & & 17,68 & 16,1 \\
\hline & & & & 19,67 & 14,6 \\
\hline & & & & 21,68 & 13,2 \\
\hline & & & & 23,68 & 12,5 \\
\hline & & & & 25,69 & 9,8 \\
\hline & & & & 28,42 & 6,8 \\
\hline \multirow[t]{10}{*}{2} & 25 & 31 & 27,0 & 0,00 & 28,4 \\
\hline & & & & 1,75 & 25,0 \\
\hline & & & & 3,75 & 24,0 \\
\hline & & & & 5,74 & 22,1 \\
\hline & & & & 7,75 & 21,7 \\
\hline & & & & 19,74 & 14,0 \\
\hline & & & & 21,73 & 11,8 \\
\hline & & & & 23,74 & 11,3 \\
\hline & & & & 25,74 & 8,1 \\
\hline & & & & 26,71 & 7,3 \\
\hline \multirow[t]{7}{*}{3} & 26 & 31 & 26,0 & 0,00 & 28,2 \\
\hline & & & & 1,78 & 25,0 \\
\hline & & & & 3,78 & 22,0 \\
\hline & & & & 5,77 & 23,0 \\
\hline & & & & 7,74 & 22,6 \\
\hline & & & & 9,74 & 19,7 \\
\hline & & & & 11,72 & 18,7 \\
\hline
\end{tabular}


Tabela 2. Cubagens rigorosas de árvores de Eucalyptus grandis.

\begin{tabular}{|c|c|c|c|c|c|}
\hline Árvore & $\begin{array}{l}\text { DAP } \\
\text { (cm) }\end{array}$ & $\begin{array}{c}\mathrm{H} \\
(\mathrm{m})\end{array}$ & $\begin{array}{l}\mathrm{HC} \\
(\mathrm{m})\end{array}$ & $\begin{array}{c}\mathrm{h} \\
(\mathrm{m})\end{array}$ & $\begin{array}{l}D_{\text {médio }} \\
(\mathrm{cm})\end{array}$ \\
\hline & & & & 13,72 & 17,0 \\
\hline & & & & 15,72 & 16,4 \\
\hline & & & & 17,72 & 14,7 \\
\hline & & & & 19,72 & 12,8 \\
\hline & & & & 21,72 & 11,5 \\
\hline & & & & 23,69 & 8,6 \\
\hline & & & & 25,74 & 7,0 \\
\hline \multirow[t]{14}{*}{4} & 25 & 29 & 25,0 & 0,00 & 28,8 \\
\hline & & & & 1,77 & 25,5 \\
\hline & & & & 3,77 & 23,8 \\
\hline & & & & 5,76 & 22,6 \\
\hline & & & & 7,76 & 21,3 \\
\hline & & & & 9,75 & 19,7 \\
\hline & & & & 11,76 & 18,6 \\
\hline & & & & 13,76 & 17,1 \\
\hline & & & & 15,76 & 15,5 \\
\hline & & & & 17,77 & 14,1 \\
\hline & & & & 19,77 & 12,7 \\
\hline & & & & 21,78 & 11,2 \\
\hline & & & & 23,80 & 7,7 \\
\hline & & & & 24,78 & 6,1 \\
\hline \multirow[t]{10}{*}{5} & 24 & 26 & 20,0 & 0,00 & 27,5 \\
\hline & & & & 1,77 & 21,8 \\
\hline & & & & 3,78 & 20,5 \\
\hline & & & & 7,77 & 17,5 \\
\hline & & & & 9,78 & 14,8 \\
\hline & & & & 11,78 & 13,6 \\
\hline & & & & 13,76 & 11,9 \\
\hline & & & & 15,75 & 10,8 \\
\hline & & & & 17,76 & 9,1 \\
\hline & & & & 19,75 & 7,7 \\
\hline \multirow[t]{9}{*}{6} & 24 & 28 & 24,0 & 0,00 & 26,0 \\
\hline & & & & 1,80 & 24,0 \\
\hline & & & & 3,81 & 23,4 \\
\hline & & & & 5,80 & 22,4 \\
\hline & & & & 7,79 & 20,3 \\
\hline & & & & 9,81 & 19,5 \\
\hline & & & & 11,81 & 18,0 \\
\hline & & & & 13,82 & 16,5 \\
\hline & & & & 15,82 & 15,9 \\
\hline
\end{tabular}


Tabela 2. Cubagens rigorosas de árvores de Eucalyptus grandis.

\begin{tabular}{|c|c|c|c|c|c|}
\hline Árvore & $\begin{array}{l}\text { DAP } \\
\text { (cm) }\end{array}$ & $\begin{array}{c}\mathrm{H} \\
\text { (m) }\end{array}$ & $\begin{array}{l}\mathrm{HC} \\
(\mathrm{m})\end{array}$ & $\begin{array}{c}h \\
(m)\end{array}$ & $\begin{array}{l}\mathrm{D}_{\text {médio }} \\
(\mathrm{cm})\end{array}$ \\
\hline \multirow{18}{*}{7} & \multirow{18}{*}{24} & \multirow{18}{*}{30} & \multirow{10}{*}{26,3} & 17,83 & 13,2 \\
\hline & & & & 19,81 & 12,4 \\
\hline & & & & 21,81 & 9,6 \\
\hline & & & & 23,80 & 8,0 \\
\hline & & & & 0,00 & 27,5 \\
\hline & & & & 1,84 & 23,3 \\
\hline & & & & 3,84 & 22,3 \\
\hline & & & & 5,82 & 21,7 \\
\hline & & & & 7,85 & 21,9 \\
\hline & & & & 9,83 & 21,2 \\
\hline & & & \multirow{22}{*}{25,0} & 11,83 & 18,5 \\
\hline & & & & 13,81 & 17,6 \\
\hline & & & & 15,81 & 15,3 \\
\hline & & & & 17,80 & 14,1 \\
\hline & & & & 19,78 & 12,4 \\
\hline & & & & 21,81 & 10,8 \\
\hline & & & & 23,80 & 8,9 \\
\hline & & & & 26,06 & 6,7 \\
\hline \multirow[t]{14}{*}{8} & \multirow[t]{14}{*}{24} & \multirow[t]{14}{*}{31} & & 0,00 & 25,0 \\
\hline & & & & 1,78 & 22,3 \\
\hline & & & & 3,78 & 22,0 \\
\hline & & & & 5,78 & 20,8 \\
\hline & & & & 7,77 & 19,8 \\
\hline & & & & 9,78 & 19,1 \\
\hline & & & & 11,78 & 17,0 \\
\hline & & & & 13,78 & 15,8 \\
\hline & & & & 15,80 & 14,5 \\
\hline & & & & 17,81 & 13,0 \\
\hline & & & & 19,81 & 11,5 \\
\hline & & & & 21,81 & 10,0 \\
\hline & & & & 23,80 & 8,5 \\
\hline & & & & 24,80 & 7,4 \\
\hline \multirow[t]{7}{*}{9} & \multirow[t]{7}{*}{24} & \multirow[t]{7}{*}{31} & \multirow[t]{7}{*}{26,0} & 0,00 & 28,3 \\
\hline & & & & 1,80 & 22,2 \\
\hline & & & & 3,80 & 21,3 \\
\hline & & & & 5,70 & 20,4 \\
\hline & & & & 7,70 & 19,7 \\
\hline & & & & 9,70 & 19,4 \\
\hline & & & & 11,68 & 17,5 \\
\hline
\end{tabular}


Tabela 2. Cubagens rigorosas de árvores de Eucalyptus grandis.

\begin{tabular}{|c|c|c|c|c|c|}
\hline Árvore & $\begin{array}{l}\text { DAP } \\
\text { (cm) }\end{array}$ & $\begin{array}{c}\mathrm{H} \\
(\mathrm{m})\end{array}$ & $\begin{array}{l}\mathrm{HC} \\
(\mathrm{m})\end{array}$ & $\begin{array}{c}\mathrm{h} \\
(\mathrm{m})\end{array}$ & $\begin{array}{l}D_{\text {médio }} \\
(\mathrm{cm})\end{array}$ \\
\hline \multirow{20}{*}{10} & \multirow{20}{*}{23} & \multirow{20}{*}{31} & \multirow{20}{*}{25,5} & 15,67 & 14,4 \\
\hline & & & & 17,67 & 13,2 \\
\hline & & & & 19,66 & 12,0 \\
\hline & & & & 21,64 & 10,6 \\
\hline & & & & 23,62 & 9,3 \\
\hline & & & & 25,62 & 6,9 \\
\hline & & & & 0,00 & 28,3 \\
\hline & & & & 1,82 & 24,0 \\
\hline & & & & 3,83 & 22,8 \\
\hline & & & & 5,84 & 21,0 \\
\hline & & & & 7,84 & 20,9 \\
\hline & & & & 9,83 & 19,0 \\
\hline & & & & 11,83 & 17,6 \\
\hline & & & & 13,83 & 15,7 \\
\hline & & & & 15,82 & 14,9 \\
\hline & & & & 17,83 & 13,1 \\
\hline & & & & 19,83 & 11,3 \\
\hline & & & & 21,83 & 10,3 \\
\hline & & & & 23,83 & 7,9 \\
\hline & & & & 25,35 & 6,8 \\
\hline
\end{tabular}

$\mathrm{H}$ : altura total da árvore;

HC: altura comercial da árvore;

h: variável altura na árvore;

$\mathrm{D}_{\text {médio: }}$ obtido de 2 diâmetros perpendiculares.

\subsection{Volumes de madeiras serradas estocados na floresta}

Para a obtenção dos volumes de madeiras serradas estocados na floresta foi gerada uma planilha de dados cujas características foram mencionadas no item 3.5 . 
A Tabela 3 apresenta as freqüências de árvores de uma população de Eucalyptus grandis de cada uma das 4 classes de diâmetro e respectiva altura média de classe.

Tabela 3. Freqüencias de DAPs, por ha, de uma floresta de Eucalyptus grandis.

\begin{tabular}{ccccc}
\hline Classe & $\begin{array}{c}\text { Altura média } \\
\text { da classe } \\
(\mathrm{m})\end{array}$ & $\begin{array}{c}\text { DAP } \\
(\mathrm{cm})\end{array}$ & $\begin{array}{c}\text { Freqüência de } \\
\text { árvores / ha }\end{array}$ & $\begin{array}{c}\text { Número de } \\
\text { árvores / ha }\end{array}$ \\
\hline 1 & 28 & 18 & 0,3760 & 273 \\
2 & 29 & 23 & 0,4573 & 332 \\
3 & 30 & 28 & 0,1611 & 117 \\
4 & 31 & 33 & 0,0055 & 4 \\
Total & & & & 726 \\
\hline
\end{tabular}

Os cálculos de volumes de madeiras serradas de cada árvore representativa de cada classe foram obtidos digitando-se o valor de cada centro de DAP e da altura média correspondente, nas devidas células da planilha de cálculos, como mostra a Tabela 4. Conjuntamente, digitam-se os valores referências estipulados como o diâmetro comercial e dos diâmetros dos centros nodosos da desrama natural e na desrama artificial. A altura comercial é calculada automaticamente, através da equação de forma da árvore em função do diâmetro comercial estipulado pela serraria, que no presente trabalho foi fixado em $13 \mathrm{~cm}$. O exemplo mostrado na Tabela 4 refere-se à terceira classe da Tabela 3. 
Tabela 4. Valores de DAP e altura $(H)$ da árvore representativa da classe da população, juntamente com os valores estipulados de diâmetro comercial (DC), diâmetro do centro nodoso na desrama natural (DCN) e diâmetro do centro nodoso na desrama artificial (DCA). A altura comercial $(\mathrm{HC})$ é calculada, automaticamente, pela equação de forma da árvore em função do DC.

\begin{tabular}{cc}
\hline Variáveis referênciais & Valores \\
\hline DAP & 28,0 \\
H & 30,0 \\
DCN & 18,0 \\
DCA & 12,0 \\
HC & 15,4 \\
DC & 13,0 \\
\hline
\end{tabular}

Depois de fornecidos esses dados a planilha gera, em uma primeira etapa (Tabela 5), o conjunto de toras de um determinado comprimento existente na árvore bem como a eventual tora complementar apical. A planilha foi programada para realizar simulações com os comprimentos $2 \mathrm{~m}, 3 \mathrm{~m}, 4 \mathrm{~m}, 5$ $\mathrm{m}$ e $6 \mathrm{~m}$. Verifica-se, então, nessa Tabela 5 , que para a altura estipulada de 30 $\mathrm{m}$ são obtidas 15 toras de $2 \mathrm{~m}$ ou 10 toras de $3 \mathrm{~m}$ ou 7 toras de $4 \mathrm{~m}$ ou 6 toras de $5 \mathrm{~m}$ ou, finalmente, 5 toras de $6 \mathrm{~m}$. A planilha oferece, portanto, 5 opções de comprimento comercial da madeira serrada.

Observa-se que a opção pelo comprimento de $4 \mathrm{~m}$, implica numa sobra apical de 2 metros. 
Tabela 5. Opções de seccionamento do tronco fornecidos pelo programa elaborado.

\begin{tabular}{|c|c|c|c|c|c|c|c|c|c|}
\hline $\begin{array}{c}\text { Número } \\
\text { de } \\
\text { toras }\end{array}$ & $\begin{array}{c}\text { Corte } \\
2 \mathrm{~m}\end{array}$ & $\begin{array}{c}\text { Número } \\
\text { de } \\
\text { toras }\end{array}$ & $\begin{array}{c}\text { Corte } \\
3 \mathrm{~m}\end{array}$ & $\begin{array}{c}\text { Número } \\
\text { de } \\
\text { toras }\end{array}$ & $\begin{array}{c}\text { Corte } \\
4 \mathrm{~m}\end{array}$ & $\begin{array}{c}\text { Número } \\
\text { de } \\
\text { toras }\end{array}$ & $\begin{array}{c}\text { Corte } \\
5 \mathrm{~m}\end{array}$ & $\begin{array}{c}\text { Número } \\
\text { de } \\
\text { toras }\end{array}$ & $\begin{array}{c}\text { Corte } \\
6 \mathrm{~m}\end{array}$ \\
\hline 1 & 2 & 1 & 3 & 1 & 4 & 1 & 5 & 1 & 6 \\
\hline 2 & 2 & 2 & 3 & 2 & 4 & 2 & 5 & 2 & 6 \\
\hline 3 & 2 & 3 & 3 & 3 & 4 & 3 & 5 & 3 & 6 \\
\hline 4 & 2 & 4 & 3 & 4 & 4 & 4 & 5 & 4 & 6 \\
\hline 5 & 2 & 5 & 3 & 5 & 4 & 5 & 5 & 5 & 6 \\
\hline 6 & 2 & 6 & 3 & 6 & 4 & 6 & 5 & 6 & 0 \\
\hline 7 & 2 & 7 & 3 & 7 & 4 & 7 & 0 & & \\
\hline 8 & 2 & 8 & 3 & 8 & 2 & & & & \\
\hline 9 & 2 & 9 & 3 & & & & & & \\
\hline 10 & 2 & 10 & 3 & & & & & & \\
\hline 11 & 2 & 11 & 0 & & & & & & \\
\hline 12 & 2 & & & & & & & & \\
\hline 13 & 2 & & & & & & & & \\
\hline 14 & 2 & & & & & & & & \\
\hline 15 & 2 & & & & & & & & \\
\hline 16 & 0 & & & & & & & & \\
\hline
\end{tabular}

Na seqüência, a planilha fornece o volume de madeira sólida de cada tora e o volume de madeira roliça total da árvore, para cada uma das opções de comprimento. Como exemplo pode-se observar na Tabela 6 , o valor de $0,68 \mathrm{~m}^{3}$ calculado para o volume total de madeira roliça da árvore representativa de uma determinada classe da população, qualquer que seja o comprimento das toras. 
É importante notar que o programa calcula, através da equação de forma da árvore, os diâmetros correspondentes às extremidades de cada tora.

Tabela 6. Volume de cada tora e total da árvore em cada uma das opções de comprimentos da tora.

\begin{tabular}{|c|c|c|c|c|c|c|c|c|c|c|c|c|c|c|}
\hline \multicolumn{3}{|c|}{$\begin{array}{c}\text { SECC } \\
2\end{array}$} & \multicolumn{3}{|c|}{$\begin{array}{c}\text { SECC } \\
3\end{array}$} & \multicolumn{3}{|c|}{$\begin{array}{c}\text { SECC } \\
4 \\
\end{array}$} & \multicolumn{3}{|c|}{$\begin{array}{c}\text { SECC } \\
5 \\
\end{array}$} & \multicolumn{3}{|c|}{$\begin{array}{c}\text { SECC } \\
6\end{array}$} \\
\hline $\begin{array}{c}\mathrm{h} \\
(\mathrm{m})\end{array}$ & $\begin{array}{c}d \\
(\mathrm{~cm})\end{array}$ & $\begin{array}{c}V \\
\left(m^{3}\right)\end{array}$ & $\begin{array}{c}\mathrm{h} \\
(\mathrm{m})\end{array}$ & $\begin{array}{c}d \\
(\mathrm{~cm})\end{array}$ & $\begin{array}{c}V \\
\left(m^{3}\right)\end{array}$ & $\begin{array}{c}\mathrm{h} \\
(\mathrm{m}) \\
\end{array}$ & $\begin{array}{c}d \\
(\mathrm{~cm})\end{array}$ & $\begin{array}{c}\mathrm{V} \\
\left(\mathrm{m}^{3}\right)\end{array}$ & $\begin{array}{c}\mathrm{h} \\
(\mathrm{m})\end{array}$ & $\begin{array}{c}\mathrm{d} \\
(\mathrm{cm})\end{array}$ & $\begin{array}{c}\mathrm{v} \\
\left(\mathrm{m}^{3}\right)\end{array}$ & $\begin{array}{c}\mathrm{h} \\
(\mathrm{m})\end{array}$ & $\begin{array}{c}\mathrm{d} \\
(\mathrm{cm})\end{array}$ & $\begin{array}{c}V^{3} \\
\left(m^{3}\right)\end{array}$ \\
\hline $\begin{array}{c}-1,3 \\
0\end{array}$ & $\begin{array}{l}29,27 \\
28,00\end{array}$ & - & $\begin{array}{c}-1,3 \\
0\end{array}$ & $\begin{array}{l}29,27 \\
28,00\end{array}$ & - & $\begin{array}{c}-1,3 \\
0\end{array}$ & $\begin{array}{l}29,27 \\
28,00\end{array}$ & & $\begin{array}{c}-1,3 \\
0\end{array}$ & $\begin{array}{l}29,27 \\
28,00\end{array}$ & & $\begin{array}{c}-1,3 \\
0\end{array}$ & $\begin{array}{l}29,27 \\
28,00\end{array}$ & \\
\hline $\begin{array}{l}0,7 \\
2,7\end{array}$ & $\begin{array}{l}27,32 \\
25,37\end{array}$ & $\begin{array}{l}\overline{0,13} \\
0,11\end{array}$ & $\begin{array}{l}1,7 \\
4,7\end{array}$ & $\begin{array}{l}26,34 \\
23,41\end{array}$ & $\begin{array}{l}\overline{0,18} \\
0,15\end{array}$ & $\begin{array}{l}2,7 \\
6,7\end{array}$ & $\begin{array}{l}25,37 \\
21,46\end{array}$ & $\begin{array}{l}\overline{0,24} \\
0,17\end{array}$ & $\begin{array}{l}3,7 \\
8,7\end{array}$ & $\begin{array}{l}24,39 \\
19,51\end{array}$ & $\begin{array}{l}\overline{0,29} \\
0,19\end{array}$ & $\begin{array}{c}4,7 \\
10,7\end{array}$ & $\begin{array}{l}23,41 \\
17,56\end{array}$ & $\begin{array}{l}\overline{0,33} \\
0,20\end{array}$ \\
\hline 4,7 & 23,41 & 0,09 & 7,7 & 20,49 & 0.11 & 10,7 & 17,56 & 0,12 & 13,7 & 14,63 & 0,12 & 16,7 & 11,71 & 0,10 \\
\hline 6,7 & 21,46 & 0,08 & 10,7 & 17,56 & 0,09 & 14,7 & 13,66 & 0,08 & 18,7 & 9,76 & 0,06 & 22,7 & 5,85 & 0,04 \\
\hline 8,7 & 19,51 & 0,07 & 13,7 & 14,63 & 0,06 & 18,7 & 9,76 & 0,04 & 23,7 & 4,88 & 0,02 & 28,7 & 0,00 & 0,01 \\
\hline 10,7 & 17,56 & 0,05 & 16,7 & 11,71 & 0,04 & 22,7 & 5,85 & 0,02 & 28,7 & 0,00 & 0,00 & & & \\
\hline 12,7 & 15,61 & 0,04 & 19,7 & 8,78 & 0,03 & 26,7 & 1,95 & 0,01 & & & & & & \\
\hline 14,7 & 13,66 & 0,03 & 22,7 & 5,85 & 0,01 & & & & & & & & & \\
\hline 16,7 & 11,71 & 0,03 & 25,7 & 2,93 & 0,01 & & & & & & & & & \\
\hline 18,7 & 9,76 & 0,02 & 28,7 & 0,00 & 0,00 & & & & & & & & & \\
\hline 20,7 & 7,80 & 0,01 & & & & & & & & & & & & \\
\hline 22,7 & 5,85 & 0,01 & & & & & & & & & & & & \\
\hline 24,7 & 3,90 & 0,00 & & & & & & & & & & & & \\
\hline 26,7 & 1,95 & 0,00 & & & & & & & & & & & & \\
\hline 28,7 & 0,00 & 0,00 & & & & & & & & & & & & \\
\hline \multicolumn{2}{|c|}{ VT $\left(\mathrm{m}^{3}\right)$} & 0,68 & & & 0,68 & & & 0,68 & & & 0,68 & & & 0,68 \\
\hline
\end{tabular}

A Tabela 7 adapta os valores da variável $\Delta$ calculados nas alturas correspondentes ás extremidades menores das toras, para cada um dos tipos de desrama adotado. 


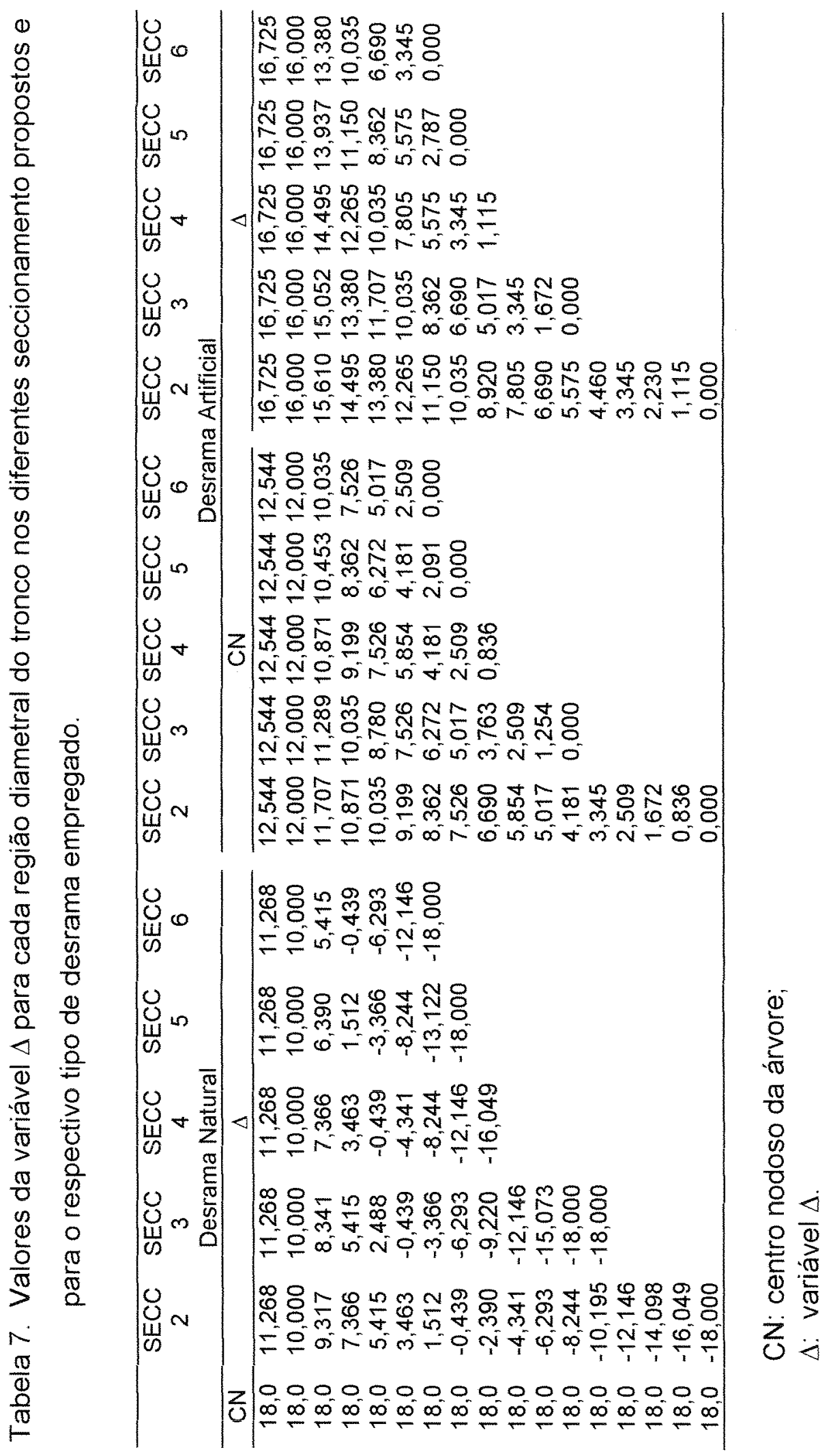


Os valores da variável $\Delta$ obtidos sob a premissa de que 0 diâmetro nodoso é constante na desrama natural tendem a ser menores do que aqueles calculados para a desrama artificial onde o centro nodoso é, normalmente, de diâmetro inferior ao diâmetro do centro nodoso da desrama natural. A explicação é dada através da compreensão da forma que o centro nodoso assume internamente na árvore quando é produzido pela desrama natural e quando é produzido pela desrama artificial. A forma do centro nodoso para a desrama natural difere da forma do centro nodoso produzido pela desrama artificial, no sentido de que, para a desrama natural o centro nodoso estimado teve forma cilíndrica de diâmetro constante de $18 \mathrm{~cm}$ (valor médio encontrado segundo medições realizadas durante as atividades de desdobro de toras realizadas neste trabalho) ao longo da altura da árvore. Na desrama artificial o diâmetro do centro nodoso da árvore variou com a altura conforme a mesma equação de forma empregada para modelar a própria árvore.

Esta diferença básica entre as dimensões de um e de outro centro nodoso na árvore justifica a realização da desrama artificial como atividade de manejo florestal responsável pela diminuição da incidência de nós na árvore. Portanto, a variável $\Delta$ permite considerar-se, no cálculo dos volumes de madeiras serradas a diferença entre um centro nodoso natural cujo diâmetro não se tem controle, para um centro nodoso administrado em função de práticas de desramas artificiais.

As Tabelas 8 e 9 apresentam os resultados dos rendimentos em madeiras serradas calculados para cada tora, ao longo do fuste da árvore, para a desrama natural e para a desrama artificial, respectivamente. Para o cálculo desses rendimentos o programa elaborado utiliza as regressões ajustadas mostradas nas Figuras 21, 22 e 23. 
Tabela 8. Rendimentos em madeiras serradas dos tipos 1, 2 e 3 para a desrama natural.

\begin{tabular}{|c|c|c|c|c|c|c|c|c|c|c|c|c|c|c|}
\hline \multicolumn{3}{|c|}{$\begin{array}{c}\text { SECC } 2-\text { RMS } \\
(\%)\end{array}$} & \multicolumn{3}{|c|}{$\begin{array}{c}\text { SECC 3-RMS } \\
(\%)\end{array}$} & \multicolumn{3}{|c|}{$\begin{array}{c}\text { SECC } 4 \text { - RMS } \\
(\%)\end{array}$} & \multicolumn{3}{|c|}{$\begin{array}{c}\text { SECC } 5-\text { RMS } \\
(\%) \\
\end{array}$} & \multicolumn{3}{|c|}{$\begin{array}{c}\text { SECC 6 - RMS } \\
(\%)\end{array}$} \\
\hline 1 & 2 & 3 & 1 & 2 & 3 & 1 & 2 & 3 & 1 & 2 & 3 & 1 & 2 & 3 \\
\hline 16,05 & 6,35 & 39,79 & 16,05 & 6,35 & 39,79 & 16,05 & 6,35 & 39,79 & 16,05 & 6,35 & 39,79 & 16,05 & 6,35 & 39,79 \\
\hline 13,16 & 5,54 & 41,96 & 13,16 & 5,54 & 41,96 & 13,16 & 5,54 & 41,96 & 13,16 & 5,54 & 41,96 & 13,16 & 5,54 & 41,96 \\
\hline 11,60 & 5,08 & 43,13 & 9,38 & 4,39 & 44,80 & 7,15 & 3,67 & 46,46 & 4,93 & 2,90 & 48,13 & 2,70 & 2,10 & 49,80 \\
\hline 7,15 & 3,67 & 46,46 & 2,70 & 2,10 & 49,80 & 0 & 0 & 53,14 & 0 & 0 & 56,47 & 0 & 0 & 59,06 \\
\hline 2,70 & 2,10 & 49,80 & 0 & 0 & 54,81 & 0 & 0 & 59,06 & 0 & 0 & 59,06 & 0 & 0 & 59,06 \\
\hline 0 & 0 & 53,14 & 0 & 0 & 59,06 & 0 & 0 & 59,06 & 0 & 0 & 59,06 & 0 & 0 & 59,06 \\
\hline 0 & 0 & 56,47 & 0 & 0 & 58,06 & 0 & 0 & 59,06 & 0 & 0 & 59,06 & 0 & 0 & 59,06 \\
\hline 0 & 0 & 59,06 & 0 & 0 & 59,06 & 0 & 0 & 59,06 & 0 & 0 & 59,06 & & & \\
\hline 0 & 0 & 59,06 & 0 & 0 & 59,06 & 0 & 0 & 59,06 & & & & & & \\
\hline 0 & 0 & 59,06 & 0 & 0 & 59,06 & & & & & & & & & \\
\hline 0 & 0 & 59,06 & 0 & 0 & 59,06 & & & & & & & & & \\
\hline 0 & 0 & 59,06 & 0 & 0 & 59,06 & & & & & & & & & \\
\hline 0 & 0 & 59,06 & 0 & 0 & 59,06 & & & & & & & & & \\
\hline 0 & 0 & 59,06 & & & & & & & & & & & & \\
\hline 0 & 0 & 59,06 & & & & & & & & & & & & \\
\hline 0 & 0 & 59,06 & & & & & & & & & & & & \\
\hline 0 & 0 & 59,06 & & & & & & & & & & & & \\
\hline
\end{tabular}

Tabela 9. Rendimentos em madeiras serradas dos tipos 1, 2 e 3 para a desrama artificial.

\begin{tabular}{|c|c|c|c|c|c|c|c|c|c|c|c|c|c|c|}
\hline \multicolumn{3}{|c|}{$\begin{array}{c}\text { SECC } 2 \text { - RMS } \\
(\%)\end{array}$} & \multicolumn{3}{|c|}{$\begin{array}{c}\text { SECC } 3-\text { RMS } \\
(\%)\end{array}$} & \multicolumn{3}{|c|}{$\begin{array}{c}\text { SECC } 4-\text { RMS } \\
(\%)\end{array}$} & \multicolumn{3}{|c|}{$\begin{array}{c}\text { SECC } 5-\text { RMS } \\
(\%)\end{array}$} & \multicolumn{3}{|c|}{$\begin{array}{c}\text { SECC } 6 \text { - RMS } \\
(\%)\end{array}$} \\
\hline 1 & 2 & 3 & 1 & 2 & 3 & 1 & 2 & 3 & 1 & 2 & 3 & 1 & 2 & 3 \\
\hline 27,26 & 11,47 & 33,04 & 27,26 & 11,47 & 33,04 & 27,26 & 11,47 & 33,04 & 27,26 & 11,47 & 33,04 & 27,26 & 11,47 & 33,04 \\
\hline 25,80 & 11,46 & 34,28 & 25,80 & 11,46 & 34,28 & 25,80 & 11,46 & 34,28 & 25,80 & 11,4 & 34,28 & 25,80 & 11,4 & 34,28 \\
\hline 25,02 & 11,43 & 34,94 & 23,89 & 11,35 & 35,89 & 22,77 & 11,24 & 36,83 & 21,65 & 11,10 & 37,78 & 20,53 & 10,92 & 38,73 \\
\hline 22,77 & 11,24 & 36,83 & 20,53 & 10,92 & 38,73 & 18,29 & 10,47 & 40,62 & 16,05 & 9,87 & 42,52 & 13,81 & 9,14 & 44,41 \\
\hline 20,53 & 10,92 & 38,73 & 17,17 & 10,18 & 41,57 & 13,81 & 9,14 & 44,41 & 10,44 & 7,79 & 47,25 & & & \\
\hline 18,29 & 10,47 & 40,62 & 13,81 & 9,14 & 44,41 & 9,32 & 7,27 & 48,20 & & & & & & \\
\hline 16,05 & 9,87 & 42,52 & 10,44 & 7,79 & 47,25 & & & & & & & & & \\
\hline 13,81 & 9,14 & 44,41 & & & & & & & & & & & & \\
\hline 11,56 & 8,27 & 46,31 & & & & & & & & & & & & \\
\hline 9,32 & 7,27 & 48,20 & & & & & & & & & & & & \\
\hline
\end{tabular}

Finalmente nas Tabelas 10 e 11 são apresentados os volumes de madeiras serradas totais e dos tipos 1, 2 e 3 referentes à árvore representativa da classe, segundo as operações de desrama natural e artificial, da árvore suposta cônica. 
Tabela 10. Volumes de madeiras serradas totais e dos tipos 1, 2 e 3 para a desrama natural nos diferentes seccionamentos do fuste da árvore de Eucalyptus grandis, suposta cônica.

\begin{tabular}{|c|c|c|c|c|c|c|c|c|c|c|c|c|c|c|}
\hline $\begin{array}{l}\text { VMS } \\
\left(\mathrm{m}^{3}\right) \\
\end{array}$ & 0,32 & $\begin{array}{c}\text { SECC } \\
2 \\
\end{array}$ & $\begin{array}{l}\text { VMS } \\
\left(\mathrm{m}^{3}\right)\end{array}$ & 0,31 & $\begin{array}{c}\text { SECC } \\
3 \\
\end{array}$ & $\begin{array}{l}\text { VMS } \\
\left(\mathrm{m}^{3}\right)\end{array}$ & 0,30 & $\begin{array}{c}\text { SECC } \\
4\end{array}$ & $\begin{array}{l}\text { VMS } \\
\left(\mathrm{m}^{3}\right)\end{array}$ & 0,28 & $\begin{array}{c}\text { SECC } \\
5\end{array}$ & $\begin{array}{l}\text { VMS } \\
\left(\mathrm{m}^{3}\right)\end{array}$ & 0,25 & $\begin{array}{c}\text { SECC } \\
6 \\
\end{array}$ \\
\hline $\begin{array}{c}\text { VMS1 } \\
(\%)\end{array}$ & $\begin{array}{c}\text { VMS2 } \\
(\%)\end{array}$ & $\begin{array}{c}\text { VMS3 } \\
(\%)\end{array}$ & $\begin{array}{c}\text { VMS1 } \\
(\%)\end{array}$ & $\begin{array}{c}\text { VMS2 } \\
(\%)\end{array}$ & $\begin{array}{c}\text { VMS3 } \\
(\%)\end{array}$ & $\begin{array}{c}\text { VMS1 } \\
(\%)\end{array}$ & $\begin{array}{c}\text { VMS2 } \\
(\%)\end{array}$ & $\begin{array}{c}\text { VMS3 } \\
(\%)\end{array}$ & $\begin{array}{c}\text { VMS1 } \\
(\%)\end{array}$ & $\begin{array}{c}\text { VMS2 } \\
(\%)\end{array}$ & $\begin{array}{c}\text { VMS3 } \\
(\%)\end{array}$ & $\begin{array}{c}\text { VMS1 } \\
(\%)\end{array}$ & $\begin{array}{c}\text { VMS2 } \\
(\%)\end{array}$ & $\begin{array}{c}\text { VMS3 } \\
(\%)\end{array}$ \\
\hline 15,07 & 6,57 & 78,36 & 17,85 & 7,67 & 74,48 & 19,47 & 8,13 & 72,40 & 21,67 & 9,03 & 69,30 & 24,36 & 9,83 & 65,82 \\
\hline $\begin{array}{c}\text { VMS1 } \\
\left(\mathrm{m}^{3}\right) \\
0.049\end{array}$ & $\begin{array}{c}\text { VMS2 } \\
\left(\mathrm{m}^{3}\right) \\
0.021\end{array}$ & $\begin{array}{c}\text { VMS3 } \\
\left(\mathrm{m}^{3}\right) \\
0254\end{array}$ & $\begin{array}{c}\text { VMS1 } \\
\left(\mathrm{m}^{3}\right) \\
0054\end{array}$ & $\begin{array}{c}\text { VMS2 } \\
\left(\mathrm{m}^{3}\right) \\
0023\end{array}$ & $\begin{array}{c}\text { VMS3 } \\
\left(\mathrm{m}^{3}\right) \\
0227\end{array}$ & $\begin{array}{c}\text { VMS1 } \\
\left(\mathrm{m}^{3}\right)\end{array}$ & $\begin{array}{c}\text { VMS2 } \\
\left(\mathrm{m}^{3}\right)\end{array}$ & $\begin{array}{c}\text { VMS3 } \\
\left(\mathrm{m}^{3}\right)\end{array}$ & $\begin{array}{c}\text { VMS1 } \\
\left(\mathrm{m}^{3}\right)\end{array}$ & $\begin{array}{c}\text { VMS2 } \\
\left(\mathrm{m}^{3}\right)\end{array}$ & $\begin{array}{c}\text { VMS3 } \\
\left(\mathrm{m}^{3}\right)\end{array}$ & $\begin{array}{c}\text { VMS1 } \\
\left(\mathrm{m}^{3}\right)\end{array}$ & $\begin{array}{c}\text { VMS2 } \\
\left(\mathrm{m}^{3}\right)\end{array}$ & $\begin{array}{c}\text { VMS3 } \\
\left(\mathrm{m}^{3}\right) \\
0164\end{array}$ \\
\hline 0,019 & 0,007 & 0,047 & 0,026 & 0,010 & 0,065 & 0,032 & 0,013 & 0,080 & 0,038 & 0,015 & 0,093 & 0,041 & 0,016 & 0,103 \\
\hline 0,013 & 0,006 & 0,042 & 0,017 & 0,007 & 0,054 & 0,019 & 0,008 & 0,061 & 0,020 & 0,008 & 0,063 & 0,019 & 0,008 & 0,061 \\
\hline 0,010 & 0,00 & 0,037 & 0,009 & 0,004 & 0,044 & 0,007 & 0,004 & 0,045 & 0,004 & 0,002 & 0,040 & & & \\
\hline 0,005 & 0,003 & 0,034 & 0,002 & 0,002 & 0,036 & 0,000 & 0,000 & 0,031 & & & & & & \\
\hline 0,002 & 0,001 & 0,030 & 0,000 & 0.000 & 0.028 & & & & & & & & & \\
\hline 0,000 & 0,000 & 0,026 & & & & & & & & & & & & \\
\hline 100 & 00 & 0,022 & & & & & & & & & & & & \\
\hline 0,000 & 0,000 & 0,017 & & & & & & & & & & & & \\
\hline
\end{tabular}

Tabela 11. Volumes de madeiras serradas totais e dos tipos 1, 2 e 3 para a desrama artificial nos diferentes seccionamentos do fuste da árvore de Eucalyptus grandis, suposta cônica.

\begin{tabular}{|c|c|c|c|c|c|c|c|c|c|c|c|c|c|c|}
\hline $\begin{array}{l}\text { VMS } \\
\left(\mathrm{m}^{3}\right) \\
\end{array}$ & 0,32 & $\begin{array}{c}\text { SECC } \\
2 \\
\end{array}$ & $\begin{array}{l}\text { VMS } \\
\left(m^{3}\right)\end{array}$ & 0,31 & $\begin{array}{c}\text { SECC } \\
3 \\
\end{array}$ & $\begin{array}{l}\text { VMS } \\
\left(\mathrm{m}^{3}\right)\end{array}$ & 0,30 & $\begin{array}{c}\text { SECC } \\
4\end{array}$ & $\begin{array}{l}\text { VMS } \\
\left(\mathrm{m}^{3}\right)\end{array}$ & 0,28 & $\begin{array}{c}\text { SECC } \\
5\end{array}$ & $\begin{array}{l}\text { VMS } \\
\left(\mathrm{m}^{3}\right)\end{array}$ & 0,25 & $\begin{array}{c}\text { SECC } \\
6 \\
\end{array}$ \\
\hline $\begin{array}{c}\text { VMS1 } \\
(\%)\end{array}$ & $\begin{array}{c}\text { VMS2 } \\
(\%)\end{array}$ & $\begin{array}{c}\text { VMS3 } \\
(\%)\end{array}$ & $\begin{array}{c}\text { VMS1 } \\
(\%)\end{array}$ & $\begin{array}{c}\text { VMS2 } \\
(\%)\end{array}$ & $\begin{array}{c}\text { VMS3 } \\
(\%)\end{array}$ & $\begin{array}{c}\text { VMS1 } \\
(\%)\end{array}$ & $\begin{array}{c}\text { VMS2 } \\
(\%)\end{array}$ & $\begin{array}{c}\text { VMS3 } \\
(\%)\end{array}$ & $\begin{array}{c}\text { VMS1 } \\
(\%)\end{array}$ & $\begin{array}{c}\text { VMS2 } \\
(\%)\end{array}$ & $\begin{array}{c}\text { VMS3 } \\
(\%)\end{array}$ & $\begin{array}{c}\text { VMS1 } \\
(\%)\end{array}$ & $\begin{array}{c}\text { VMS2 } \\
(\%)\end{array}$ & $\begin{array}{c}\text { VMS3 } \\
(\%)\end{array}$ \\
\hline 33,34 & 17,93 & 68,66 & 31,57 & 17,20 & 66,43 & 30,45 & 17,00 & 68,17 & 29,77 & 16,87 & 68,42 & 0,29 & 0,17 & 0,66 \\
\hline $\begin{array}{c}\text { VMS1 } \\
\left(\mathrm{m}^{3}\right) \\
0,107\end{array}$ & $\begin{array}{c}\text { VMS2 } \\
\left(\mathrm{m}^{3}\right) \\
0,057\end{array}$ & $\begin{array}{c}\text { VMS3 } \\
\left(\mathrm{m}^{3}\right) \\
0,220\end{array}$ & $\begin{array}{c}\text { VMS1 } \\
\left(\mathrm{m}^{3}\right) \\
0,098\end{array}$ & $\begin{array}{c}\text { VMS2 } \\
\left(\mathrm{m}^{3}\right) \\
0,053\end{array}$ & $\begin{array}{l}\text { VMS3 } \\
\left(\mathrm{m}^{3}\right) \\
0,206\end{array}$ & $\begin{array}{c}\text { VMS1 } \\
\left(\mathrm{m}^{3}\right) \\
0,091\end{array}$ & $\begin{array}{c}\text { VMS2 } \\
\left(\mathrm{m}^{3}\right) \\
0,051\end{array}$ & $\begin{array}{c}\text { VMS3 } \\
\left(\mathrm{m}^{3}\right) \\
0,205\end{array}$ & $\begin{array}{c}\text { VMS1 } \\
\left(\mathrm{m}^{3}\right) \\
0,083\end{array}$ & $\begin{array}{c}\text { VMS2 } \\
\left(\mathrm{m}^{3}\right) \\
0,047\end{array}$ & $\begin{array}{c}\text { VMS3 } \\
\left(\mathrm{m}^{3}\right) \\
0,192\end{array}$ & 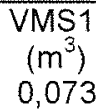 & 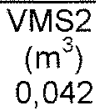 & $\begin{array}{c}\text { VMS3 } \\
\left(\mathrm{m}^{3}\right) \\
0,165\end{array}$ \\
\hline 0,029 & 0,013 & 0,041 & 0,039 & 0,019 & 0,059 & 0,046 & 0,023 & 0,074 & 0,051 & 0,026 & 0,088 & 0,053 & 0,028 & 0,100 \\
\hline 0,023 & 0,011 & 037 & 0,027 & 0,014 & 0,050 & 0,026 & 0,015 & 0,059 & 0,024 & 0,015 & 0,064 & 0,020 & 0,013 & 0,065 \\
\hline 0,018 & 0,009 & 0,033 & 0,017 & 0,010 & 0,041 & 0,013 & 0,009 & 0,043 & 0,009 & 0,007 & 0,040 & & & \\
\hline 0,013 & 0,008 & 0,029 & 0,010 & 0,007 & 0,032 & 0,005 & 0,004 & 0,028 & & & & & & \\
\hline 0,010 & 0,006 & 0,025 & 0,005 & 0,004 & 0,024 & & & & & & & & & \\
\hline 0,007 & 004 & 0,022 & & & & & & & & & & & & \\
\hline 0,004 & 0,003 & 0,018 & & & & & & & & & & & & \\
\hline 0,003 & 0,002 & 014 & & & & & & & & & & & & \\
\hline
\end{tabular}

A título de comparação estão sendo mostrados nas Tabelas $12 \mathrm{e}$ 13 os volumes de madeiras serradas totais e dos tipos 1, 2 e 3 de uma árvore representativa de uma determinada classe, modelada segundo a equação de forma de Ormerod sob desrama natural e artificial. 
Tabela 12.- Volumes de madeiras serradas totais e dos tipos 1, 2 e 3 para a desrama natural nos diferentes seccionamentos da árvore de Eucalyptus grandis, modelada segundo Ormerod.

\begin{tabular}{|c|c|c|c|c|c|c|c|c|c|c|c|c|c|c|}
\hline $\begin{array}{l}\text { VMS } \\
\left(\mathrm{m}^{3}\right) \\
\end{array}$ & 0,49 & $\begin{array}{c}\text { SECC } \\
2 \\
\end{array}$ & $\begin{array}{l}\text { VMS } \\
\left(\mathrm{m}^{3}\right) \\
\end{array}$ & 0,47 & $\begin{array}{c}\text { SECC } \\
3\end{array}$ & $\begin{array}{l}\text { VMS } \\
\left(\mathrm{m}^{3}\right)\end{array}$ & 0,45 & $\begin{array}{c}\text { SECC } \\
4 \\
\end{array}$ & $\begin{array}{l}\text { VMS } \\
\left(\mathrm{m}^{3}\right)\end{array}$ & 0,44 & $\begin{array}{c}\text { SECO } \\
5 \\
\end{array}$ & $\begin{array}{l}\text { VMS } \\
\left(\mathrm{m}^{3}\right)\end{array}$ & 0,42 & $\begin{array}{c}\text { SECC } \\
6 \\
\end{array}$ \\
\hline $\begin{array}{c}\text { VMS1 } \\
(\%)\end{array}$ & $\begin{array}{c}\text { VMS2 } \\
(\%)\end{array}$ & $\begin{array}{c}\text { VMS3 } \\
(\%)\end{array}$ & $\begin{array}{c}\text { VMS1 } \\
(\%)\end{array}$ & $\begin{array}{c}\text { VMS2 } \\
(\%)\end{array}$ & $\begin{array}{c}\text { VMS3 } \\
(\%)\end{array}$ & $\begin{array}{c}\text { VMS1 } \\
(\%)\end{array}$ & $\begin{array}{c}\text { VMS2 } \\
(\%)\end{array}$ & $\begin{array}{c}\text { VMS3 } \\
(\%)\end{array}$ & $\begin{array}{c}\text { VMS1 } \\
(\%)\end{array}$ & $\begin{array}{c}\text { VMS2 } \\
(\%)\end{array}$ & $\begin{array}{c}\text { VMS3 } \\
(\%)\end{array}$ & $\begin{array}{c}\text { VMS1 } \\
(\%)\end{array}$ & $\begin{array}{c}\text { VMS2 } \\
(\%)\end{array}$ & $\begin{array}{c}\text { VMS3 } \\
(\%)\end{array}$ \\
\hline 15,48 & 6,70 & 77,82 & 17,70 & 7,49 & 74,81 & 19,78 & 8,24 & 71,98 & 21,34 & 8,90 & 69,76 & 23,50 & 9,55 & 66,95 \\
\hline $\begin{array}{c}\text { VMS1 } \\
\left(\mathrm{m}^{3}\right) \\
0,076\end{array}$ & $\begin{array}{c}\text { VMS2 } \\
\left(\mathrm{m}^{3}\right) \\
0,033\end{array}$ & $\begin{array}{c}\text { VMS3 } \\
\left(\mathrm{m}^{3}\right) \\
0,384\end{array}$ & $\begin{array}{c}\text { VMS1 } \\
\left(\mathrm{m}^{3}\right) \\
0,084\end{array}$ & $\begin{array}{c}\text { VMS2 } \\
\left(\mathrm{m}^{3}\right) \\
0,035\end{array}$ & $\begin{array}{c}\text { VMS3 } \\
\left(\mathrm{m}^{3}\right) \\
0,354\end{array}$ & $\begin{array}{c}\text { VMS1 } \\
\left(\mathrm{m}^{3}\right) \\
0,090\end{array}$ & $\begin{array}{c}\text { VMS2 } \\
\left(\mathrm{m}^{3}\right) \\
0,037\end{array}$ & $\begin{array}{c}\text { VMS3 } \\
\left(\mathrm{m}^{3}\right) \\
0,327\end{array}$ & $\begin{array}{c}\text { VMS1 } \\
\left(\mathrm{m}^{3}\right) \\
0,095\end{array}$ & $\begin{array}{c}\text { VMS2 } \\
\left(\mathrm{m}^{3}\right) \\
0,040\end{array}$ & $\begin{array}{c}\text { VMS3 } \\
\left(\mathrm{m}^{3}\right) \\
0,310\end{array}$ & $\begin{array}{c}\text { VMS1 } \\
\left(\mathrm{m}^{3}\right) \\
0,098\end{array}$ & $\begin{array}{c}\text { VMS2 } \\
\left(\mathrm{m}^{3}\right) \\
0,040\end{array}$ & $\begin{array}{c}\text { VMS3 } \\
\left(\mathrm{m}^{3}\right) \\
0,280\end{array}$ \\
\hline 0,021 & 0,008 & 0,050 & 0,030 & 0,012 & 0,071 & 0,039 & 0,015 & 0,091 & 0,046 & 0,018 & 0,108 & 0,053 & 0,021 & 0,124 \\
\hline 0,017 & 0,007 & 0,047 & 0,024 & 0,010 & 0,064 & 0,028 & 0,011 & 0,077 & 0,032 & 0,013 & 0,086 & 0,034 & 0,014 & 0,091 \\
\hline 0,015 & 0,006 & 0,043 & 0,017 & 0,007 & 0,057 & 0,017 & 0,007 & 0,065 & 0,015 & 0,007 & 0,067 & 0,012 & 0,006 & 0,064 \\
\hline 0,011 & 0,005 & 0,041 & 0,009 & 0,005 & 0,051 & 0,006 & 0,003 & 0,054 & 0,002 & 0,002 & 0,048 & & & \\
\hline 0,007 & 0,003 & 0,039 & 0,003 & 0,002 & 0,045 & 0,000 & 0,000 & 0,040 & & & & & & \\
\hline 0,004 & 0,002 & 0,036 & 0,000 & 0,000 & 0,037 & & & & & & & & & \\
\hline 0,001 & 0,001 & 0,033 & 0,000 & 0,000 & 0,029 & & & & & & & & & \\
\hline 0,000 & 0,000 & 0,029 & & & & & & & & & & & & \\
\hline 100 & 0,000 & 0,026 & & & & & & & & & & & & \\
\hline 0,000 & 000 & 0,022 & & & & & & & & & & & & \\
\hline 0,000 & 0,000 & 0,018 & & & & & & & & & & & & \\
\hline
\end{tabular}

Tabela 13. Volumes de madeiras serradas totais e dos tipos 1, 2 e 3 para a desrama artificial nos diferentes seccionamentos da árvore de Eucalyptus grandis modelada segundo Ormerod.

\begin{tabular}{|c|c|c|c|c|c|c|c|c|c|c|c|c|c|c|}
\hline $\begin{array}{l}\mathrm{VMS} \\
\left(\mathrm{m}^{3}\right) \\
\end{array}$ & 0,49 & $\begin{array}{c}\text { SECC } \\
2 \\
\end{array}$ & $\begin{array}{l}\text { VMS } \\
\left(\mathrm{m}^{3}\right)\end{array}$ & 0,47 & $\begin{array}{c}\text { SECC } \\
3 \\
\end{array}$ & $\begin{array}{l}\text { VMS } \\
\left(\mathrm{m}^{3}\right) \\
\end{array}$ & 0,45 & $\begin{array}{c}\text { SECC } \\
4 \\
\end{array}$ & $\begin{array}{l}\text { VMS } \\
\left(\mathrm{m}^{3}\right) \\
\end{array}$ & 0,44 & $\begin{array}{c}\text { SECC } \\
5 \\
\end{array}$ & $\begin{array}{l}\mathrm{VMS} \\
\left(\mathrm{m}^{3}\right) \\
\end{array}$ & 0,42 & $\begin{array}{c}\text { SECC } \\
6 \\
\end{array}$ \\
\hline $\begin{array}{c}\text { VMS1 } \\
(\%)\end{array}$ & $\begin{array}{c}\text { VMS2 } \\
(\%)\end{array}$ & $\begin{array}{c}\text { VMS3 } \\
(\%)\end{array}$ & $\begin{array}{c}\text { VMS1 } \\
(\%)\end{array}$ & $\begin{array}{c}\text { VMS2 } \\
(\%)\end{array}$ & $\begin{array}{c}\text { VMS3 } \\
(\%)\end{array}$ & $\begin{array}{c}\text { VMS1 } \\
(\%)\end{array}$ & $\begin{array}{c}\text { VMS2 } \\
(\%)\end{array}$ & $\begin{array}{c}\text { VMS3 } \\
(\%)\end{array}$ & $\begin{array}{c}\text { VMS1 } \\
(\%)\end{array}$ & $\begin{array}{c}\text { VMS2 } \\
(\%)\end{array}$ & $\begin{array}{c}\text { VMS3 } \\
(\%)\end{array}$ & $\begin{array}{c}\text { VMS1 } \\
(\%)\end{array}$ & $\begin{array}{c}\text { VMS2 } \\
(\%)\end{array}$ & $\begin{array}{c}\text { VMS3 } \\
(\%)\end{array}$ \\
\hline 39,99 & 19,08 & 62,18 & 39,57 & 18,96 & 61,91 & 39,13 & 18,84 & 61,61 & 38,30 & 18,60 & 61,38 & 38,21 & 18,56 & 60,92 \\
\hline $\begin{array}{l}\text { VMS1 } \\
\left(\mathrm{m}^{3}\right)\end{array}$ & $\begin{array}{c}\text { VMS2 } \\
\left(\mathrm{m}^{3}\right)\end{array}$ & $\begin{array}{c}\text { VMS3 } \\
\left(\mathrm{m}^{3}\right)\end{array}$ & $\begin{array}{l}\text { VMS1 } \\
\left(\mathrm{m}^{3}\right)\end{array}$ & $\begin{array}{c}\text { VMS2 } \\
\left(\mathrm{m}^{3}\right)\end{array}$ & $\begin{array}{c}\text { VMS3 } \\
\left(\mathrm{m}^{3}\right)\end{array}$ & $\begin{array}{c}\text { VMS1 } \\
\left(\mathrm{m}^{3}\right)\end{array}$ & $\begin{array}{c}\text { VMS2 } \\
\left(\mathrm{m}^{3}\right)\end{array}$ & $\begin{array}{c}\text { VMS3 } \\
\left(\mathrm{m}^{3}\right)\end{array}$ & $\begin{array}{c}\text { VMS1 } \\
\left(\mathrm{m}^{3}\right)\end{array}$ & $\begin{array}{c}\text { VMS2 } \\
\left(\mathrm{m}^{3}\right)\end{array}$ & $\begin{array}{c}\text { VMS3 } \\
\left(\mathrm{m}^{3}\right)\end{array}$ & $\begin{array}{l}\text { VMS1 } \\
\left(\mathrm{m}^{3}\right)\end{array}$ & $\begin{array}{c}\text { VMS2 } \\
\left(\mathrm{m}^{3}\right)\end{array}$ & $\begin{array}{c}\text { VMS3 } \\
\left(\mathrm{m}^{3}\right)\end{array}$ \\
\hline $\begin{array}{l}\text { VMS1 } \\
\text { (m3) }\end{array}$ & $\begin{array}{r}\text { VMS2 } \\
\text { (m3) }\end{array}$ & $\begin{array}{c}\text { VMS3 } \\
(\mathrm{m} 3)\end{array}$ & $\begin{array}{l}\text { VMS1 } \\
\text { (m3) }\end{array}$ & $\begin{array}{c}\text { VMS2 } \\
\text { (m3) }\end{array}$ & $\begin{array}{c}\text { VMS3 } \\
\text { (m3) }\end{array}$ & $\begin{array}{r}\text { VMS1 } \\
(\mathrm{m} 3)\end{array}$ & $\begin{array}{c}\text { VMS2 } \\
\text { (m3) }\end{array}$ & $\begin{array}{c}\text { VMS3 } \\
\text { (m3) }\end{array}$ & $\begin{array}{r}\text { VMS1 } \\
\text { (m3) }\end{array}$ & $\begin{array}{r}\text { VMS2 } \\
\text { (m3) }\end{array}$ & $\begin{array}{c}\text { VMS3 } \\
\text { (m3) }\end{array}$ & $\begin{array}{r}\text { VMS1 } \\
(\mathrm{m} 3)\end{array}$ & $\begin{array}{c}\text { VMS2 } \\
\text { (m3) }\end{array}$ & $\begin{array}{c}\text { VMS3 } \\
\text { (m3) }\end{array}$ \\
\hline 0,196 & 0,094 & 0,305 & 0,186 & 0,089 & 0,291 & 0,176 & 0,085 & 0,277 & 0,169 & 0,082 & 0,270 & 0,157 & 0,076 & 0,250 \\
\hline 0,034 & 0,015 & 042 & 0,049 & $\overline{0,021}$ & 0,061 & 0,061 & 0,027 & 0,078 & 0,072 & 0,032 & 0,094 & 0,080 & 0,036 & 0,109 \\
\hline 0,030 & 0,013 & 039 & 0,040 & 0,018 & 0,054 & 0,047 & 0,022 & 0,067 & 0,050 & 0,024 & 0,077 & 0,050 & 0,025 & 0,083 \\
\hline 0,027 & 0,012 & 0,036 & 0,032 & 0,015 & 0,048 & 0,034 & 0,0 & 0,056 & 0,031 & 0,017 & 0,059 & 0,026 & 0,015 & 0,057 \\
\hline 0,023 & 0,011 & 034 & 0,025 & 0,013 & 0,042 & 0,022 & 0,012 & 0,044 & 0,016 & 0,010 & 0,040 & & & \\
\hline 0 & 0,010 & 31 & 0,019 & 0,010 & 0,035 & 0,013 & 0,008 & 0,032 & & & & & & \\
\hline 017 & 0,008 & 028 & 0,013 & 0,007 & 0,029 & & & & & & & & & \\
\hline 0,014 & 0,007 & 0,025 & 0,008 & 0,005 & 0,022 & & & & & & & & & \\
\hline 0,011 & 0,006 & 022 & & & & & & & & & & & & \\
\hline & & 19 & & & & & & & & & & & & \\
\hline 0,006 & 0,004 & 016 & & & & & & & & & & & & \\
\hline 004 & 0,003 & 0,013 & & & & & & & & & & & & \\
\hline
\end{tabular}


A Figura 25 mostra os diferentes volumes de madeira serrada de diferentes classes de qualidade obtidos com emprego de duas equações de forma: a cônica e a de Ormerod. O modelo gerado pela equação de forma da árvore suposta perfeitamente cônica estimou volumes menores que o modelo gerado pela equação de forma de Ormerod, fato que já era esperado por apresentar uma taxa de afilamento do fuste mais elevada.

Os volumes de madeiras serradas estocados na floresta variam dependendo das equações de forma utilizadas para modelar a árvore, porém não há impacto nas taxas de rendimento.

A desrama natural e/ou artificial implicaram na produção de diferentes volumes de madeira serrada dos tipos 1, 2 e 3 . O emprego da operação de desrama artificial aumentou as quantidades de madeira serrada dos tipos 1 e 2 e diminuiu a do tipo 3 em relação ao emprego da desrama natural para quaisquer das equações de forma utilizadas.

A desrama artificial aplicada corretamente e realizada desde os primeiros anos, induz a formação de uma maior quantidade de madeira "clear" ao restringir a ocorrência de nós a uma reduzida área no centro do tronco. Este fato explica o aumento do volume de madeira serrada do tipo 1 e 2 e a diminuição do volume de madeira serrada do tipo 3 na desrama artificial em relação a desrama natural. Esta operação portanto minimiza a presença de nós em todo o volume comercial do tronco, aumentando o rendimento em madeira serrada de qualidade superior resultando na redução de madeira serrada de pior qualidade. 


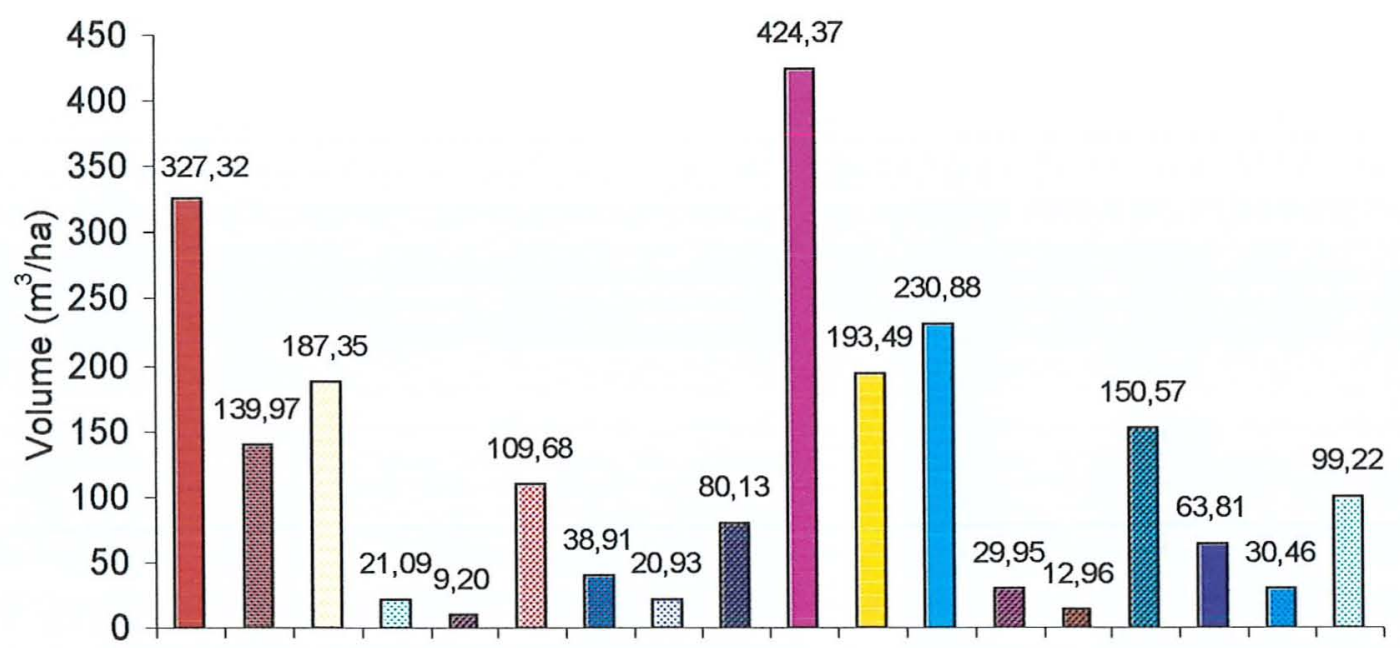

$\square$ Volume total de madeira roliça com a equação de forma cônica

圈 Volume total de madeira serrada com a equação de forma cônica

$\square$ Volume de resíduo coma equação de forma cônica

๑ Volume de maderia serrada do tipo 1 na desrama natural com a equação de forma cônica

圈 Volume de maderia serrada do tipo 2 na desrama natural com a equação de forma cônica

圆 Volume de maderia serrada do tipo 3 na desrama natural com a equação de forma cônica

圆 Volume de maderia serrada do tipo 1 na desrama artificial com a equação de forma cônica

⿴囗大 Volume de maderia serrada do tipo 2 na desrama artificial com a equação de forma cônica

圆 Volume de maderia serrada do tipo 3 na desrama artificial com a equação de forma cônica

$\square$ Volume total de madeira roliça coma equação de forma de Ormerod

$\square$ Volume total de madeira serrada com a equação de forma de Ormerod

$\square$ Volume de resíduo com a equação de forma de Ormerod

圈 Volume de maderia serrada do tipo 1 na desrama natural com a equação de forma de Ormerod

图 Volume de maderia serrada do tipo 2 na desrama natural com a equação de forma de Ormerod

圆 Volume de maderia serrada do tipo 3 na desrama natural com a equação de forma de Ormerod

q Volume de maderia serrada do tipo 1 na desrama artificial com a equação de forma de Ormerod

圆 Volume de maderia serrada do tipo 2 na desrama artificial com a equação de forma de Ormerod

因 Volume de maderia serrada do tipo 3 na desrama artificial com a equação de forma de Ormerod

Figura 25 - Volumes de madeira roliça, madeiras serradas total e dos tipos 1, 2 e 3 e de resíduos estocados em uma floresta de Eucalyptus grandis calculados por duas diferentes equações de forma sob desrama natural e desrama artificial. 


\section{CONCLUSÕES}

- Aumento no diâmetro mínimo da tora não implica, necessariamente, em aumento do rendimento em madeira serrada, embora a tendência seja a de aumento do rendimento com o aumento desse diâmetro.

- A diferença entre os sistemas de desdobro aumenta com o aumento do diâmetro da tora, mas somente a partir do ponto em que o diâmetro utilizado possibilite o aproveitamento de uma peça da costaneira, que por sua vez possibilite a obtenção de mais de uma peça serrada.

- O sistema de desdobro por cortes tangenciais balanceados é mais indicado para os diâmetros comumente encontrados em reflorestamentos jovens, com diâmetros inferiores a $26 \mathrm{~cm}$, analisados em comparação ao sistema de desdobro por cortes tangenciais de máximo aproveitamento, pela vantagem de minimizar os efeitos das tensões residuais, para diferenças não significativas de rendimentos.

- Os volumes de madeiras serradas estocados na floresta variam dependendo das equações de forma utilizadas para modelar a árvore, porém não há impacto nas taxas de rendimento.

- A dupla espessura do anel de madeira isenta de nós, dada pela diferença entre o diâmetro da árvore e o diâmetro do centro nodoso fornece indicações para a quantificação de diferentes tipos de madeira serrada.

- O uso da desrama artificial aumenta a quantidade de madeira serrada do tipo 1 (melhor qualidade) na floresta e diminui a quantidade de madeira do tipo 3 (pior qualidade). 


\section{REFERÊNCIAS BIBLIOGRÁFICAS}

AGUIAR, F.B. Efeito de intensidade de desbastes sobre o crescimento em altura e diâmetro de Eucalyptus citriodora Hook. IPEF, v.48, p.1-7, 1995.

ALBINO, J.C.; TOMAZELLO FILHO, M. Evolução de crescimento de espécies e procedências de Eucalyptus em três regiões bioclimáticas do Estado de São Paulo; Piracicaba: ESALQ, 1982. 38p. (Boletim de Pesquisa).

ALVES, T.C. Estimativas de consumo de madeira sólida no Brasil. http:Ilwww. abimci.com.br, (02 Fev. 2002)

ASSIS, M.S. Estado de la tecnologia em usos no tradicionales de la madera de eucalipto em el mercosul y outros paises. In: SEMINÁRIO INTERNACIONAL SOBRE PRODUTOS SÓLIDOS DE MADEIRA DE ALTA QUALIDADE TECNOLÓGICA, 1., Viçosa, 1999. Anais. Viçosa: UFV, 1999, p.82-105. 
BATISTA, J. L. Mensuração de árvores: uma introdução a dendrometria. Piracicaba: IPEF, 2001. 49p.

BRANDÃO, A.T.O. Algumas considerações sobre a desrama e sua influência na produção de madeira. Piracicaba: ESALQ, 1984. 17p.

BRENDENKAMP, B.V. Some effects of prunning on the growth and timber quality of Eucalyptus grandis in Zululand. Silvicultura, v.8, n.31, p.583588,1983

CASER, R.L. Variações genéticas e interações com locais em Pinus tropicais e suas associações com parâmetros climáticos. Piracicaba, 1984. 104p. Dissertação (Mestrado) - Escola Superior de Agricultura "Luiz de Queiroz", Universidade de São Paulo.

FINGER, C.A.G. Fundamentos de biometria florestal. Santa Maria: Cupeffatec, 1992. 269p.

FREITAS, A. R.; NETO, O. B.; Avanços tecnológicos no avanço e uso de produtos florestais: Produção de madeira serrada para Eucaliptos. IApresentado ao $1^{\circ}$ Congresso Florestal Pan-americano, $7^{\circ}$ Congresso Florestal Brasileiro, Curitiba, 1993/ 
GARCIA, J.N. Técnicas de desdobro de eucalipto. In: SEMINÁRIO INTERNACIONAL DE UTILIZAÇÃO DE EUCALIPTO PARA SERRARIA, São Paulo, 1995. Anais. Piracicaba: IPEF, 1995. p.59-67.

GOLFARI, L. Zoneamento Ecológico do Estado de Minas Gerais para Reflorestamento. Belo Horizonte: Centro de Pesquisa Florestal da Região do Cerrado, 1975. 65p (Série Técnica, 3).

KAGEYAMA, P.Y. Variação genética entre procedências de uma população de Eucalyptus grandis (Hill) Maiden. Piracicaba, 1980. 125p. Tese (Doutorado) - Escola Superior de Agricultura "Luiz de Queiroz", Universidade de São Paulo.

KRAMER, P.J.; KOZLOWSKI, T. Fisiologia das árvores. Lisboa: Fundação Calouste Gulbenkian, 1960. 745p.

LARGUIA, H. Ecologia e fitoclimatologia. Anuário Brasileiro Florestal, v.5, n. 8, p.78-198, 1967.

LIMA, I.L. Variação de propriedades indicativas da tensão de crescimento em função da posição na árvore e da intensidade de desbaste. Piracicaba, 2000. 130p. Dissertação (Mestrado) - Escola Superior de Agricultura "Luiz de Queiroz", Universidade de São Paulo. 
LIMA, W. P. Impacto ambiental do eucalipto 2.ed. São Paulo: EDUSP, 1993. 202p.

MACEDO, R.L.G. Avaliação holística da fase juvenil do teste de introdução de espécies de Eucalyptus na Baixada Cuiabana. Curitiba, 1991. 257p. Tese (Doutorado) - Universidade Federal do Paraná.

MACKAY, E. Dasometria. Madrid: Escuela Técnica de Ingénieros de Montes, 1964. 759p.

MIRANDA, M.J.A.C. Estudo da influência do espaçamento de plantio de Eucalyptus saligna Smith no rendimento de madeira serrada, nas condições verde e seca. Piracicaba, 1997. 177p. Tese (Mestrado) Escola Superior de Agricultura "Luiz de Queiroz", Universidade de São Paulo.

MOHAMMED, C. Pruning associated stem defects in plantation E. nitens and E. globulus grown for sawlog and veneer in Tasmania. In: THE FUTURE OF EUCALYPTS FOR WOOD PRODUCTS MEETING, 1., Tasmania, 2000. Tasmania: IUFRO, 2000. p.357-364. 
MONTAGNA, R.G., ASSINI, J.L., PONCE, R.H., Desdobro de eucalipto visando a diminuir o efeito das tensões de crescimento. In: CONGRESSO FLORESTAL BRASILEIRO, 6., 1993, Campos do Jordão. Anais. São Paulo: SBS/SBEF, 1990, 801p. p. 712-714.

NICOLIELO, N. Aspectos gerais sobre manejo florestal em florestas homogêneas de Pinus sp. São Paulo: Sociedade Brasileira de Silvicultura, 1987. 135p.

OTTE, G. Experiências e controle da qualidade da madeira de eucaliptos e oportunidades no mercado internacional e nacional. In: SEMINÁRIO MADEIRA DE EUCALIPTO: TENDÊNCIAS E USOS. Piracicaba, 2001. Piracicaba: IPEF, 2001. 50p.

PASZTOR, Y.P.C. Seleção de fenótipos. Silvicultura em São Paulo, V.1, n.2, p.265-283, 1962.

PENFORD, A.R.; WILLIS, J.L. The eucalypts. London: Leonard Hill, 1961. $86 p$.

PHILIPSON, A. Ecologia e fitoclimatologia florestais. Anuário Brasileiro de Economia Florestal, v.6, n.6, p.283-292, 1953. 
PICKEL, D.B.J. Criação da forma florestal das árvores. Anuário Brasileiro de Economia Florestal, v.1, n.1, p.49-70, 1948.

PONCE, R. H. Madeira Serrada de eucalipto: desafios e perspectivas. In. IUFO- CONFERENCE ON SILVICULTURE AND IMPROVEMENT OF EUCALYPTS. Salvador, 1997. Proceedings, Colombo: EMBRAPA, 1997. v.3, p.50-58.

ROSA, P.R.F. Teste de procedência de Pinus oocarpa schield em três regiões do Estado de São Paulo. Jaboticabal, 1982. 84p. Dissertação (Mestrado) - Faculdade de Ciências Agrárias, Universidade Estadual Paulista. "Julio de Mesquita".

SCHILLING, A. C.; SCHNEIDER, P.R.; HASELEIN, C.; FINGER, C. A. Influência de diferentes intensidades de desrama sobre porcentagem de lenho tardio e quantidade de nós da madeira de primeiro desbaste de Pinus elliottii Engelman. Revista Ciência Florestal, v.8, n.1, p.115-127, nov. 1998.

SEITZ, R.A. Manual de poda de espécies arbóreas florestais. Curitiba: FUPEF, 1995. 90p.

SILVEIRA, D.R. Exportações de madeira serrada brasileira de folhosas e coniferas. http:llwww.mdic.gov.brlsecex, (02 Fev. 2002) 
SIMÕES, J.W. Formação e manejo de povoamento florestais. Brasilia: IBDF, 1981. 131p.

SIMULA, M.T.; TISSARI, J.T. Market prospects for eucalypts solid products in the european common market. In: SEMINÁRIO INTERNATIONAL DE PRODUTOS SÓLIDOS DE MADEIRA DE ALTA TECNOLOGIA, 1, Belo Horizonte, 1998. Anais. Belo Horizonte: SIF;UFV, 1998. p.29-48.

SOTE, F. Estimativas de volume de madeira serrada exportada no Brasil. http:llwww. stcp.com.br, (02 Fev. 2002)

VALE, R.S. Efeito da desrama artificial no crescimento e na qualidade de madeira de clones de eucaliptos, em sistemas agro-silvo-pastoril. Lavras, 2000. 96p. Dissertação (Mestrado) - Universidade Federal de Lavras.

VILLIERS, A. M. de. Utilization problems with some eucalypts. In: FORUM UTILIZATION PROBLEMS WITH SOME EUCALYPTS IN SOUTH AFRICA, 2, África, 1973. Anais. Äfrica: IUFRO, 1973. p.238-255.

YARED, J.A.G. Comportamento e variabilidade de procedências de Cordia alliodora (Ruiz e Pav.) Oken, no planalto do Tapajós-Belterra-PA. Piracicaba, 1983. 108p. Dissertação (Mestrado) - Escola Superior de Agricultura "Luiz de Queiroz", Universidade de São Paulo. 